UNIVERSIDADE DE SÃO PAULO

FACULDADE DE SAÚDE PÚBLICA

DEPARTAMENTO DE EPIDEMIOLOGIA

\title{
USO DA CIF EM FISIOTERAPIA: UMA FERRAMENTA PARA A OBTENÇÃO DE DADOS SOBRE FUNCIONALIDADE
}

\section{Eduardo Santana de Araujo}

Tese apresentada ao Programa de PósGraduação em Saúde Pública da Faculdade de Saúde Pública da Universidade de São Paulo, como requisito para a obtenção do título de Doutor.

Orientadora: Profa. Dra. Cassia Maria Buchalla

\section{São Paulo}


USO DA CIF EM FISIOTERAPIA: UMA FERRAMENTA PARA A OBTENÇÃO DE DADOS SOBRE FUNCIONALIDADE

\section{Eduardo Santana de Araujo}

Tese apresentada ao Programa de PósGraduação em Saúde Pública da Faculdade de Saúde Pública da Universidade de São Paulo, como requisito para a obtenção do título de Doutor em Ciências

Área de concentração: Epidemiologia

Orientadora: Profa. Dra. Cassia Maria Buchalla

São Paulo 
É expressamente proibida a comercialização deste documento, tanto na sua forma impressa quanto eletrônica. Sua reprodução total ou parcial é permitida para finalidades acadêmicas e científicas, desde que, na reprodução figure a identificação do autor, o título, a instituição e o ano da tese. 


\section{AGRADECIMENTOS}

Agradeço por todas as oportunidades que a vida me dá. Aqui, especialmente, por poder freqüentar a Faculdade de Saúde Pública: o lugar mais aconchegante da enlouquecedora cidade de São Paulo. Se eu não voltar a estudar aqui, sentirei saudades!

Aos familiares que me apoiaram e à Profa. Cassia, meus agradecimentos. Alguns nascem para fazer o que fazem. Ou gostam tanto do que fazem que se tornam especiais. Agradeço imensamente à professora que jamais me disse como as coisas são, mas sempre me estimulou a pensar sobre as coisas. Sinto ser esse o melhor caminho para continuar aprendendo.

Algumas pessoas especiais no caminho foram Ana Cristhina de Oliveira Brasil, Paulo Crócomo, Ricardo Lotif e Rivaldo Rodrigues Novaes. Com esses, aprendi que os sonhos, quando divididos, multiplicam-se.

Tive apoio de diversas formas das seguintes entidades: Associação Brasileira de Ensino em Fisioterapia, Associação Brasileira de Fisioterapia, Associação Brasileira de Fisioterapia do Trabalho, Conselho Federal de Fisioterapia e Terapia Ocupacional, Conselho Federal de Fonoaudiologia (e sociedades científicas da área), Ordem dos Hospitaleiros Ortodoxos, Sociedade Brasileira de Fisioterapia e Universidade de São Paulo.

A todos, meu muito obrigado! 
Araujo ES. Uso da CIF em Fisioterapia: uma ferramenta para obtenção de dados sobre funcionalidade. [tese de doutorado]. São Paulo: Faculdade de Saúde Pública da Universidade de São Paulo; 2012.

\section{RESUMO}

Introdução. A linguagem comum e padronizada oferecida pela Classificação Internacional de Funcionalidade, Incapacidade e Saúde (CIF) permite a categorização dos estados de saúde relacionados à funcionalidade e incapacidade facilitando a construção de sistemas de informação. Ainda hoje, o uso da CIF é limitado pela sua complexidade. Alguns instrumentos para facilitar sua aplicação foram criados sem, no entanto, suprir todas as necessidades para seu uso em algumas áreas. O objetivo deste trabalho é construir facilitadores para que a CIF possa ser aplicada na área de Fisioterapia. Métodos. Foram desenvolvidos três estudos: dois consensos com especialistas e uma análise do uso da CIF em um inquérito de saúde, apresentados no formato de artigos científicos. Os dois primeiros estudos estruturam ferramentas de coleta de dados por meio adaptado da técnica Delphi e o terceiro estudo explora o uso da CIF como ferramenta classificatória de resultados de um inquérito de saúde aplicado em pessoas com incapacidades. Resultados. Um conjunto de categorias relevantes da CIF para Fisioterapia Geral e para cada especialidade da área reconhecida pela Classificação Brasileira de Ocupações foi definido (primeiro artigo). Foi estruturada uma proposta de ferramenta classificatória para uso em Fisioterapia do Trabalho (segundo artigo). O terceiro artigo apresenta benefícios do uso da CIF em inquéritos de saúde como meio de geração de dados sobre a incapacidade. Conclusões. Os estudos indicam que a operacionalização da CIF será mais adequada se houver um menor número de categorias em uso. Em princípio, sugere-se três simplificações: redução do número de categorias, escolha de categorias de baixo nível de complexidade (segundo estrutura da classificação) e uso do qualificador "não especificado".

Descritores: CIF, Epidemiologia, Fisioterapia, Funcionalidade. 
Araujo ES. Using ICF on Physiotherapy: a tool for data collection about functioning. [doctoral thesis]. São Paulo (BR): Faculty of Public Health. São Paulo University; 2012.

\begin{abstract}
Introduction. The common language and standard offered by the International Classification of Functioning, Disability and Health (ICF) enables the categorization of functioning and disability, facilitating the construction of information systems. Even today, the completed use of ICF is limited by its complexity. Some tools aimed to facilitate its application were created withoutcovering all the needs for its use by some areas. The objective of this thesis is topropose facilitators to ICF application in the field of Physical Therapy. Methods. We developed three studies: two consensuses with experts and a review of the use of the ICF in a health survey, presented in the format of scientific papers. The first two studies structured data collection tools through Delphi technique adapted and the third study explores the use of the ICF as a tool for classifying the results of a health survey applied to a population with disabilities. Results. A set of ICF categories relevant to General Physiotherapy and for each specialty recognized by the Brazilian Classification of Occupations was defined (first article). We got a classification tool for use by Physiotherapists of Occupational Health (second article). The third article presents the benefits of using the ICF in health surveys as a way to generate data on disability. Conclusions. The use of the ICF is facilitated by a list with a small number of categories. Actually, it is suggested three simplifications: reducing the number of categories, selecting categories of low complexity (second classification structure) and use of the "unspecified" qualifier.
\end{abstract}

Descriptors: ICF, Epidemiology, Physiotherapy, Functioning. 


\section{ÍNDICE}

APRESENTAÇÃO

1. INTRODUÇÃO

2.1 - OBJETIVO GERAL

2.2 - OBJETIVOS ESPECÍFICOS

4.1 - MANUSCRITO 1

4.2 - MANUSCRITO 2

4.3 - MANUSCRITO 3 
5. CONSIDERAÇÕES FINAIS

6. REFERÊNCIAS

BIBLIOGRÁFICAS

139 


\section{APRESENTAÇÃO}

Esta tese de doutorado tem como objetivo desenvolver facilitadores que estimulem o uso da CIF na área de Fisioterapia. Visando esse objetivo desenvolvemos um trabalho aqui contextualizado cujos resultados são apresentados no formato de três artigos científicos.

O primeiro artigo é sobre a construção de ferramentas baseada em consensos que facilitem a aplicação da CIF nas especialidades fisioterapêuticas. Foi publicado em 2011, na Revista Fisiobrasil, volume 105, número 15, páginas 22 a 27, e teve o objetivo de selecionar categorias da classificação para que instrumentos de coleta de dados de funcionalidade possam ser desenvolvidos de forma a facilitar a aplicação da CIF por especialistas da área da Fisioterapia.

O segundo artigo aborda o processo de criação de um instrumento de coleta de dados de funcionalidade para uso em Fisioterapia do Trabalho, criado a partir de categorias mais relevantes da CIF para essa área. O objetivo foi criar uma ferramenta capaz de gerar dados que possam ser traduzidos em informações sobre funcionalidade e incapacidade na área de Saúde do Trabalhador.

O terceiro artigo se refere a uma adequação da CIF para uso em um inquérito de saúde. Os inquéritos podem ser uma forma de conhecimento do estado de saúde da população por meio da geração de informações que vão além dos dados do sistema de morbidade e mortalidade. A classificação é uma ferramenta capaz de permitir uma abordagem mais ampla, uma vez que aborda características do ambiente. Assim, o estudo pretendeu mostrar a viabilidade do uso da CIF nesse tipo de pesquisa, quando se tem o interesse de conhecer aspectos mais detalhados da funcionalidade humana.

Uma introdução ao tema e um capítulo de considerações finais fazem a ligação entre esses três trabalhos desenvolvidos durante o Programa de Pós-graduação. 


\section{INTRODUÇÃO}

A Classificação Internacional de Funcionalidade, Incapacidade e Saúde (CIF) foi aprovada pela Organização Mundial da Saúde (OMS) em 2001 e indicada para uso pelos países membros por força da Resolução OMS 54.21/2001 (WHO, 2001). A criação da CIF veio da necessidade de se obter informações mais detalhadas sobre funcionalidade e incapacidade. Ela tem importância reconhecida nas áreas do ensino, da pesquisa, da clínica e permite diferentes abordagens em setores como Educação, Estatísticas de Saúde, Políticas Públicas, Saúde, Seguridade Social, entre outros (WHO, 2001).

Após a transição epidemiológica e o aumento da expectativa de vida tornou-se necessário conhecer os efeitos da idade na funcionalidade. Na epidemiologia, a CIF pode servir como ferramenta estatística geradora de dados relativos à funcionalidade e incapacidade humanas, com a vantagem de permitir a identificação de fatores que determinam maior ou menor incapacidade e participação, considerando os aspectos ambientais e pessoais. Na clinica, seu uso uniformiza conceitos e padroniza a linguagem. Com isso, facilita a comunicação entre profissionais e gestores, garantindo o estabelecimento de melhores estratégias de saúde e de controle administrativo (WHO, 2002).

A classificação contém duas partes: uma com itens ou categorias para a funcionalidade e outra sobre o contexto geral. A funcionalidade está dividida em três componentes: Funções do Corpo, Estruturas do Corpo e Atividade e Participação. O contexto em duas: Fatores Ambientais e Fatores Pessoais. Todos esses componentes podem ser codificados, exceto os fatores pessoais (sexo, etnia, idade, cultura, entre outros) que, no entanto, são considerados influenciadores do desempenho das atividades 
e da participação social e devem ser considerados, como defende a própria classificação (OMS, 2001).

A CIF é uma classificação completa e seu uso, por uma equipe multidisciplinar pode ser mais trabalhoso. Por ser completa e complexa, a CIF torna-se um instrumento de difícil implantação e uso. Além disso, para aplicação da classificação na íntegra, é necessária a formação de equipes interdisciplinares completas, envolvendo a área da saúde e outras áreas do conhecimento. Um mecanismo encontrado para facilitar sua adoção foi a criação de listas resumidas. Os "core sets" foram uma das primeiras formas de listas resumidas apresentadas. Trata-se de um conjunto pré-definido de categorias relacionadas a determinadas doenças, áreas de atuação, profissões, especialidades ou objetivos. Até o momento foram desenvolvidos vários "core sets" específicos para uso em certas condições de saúde, tais como, "core set" da CIF para uso em pacientes com fibromialgia (Schwarzkopf SR, Ewert T, Dreinhofer KE, Cieza A, et al.,2008), “core set" da CIF para uso em pacientes com artrite reumatoide (Kirchberger I, Glaessel A, Stucki G, Cieza A., 2007), “core set” da CIF para uso em pacientes com Doença Pulmonar Obstrutiva Crônica (Armin Stucki A et al, 2004), dentre outros (Brockow, 2004).

Os "core sets" foram desenvolvidos por um método que inclui, entre outras etapas, um processo de consenso baseado na técnica "Delphi” (Weigl M, 2004). É um projeto multicêntrico e internacional no qual são desenvolvidas e validadas essas ferramentas. O uso dos "core sets" tem facilitado a adoção da CIF, mesmo que em partes (Riberto, 2011). No entanto, esses instrumentos têm sofrido críticas, em especial por serem listas baseadas em doenças (McIntyre A, Tempest S., 2007), tornando o uso da classificação limitado, já que a situação na qual a doença é resultado de alterações na funcionalidade não pode ser apresentada por esse modelo. Já as listas baseadas em 
áreas, profissões, especialidades e objetivos são menos criticadas. (Finger ME et al, 2006).

A CIF apresenta um modelo multidirecional e multidimensional, no qual o estado de funcionalidade é resultado de diversos fatores, que incluem os fatores ambientais e pessoais, e que devem ser considerados ao se analisar as condições da pessoa. Assim, ao se analisar uma situação de incapacidade, todos os aspectos, inclusive os ambientais e pessoais, devem ser considerados, tanto do ponto de vista positivo como negativo, influindo na funcionalidade. A funcionalidade é um termo guarda chuva, que inclui atividade e participação.

Uma das críticas feitas ao modelo dos "core sets" para uso em doenças específicas, como aqueles que são estruturados para classificar a situação de indivíduos com determinada condição (exemplo: "core set" da CIF para uso em pacientes com Fibromialgia), é que impõem categorias pré-definidas da CIF, relacionadas a alterações causadas pela doença. Assim, o modelo de funcionalidade passa a ser linear, com condições resultantes da doença, sem que as variações pessoais, culturais e ambientais sejam consideradas. (McIntyre A, Tempest S, 2007). Essa linearidade estaria contrapondo a multidirecionalidade do modelo de funcionalidade e incapacidade proposto na CIF (Sampaio et al, 2005). Nesse sentido, um “core set” genérico (como o exemplo de projeto disponível na página eletrônica http://www.icf-researchbranch.org/icf-core-sets-projects/diverse-situations.html), ou por área, por profissão ou por objetivo (como ajudar na definição sobre a concessão de benefícios), parece ser mais adequado, já que a condição de saúde faz parte desse modelo de funcionalidade e incapacidade e as áreas, profissões e objetivos não fazem. 
Tal modelo multidimensonal e multidirecional de funcionalidade e incapacidade da OMS foi publicado juntamente com a CIF (Figura 1). Ele rejeita a existência exclusiva de uma situação de linearidade que indicaria a restrição da participação como consequência da incapacidade, a incapacidade como exclusiva consequência da deficiência e a deficiência como exclusiva consequência da doença.

Figura 1 - Interação entre os componentes da CIF.

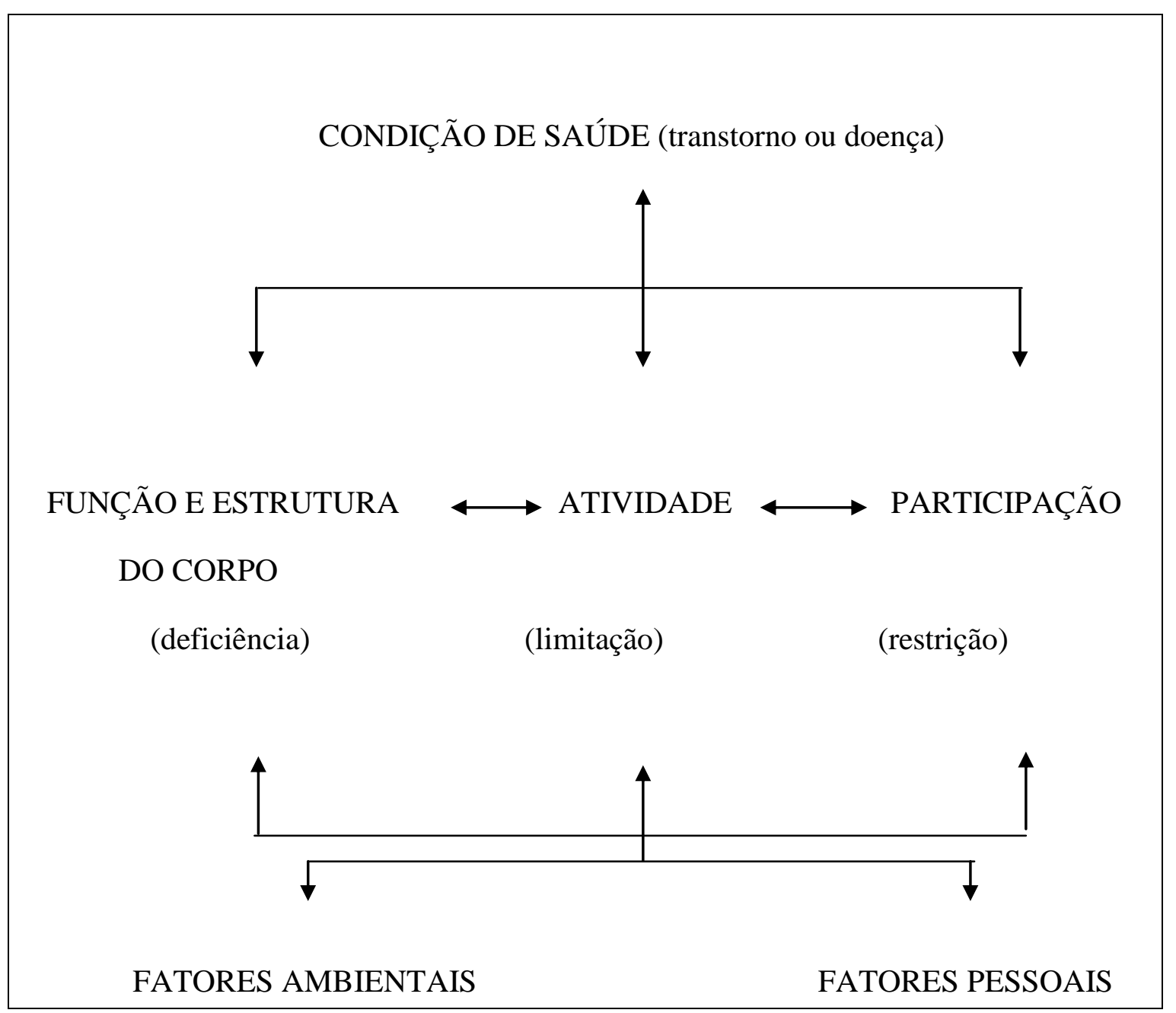

Fonte: OMS (2001).

O novo modelo proposto admite a multidirecionalidade, permitindo, por exemplo, que a doença seja resultado de alterações da funcionalidade e não a causadora 
dessas alterações. Permite ainda o entendimento da situação diferenciada de incapacidade em pessoas com a mesma doença, já que são influenciadas por contextos diferentes.

O papel do contexto é fundamental no desempenho das atividades e participação social das pessoas, sendo esse, muitas vezes, o objeto de intervenção para melhoria do estado de funcionalidade ou para a prevenção da incapacidade.

O modelo também apresenta diferentes dimensões:

- A dimensão biológica, representada pelo componente de FUNÇÕES E ESTRUTURAS DO CORPO;

- A dimensão patológica, representada pelo componente CONDIÇÃO DE SAÚDE (TRANSTORNO OU DOENÇA);

- A dimensão do contexto no qual o indivíduo vive, representada pelos componentes FATORES AMBIENTAIS e FATORES PESSOAIS;

- A dimensão da capacidade e do desempenho, representada pelos componentes ATIVIDADES e PARTICIPAÇÃO.

Duas classificações de referência da Família de Classificações da OMS estão contempladas neste modelo. Além da CIF, a Classificação Estatística Internacional de Doenças e Problemas Relacionados à Saúde (CID) também se faz presente na representação do componente CONDIÇÃO DE SAÚDE (TRANSTORNO OU DOENÇA). Já o componente de FATORES PESSOAIS não está contemplado em nenhuma das classificações da OMS. 
Esse modelo, também explorado no Estudo 1 do presente trabalho, é diferente da abordagem linear, apresentada na década de 1980, quando a OMS elaborou, para ser usada em pesquisa, uma classificação para as consequiências das condições de saúde, a Classificação Internacional de Deficiências, Incapacidades e Desvantagens. Tal classificação tinha como referencial teórico a incapacidade em três dimensões, estruturadas como consequência de uma doença (ou lesão) numa sequência linear. Assim, as consequências das doenças se manifestavam como danos no nível corporal, traduzidos como deficiências. Por sua vez, a incapacidade era definida como a falta de habilidade pessoal para realizar tarefas básicas, causada pela deficiência. Já a desvantagem experimentada ao desempenhar um papel social era o resultado final da sequência lógica de eventos.

Dentre os questionamentos a este modelo, estava a progressão fixa de uma sequência de eventos baseadas em acometimentos biológicos e clínicos. A partir de então, a OMS, na década seguinte, deu início a uma revisão do modelo, com o intuito de considerar a influência contextual no desempenho humano.

A ideia do novo modelo, apresentado na Figura 1, é articular as possibilidades e compreender as conexões existentes. Sem dúvida, o foco da análise da funcionalidade e incapacidade é a multidimensionalidade do fenômeno, sem permissão para uma única rede de direcionamento possível entre as dimensões da CIF e com realidades produzidas por situações individualizadas e autônomas (Sampaio e Luz, 2009). Assim, a dúvida que se estabelece é: será que os "core sets" da CIF representam uma noção que, a despeito do modelo multidirecional, retrocede ao modelo linear? (McIntyre \& Tempest,2007).

É importante ressaltar que a execução do modelo de funcionalidade e incapacidade da OMS na prática profissional não implica na codificação pela CIF ou 
pela CID. O modelo é um guia de como se pensar sobre a funcionalidade humana, dentro de um panorama de múltiplas possibilidades. Paralelamente, as classificações oferecem uma linguagem-padrão e também servem para padronização da nomenclatura sobre doenças (CID) e da nomenclatura sobre funcionalidade (CIF).

No entanto, o uso da codificação pode suprir a necessidade contemporânea de se estabelecer uma linguagem também comum para geração de dados sobre funcionalidade. Enfim, tudo que nos aproxima do uso da CIF, como a sua ampla abordagem sobre funcionalidade, acaba nos afastando do uso. Se os "core sets" (que são facilitadores) não puderem ser adequados ou se não obedecerem ao novo modelo proposto, bateremos de frente com as barreiras de operacionalidade da CIF.

Assim, outras formas de facilitar o uso do instrumento sem distanciamento do modelo de funcionalidade e incapacidade têm sido discutidas. Uma delas é uma forma alternativa de "core set", como a criação de listas resumidas baseadas em áreas de atuação, sendo que a funcionalidade e a incapacidade podem ou não estar diretamente relacionadas à presença de doenças (Finger, 2006).

Segundo Sampaio e Madel (2009), há barreiras para uso da CIF, como a falta de conhecimento dos profissionais acerca da classificação. As autoras expressam que os fisioterapeutas brasileiros, até 2009, não tinham contato diário e efetivo com a classificação e tampouco conhecem o modelo de funcionalidade proposto pela OMS, a sua maior inovação.

Segundo os trabalhos publicados desde o lançamento da classificação pela OMS, o modelo multidirecional deve ser absorvido para que a CIF seja efetivamente utilizada (Di Nubila et al, 2011). A Fisioterapia é uma das áreas que mais tem adotado CIF no 
mundo. Isto se dá, principalmente, pela necessidade de se unificar a linguagem diagnóstica destes profissionais (Palisano, 2006).

Com o passar do tempo, vários instrumentos de medida foram criados para nortear a prática clínica, na busca de uma linguagem comum. A CIF é um instrumento capaz de traduzir grande parte dessas ferramentas, como a Medida de Independência Funcional, Escala de Barthel, Escala de Força Muscular de Kendal, dinamometria isocinética, baropodometria, eletromiografia de superfície, entre outros recursos, com a intenção unificar a nomenclatura da notificação de alterações da funcionalidade (Machado, 2008).

Além disso, o uso de diferentes instrumentos (escalas, questionários, etc.) dificulta a prática interdisciplinar, uma vez que cada um deles é interpretado facilmente apenas por determinado grupo de profissionais. A CIF, neste caso, estimulando um padrão comum, facilita o contato interprofissional. Ela traz uma nomenclatura padronizada que pode ser usada tanto na diagnose como no acompanhamento e para a alta de pacientes que se submetem a tratamento do estado de funcionalidade. $\mathrm{O}$ uso do qualificador, número que complementa cada categoria da CIF transformando-a em um código e dando a magnitude do problema, identifica a melhora parcial ou completa de determinada função, por exemplo. Um paciente pode ter um diagnóstico que é codificado com b710.3 - perda grave da mobilidade articular - e ter melhorado após tratamento. O código da CIF permite acompanhar essa melhora, e o qualificador passa de “.3” (perda grave) para “.1” (perda leve da mobilidade articular - b710.1). Desta feita, não importa se o instrumento utilizado foi a goniometria convencional ou a fotogoniometria computadorizada. A linguagem está padronizada por meio do uso de um código e ainda permite o entendimento da evolução por todos os profissionais da 
área da saúde, já que o resultado não está expresso em graus e sim em códigos, permitindo interpretação comum e padronizada (Rauch A, Cieza A, Stucki G, 2009).

\section{1 - A Fisioterapia como disciplina da área de Funcionalidade Humana}

A área da Fisioterapia, desde sua regulamentação no Brasil em 1969, passa por aparecimento de novas especialidades e áreas de atuação específicas. Um exemplo é a Fisioterapia do Trabalho, que é voltada à saúde do trabalhador, e aborda os aspectos da ergonomia, da biomecânica e da atividade física laboral. Tem como objetivo evitar e tratar as manifestações cinesiopatológicas de origem ocupacional, que podem gerar incapacidades, prejudicar tanto o rendimento do profissional como sua vida social. Esse especialista tem como atribuições a educação em saúde, a análise de fatores ambientais que interferem na saúde do trabalhador e o desenvolvimento de programas preventivos coletivos. Segundo a Resolução COFFITO 259, o Fisioterapeuta do Trabalho deve "analisar e quantificar as demandas observadas através de estudos ergonômicos aplicados, para assegurar a melhor interação entre o trabalhador e a sua atividade, considerando a capacidade humana e suas limitações, fundamentado na observação das condições biomecânicas, fisiológicas e cinesiológicas-funcionais".

Dessa maneira, a prática fisioterapêutica volta-se ao estudo da funcionalidade relacionada ao movimento humano, que não pode ser expressada apenas por meio da linguagem da Classificação Estatística Internacional de Doenças e Problemas Relacionados à Saúde. Portanto, a CIF pode ser uma ferramenta capaz de traduzir dados obtidos na prática fisioterapêutica especializada, por uma linguagem comum, possibilitando a geração de informações importantes sobre aspectos da funcionalidade humana. 
Até o presente momento, o único instrumento classificatório utilizado no fornecimento de informações para controle dos agravos à saúde é a Classificação Estatística Internacional de Doenças e Problemas Relacionados à Saúde.. Trata-se de uma ferramenta de suma importância para o desenvolvimento de políticas públicas e de estratégias de controle e prevenção, pois é utilizada a nível mundial, para as estatísticas de mortalidade e de morbidade. No entanto, a CIF mostra-se como uma ferramenta rica e adequada para que se conheçam as interrelações entre o ambiente, a capacidade e desempenho das atividades humanas, incluindo sua participação social.

Com a utilização da CIF, poderão ser identificadas condições além das relacionadas à saúde, como as do meio ambiente, os recursos a que as pessoas têm acesso, de forma a permitir uma visão mais ampla das circunstâncias que favorecem ou dificultam a resolução dos quadros apresentados. As ações de controle devem contemplar os grupos populacionais priorizando os mais vulneráveis, como aqueles em situação de precariedade, sob alguma forma de discriminação, inseridos em atividades de maior risco para a saúde, entre outros, na perspectiva de superar desigualdades. Grupos vulneráveis, tanto em relação à saúde quanto em relação às condições de trabalho ou da participação social como um todo, poderão ser definidos a partir da análise da situação de saúde local e das condições de funcionalidade de cada indivíduo.

Os contextos sociais, psicológicos e ambientais são essenciais para a saúde e para a qualidade de vida. Considerando o atual paradigma, os profissionais de saúde devem basear-se no modelo multidimensional de funcionalidade apresentado na CIF para um completo entendimento dos processos de saúde. Uma mesma doença diagnosticada em diferentes pacientes não causará, necessariamente, as mesmas repercussões funcionais (Sampaio, 2005), assim como uma mesma alteração funcional/deficiência diagnosticada em diferentes pacientes não causará as mesmas 
incapacidades/limitações e restrições. Assim, o mais importante na prática fisioterapêutica é considerar a funcionalidade como o ponto central para avaliação e determinação de condutas (Brockow, 2004).

O uso da CIF pode traduzir o estado de funcionalidade de clientes submetidos à recursos fisioterapêuticos, bem como, acompanhá-lo por meio de um sistema codificado gerador de informações e indicadores, o que pode auxiliar os fisioterapeutas, os outros profissionais da saúde e os gestores durante a organização das informações e no estabelecimento de estratégias de saúde baseadas nas situações reais, amplamente conhecidas, e não apenas pelo conhecimento das doenças, como ocorre atualmente.

O Conselho Federal de Fisioterapia e Terapia Ocupacional - COFFITO normatizou, recentemente, o uso da classificação pelos profissionais jurisdicionados por força da Resolução 370 de 6 de novembro de 2009. Dessa forma, a CIF deverá ser introduzida como ferramenta na prática profissional por meio de treinamentos especializados ou como conteúdo básico na formação profissional.

Além do COFFITO, o Conselho Nacional de Saúde (CNS), por meio da Resolução 452/2012, também instituiu a CIF no âmbito do Sistema Único de Saúde (SUS). Embora ainda seja necessária a definição de ferramentas operacionais para uso da classificação, que sejam compatíveis com a realidade dos serviços, já há uma forte indicação para instituição do instrumento.

A publicação do modelo de funcionalidade e da CIF fornece subsídios para criação de políticas públicas abrangentes. $\mathrm{O}$ uso dessa classificação poderá contribuir para que se conheça, com maior grau de detalhamento, o estado de pessoas com incapacidade ou com risco de desenvolverem incapacidades, e os recursos necessários para promover a funcionalidade. 


\section{OBJETIVOS}

\section{1 - OBJETIVO GERAL}

O objetivo deste trabalho é criar instrumentos operacionais de coleta de dados relativos à funcionalidade e incapacidade utilizando as categorias da CIF mais relevantes para cada tipo de aplicação.

\section{2 - OBJETIVOS ESPECÍFICOS}

Os objetivos específicos deste trabalho são:

a) propor um instrumento geral, baseado na CIF, para cada especialidade do fisioterapeuta reconhecida pela Classificação Brasileira de Ocupações (CBO);

b) propor um instrumento específico, baseado na CIF, para a especialidade de Fisioterapia do Trabalho;

c) propor o uso de categorias da CIF para conhecimento amplo da situação de saúde de pessoas com incapacidades por meio de inquéritos de saúde; 


\section{MÉTODOS}

O Quadro 1 apresenta os objetivos do presente trabalho e os artigos preparados para responder a cada um deles.

Quadro 1 - Objetivos propostos e Estudos realizados

\begin{tabular}{|c|c|c|c|}
\hline Estudo & Objetivos & $\begin{array}{c}\text { Revistas para } \\
\text { submissão }\end{array}$ & Situação do artigo \\
\hline Estudo 1 & $\begin{array}{l}\text { Criação de instrumento } \\
\text { baseado na CIF para } \\
\text { especialidades } \\
\text { fisioterapêuticas }\end{array}$ & Revista Fisiobrasil & Publicado \\
\hline Estudo 2 & $\begin{array}{l}\text { Criação de instrumento } \\
\text { baseado na CIF para } \\
\text { Fisioterapia do Trabalho }\end{array}$ & Acta Fisiatrica & Submetido \\
\hline Estudo 3 & $\begin{array}{l}\text { Proposição de uso da CIF } \\
\text { em inquérito de saúde }\end{array}$ & $\begin{array}{c}\text { Cadernos de Saúde } \\
\text { Pública }\end{array}$ & A ser submetido \\
\hline
\end{tabular}

Os métodos empregados para a realização de cada trabalho estão descritos nos respectivos artigos, assim como seus resultados. O conjunto dos resultados obtidos é sumarizado na parte final deste trabalho.

A formatação de cada estudo obedece às normas específicas das revistas para as quais os estudos foram ou serão submetidos, e são indicadas no Quadro 2. 
Quadro 2 - Normas das revistas a que foram ou serão submetidos os artigos deste trabalho

\begin{tabular}{|l|l|l|}
\hline Periódico & Página eletrônica das normas & Página eletrônica da revista \\
\hline Fisiobrasil & $\underline{\text { www.fisiobrasil.com.br/artigos }}$ & $\underline{\text { www.fisiobrasil.com.br/default }}$ \\
\hline Acta & $\underline{\text { www.actafisiatrica.org.br/v1/frmInstru }}$ & $\underline{\text { www.actafisiatrica.org.br }}$ \\
Fisiátrica & $\underline{\text { coes.aspx }}$ & \\
Caderno de & $\underline{\text { http://www4.ensp.fiocruz.br/csp/index }}$ & $\underline{\text { http://www.ensp.fiocruz.br/porta }}$ \\
Páde & $\underline{\text { htm }}$ & $\underline{\text { l-ensp }}$ \\
\hline
\end{tabular}




\section{RESULTADOS}

4.1 - Estudo 1: publicado na Revista Fisiobrasil (2011) 105;15: 22-7.

\section{Uma proposta de uso da CIF em Fisioterapia}

\section{Eduardo Santana Araujo}

Departamento de Epidemiologia da Faculdade de Saúde Pública da Universidade de São Paulo.

edusantana@usp.br

Endereço para correspondência: Rua Maracatu, 102 - casa 1. Cotia/SP.

\section{Cassia Maria Buchalla}

Departamento de Epidemiologia da Faculdade de Saúde Pública da Universidade de São Paulo.

cmbuchal@usp.br

Endereço para correspondência: Av. Dr. Arnaldo, 715. São Paulo/SP. 


\section{Resumo}

Embora a CIF tenha sido criada em 2001, ainda não tem sido adotada em larga escala na área de Fisioterapia por conta de algumas barreiras que impedem seu uso na prática clínica, em especial a sua extensão. Ao analisarmos todas as possibilidades de uso de suas categorias e qualificadores, foi possível estabelecer uma forma rápida, capaz de transpor barreiras de implantação na prática fisioterapêutica, por meio de um processo de consenso. Mesmo com a necessidade de validação, concluímos que o produto final deste trabalho, chamado "Avaliação Baseada nos Componentes, Domínios e Adaptações da CIF - ABCDACIF”, é uma ferramenta capaz de permitir a adoção e implantação da CIF em Fisioterapia, inclusive como instrumento gerador de informações epidemiológicas sobre funcionalidade humana.

Palavras-chave: consenso, epidemiologia, fisioterapia. 


\begin{abstract}
Although the ICF was established in 2001, it has not been adopted yet on a large scale in the area of Physiotherapy because of some barriers that makes impossible its use in clinical practice, due its extension. By analyzing all the possibilities for use of its categories and qualifiers, we could establish a quickly version, that can be able to overcome barriers to deployment in physical therapy practice. We used a consensus process. Even with the need for validation, we conclude that the final product of this work, called "Assessment Based on Components, Domains and Adaptations of ICF ABCDAICF", is a tool to enable the adoption and implementation of the ICF in Physical Therapy, including a way to generator epidemiological information on human functioning.
\end{abstract}

Descriptors: consensus, epidemiology, physical therapy. 


\section{Introdução}

A Classificação Internacional de Funcionalidade, Incapacidade e Saúde (CIF) foi lançada pela Organização Mundial de Saúde em 2001 (OMS, 2003) e indicada para uso pelos países membros. A CIF foi criada para responder às necessidades de se conhecer as conseqüências das doenças e do envelhecimento. Com o aumento da expectativa de vida da população tornou-se fundamental conhecer as condições de vida das pessoas com doenças crônicas e mesmo aquelas saudáveis, vivendo um processo de envelhecimento. A CIF permite conhecer os estados de funcionalidade, incapacidade, graus de atividade e de participação. A classificação inclui, também, aspectos ambientais quer sejam facilitadores ou barreiras, e propõe o uso de fatores pessoais na determinação dos aspectos envolvidos nas condições de saúde e de vida das pessoas.

Durante a sua preparação, a classificação foi testada em 61 países, mas sua adoção pelos serviços de saúde tem sido lenta. Como um instrumento amplo, a classificação contém 1424 categorias de funcionalidade (OMS, 2003) sua utilização de forma integral deve ser feita por equipe multiprofissional. No entanto, várias áreas têm usado parte da classificação para caracterizar e acompanhar a evolução de pacientes. Esta forma de uso tem se dado por meio de listas curtas, contendo apenas as categorias de interesse para aquela condição de saúde ou área profissional.

O uso da CIF apresenta vantagens do ponto de vista de equipe pois unifica a linguagem, de acompanhamento do paciente e do ponto de vista epidemiológico pois permite conhecer os determinantes ou fatores que interferem na funcionalidade da pessoa vivendo com determinada condição de saúde.

A Fisioterapia é uma das principais áreas da saúde com experiência na implantação da CIF no mundo. Sua aplicação permite o controle dos resultados dos serviços prestados, por isso tem sido utilizado por planos de saúde na Europa em grandes serviços de recuperação funcional (Rauch A, Cieza A, Stucki G, 2008).

Sua abrangência deve-se ao modelo inovador que propõe um modelo de abordagem biopsicossocial (figura 1). A estrutura da classificação tem os seguintes componentes: funções do corpo, estruturas do corpo, atividades \& participação e fatores ambientais. Cada parte é dividida em capítulos e estes em agrupamentos e categorias, em uma estrutura hierarquizada. Além do código da categoria (ou subcategoria, nível 
mais especifico) a proposta é usar qualificadores para as várias condições. Cada componente da CIF tem seu qualificador de intensidade, desempenho, etc.

Figura 1 - Interação entre os componentes da CIF.

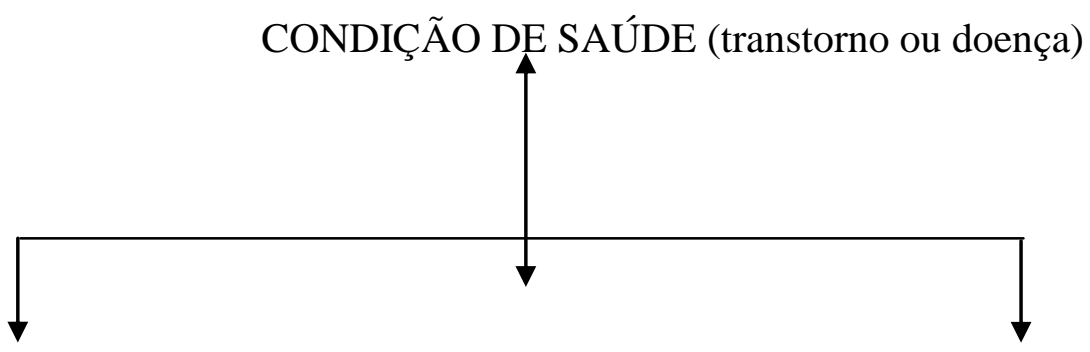

FUNÇÃO E ESTRUTURA

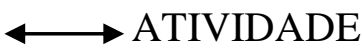

PARTICIPAÇÃO

DO CORPO (deficiência)

(limitação)

(restrição)

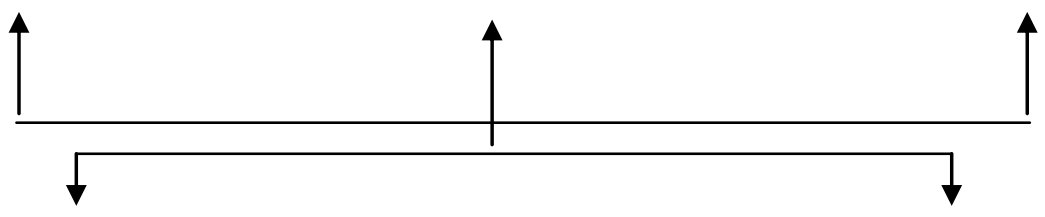

FATORES AMBIENTAIS

FATORES PESSOAIS

Adaptação: OMS (2001).

Com o objetivo de facilitar a aplicação da CIF na área de Fisioterapia, este estudo preparou listas com as categorias relevantes da classificação e uma proposta para seu uso pelas várias especialidades da área. 


\section{Métodos}

Participaram da elaboração da lista de categorias da CIF profissionais da área de Fisioterapia identificados pelas especialidades estabelecidas no Código Brasileiro de Ocupações (CBO). Inicialmente, 74 profissionais das diferentes especialidades e de diversas regiões do país se colocaram à disposição para participar voluntariamente da pesquisa. Todos receberam uma mensagem por via eletrônica, com o convite, os detalhes da pesquisa e a declaração de aceite em relação à participação no estudo. Foilhes enviado um material descritivo sobre a CIF e um questionário para indicar as categorias da CIF aplicáveis para sua especialidade, também por meio eletrônico, no sito do Laboratório de Estudos Populacionais (LEP) da Faculdade de Saúde Pública da Universidade de São Paulo. A disponibilização dos formulários está no link http://www.fsp.usp.br/site/paginas/mostrar/556.

O material descritivo disponibilizado continha dois arquivos, sendo o primeiro para leitura obrigatória e o segundo para observação complementar. O primeiro arquivo tratava-se da tradução de um documento feito pelos grupos de trabalho, submetido à OMS para disponibilização na página eletrônica, denominado ICF Overview. O outro arquivo era a versão da CIF em Português. A possibilidade para resposta ao questionário só foi aberta aos que declararam entendimento satisfatório sobre a ferramenta após acesso ao material.

O prazo para resposta foi de 30 dias após a disponibilização do material sobre a CIF aos 74 potenciais participantes. Na metade do período, todos receberam uma mensagem de alerta sobre o prazo de entrega.

Todas as respostas, que consistiam na seleção das categorias da CIF em $1^{\circ}$ nível aplicáveis para cada especialidade, foram computadas pelo banco de dados formatado no LEP, sendo que foi considerado como consenso a opção positiva em determinada categoria da CIF por, pelo menos, $80 \%$ dos respondentes (Finger ME, 2006).

As categorias de primeiro nível são as categorias mais gerais e amplas para cada domínio. Essas categorias são dividas em outros níveis, mais específicos e detalhados. Algumas delas chegam ao $4^{\circ}$ nível. Apesar disso, a classificação apresenta o $1^{\circ}$ nível do componente "Atividades e Participação" como a matriz da informação da CIF, por 
contemplar a classificação da capacidade, relacionada ao estado das "Funções e Estruturas", e do desempenho, relacionado aos "Fatores Contextuais” (OMS, 2003). 
Com base nas categorias selecionadas foi possível estabelecer uma lista mínima de categorias da CIF para cada especialidade, estabelecendo uma matriz para estruturação de um posterior instrumento de avaliação baseado na estrutura da classificação.

Inicialmente, a amostra era formada por 1 profissional da Região Norte, 7 da Região Nordeste, 14 da Região Centro-Oeste, 22 da Região Sul e 30 da Região Sudeste. As especialidades previamente determinadas seguiram os critérios da $\mathrm{CBO}$ e foram: Acupuntura, Esportiva, Geral, Neurofuncional, Osteopatia, Quiropraxia, Respiratória, Trabalho e Traumato-Ortopedia Funcional. 


\section{Resultados}

Dos 74 potenciais participantes, $39(52,7 \%)$ responderam à pesquisa e consideraram o material descritivo satisfatório, com a seguinte distribuição por região do país:

- Região Centro-Oeste - 7 participantes;

- Região Nordeste - 4 participante;

- Região Sudeste - 13 participantes;

- Região Sul - 15 participantes.

Segundo as especialidades distribuídas de acordo com o conteúdo da CBO, tivemos: 7 participantes especialistas em Acupuntura, 1 em Fisioterapia Esportiva, 4 em Fisioterapia Geral, 12 em Fisioterapia Neurofuncional, 2 em Osteopatia, 1 em Quiropraxia, 5 em Fisioterapia Respiratória, 3 em Fisioterapia do Trabalho e 4 em Traumato-Ortopedia Funcional.

Dos profissionais participantes do grupo de Fisioterapia Geral, 3 identificaramse como especialistas em Saúde Pública e 1 como especialista em Fisioterapia OncoFuncional, especialidades que não constam na Classificação Brasileira de Ocupações, apesar de fazerem parte de programas de formação de especialistas. Os quadros abaixo apresentam o consenso das especialidades no uso das categorias da CIF, incluindo as categorias de funcionalidade e as categorias de fatores ambientais:

As siglas FA, FE, FN, FO, FQ, FR, FT, FTO, ONCO e SP significam, respectivamente, fisioterapeuta acupunturista, fisioterapeuta esportivo, fisioterapeuta neurofuncional, fisioterapeuta osteopata, fisioterapeuta quiropraxista, fisioterapeuta pneumofuncional, fisioterapeuta do trabalho, fisioterapeuta traumato-ortopedista funcional, fisioterapeuta oncofuncional e fisioterapeuta sanitarista. As duas últimas não estavam previstas anteriormente, porém, substituíram a Fisioterapia Geral (FG). 
Quadro 1 - Categorias de Funcionalidade, segundo consenso das especialidades

\begin{tabular}{|c|c|c|c|c|c|c|c|c|c|c|}
\hline & FA & FE & FN & FO & FQ & FR & FT & FTO & ONCO & SP \\
\hline b1 Funções mentais & $\mathrm{X}$ & $X$ & $X$ & & $\mathrm{X}$ & $\mathrm{X}$ & & & $X$ & \\
\hline $\begin{array}{l}\text { b2 Funções sensoriais e } \\
\text { dor }\end{array}$ & $\mathrm{X}$ & $\mathrm{X}$ & $\mathrm{X}$ & $\mathrm{X}$ & $\mathrm{X}$ & $\mathrm{X}$ & & $X$ & $\mathrm{X}$ & $\mathrm{X}$ \\
\hline $\begin{array}{l}\text { b3 Funções da voz e da } \\
\text { fala }\end{array}$ & & $X$ & & & & & & & $X$ & $\mathrm{X}$ \\
\hline $\begin{array}{l}\text { b4 Funções } \\
\text { cardiovasculares, } \\
\text { hematológicas, } \\
\text { imunológicas e } \\
\text { respiratórias }\end{array}$ & $\mathrm{X}$ & $X$ & & $\mathrm{X}$ & $\mathrm{X}$ & $\mathrm{X}$ & $\mathrm{X}$ & & $X$ & $\mathrm{X}$ \\
\hline $\begin{array}{l}\text { b5 Funções digestivas, } \\
\text { metabólicas e endócrinas }\end{array}$ & $X$ & $\mathrm{X}$ & & $\mathrm{X}$ & $X$ & $\mathrm{X}$ & & & $\mathrm{X}$ & \\
\hline $\begin{array}{l}\text { b6 Funções geniturinárias } \\
\text { e reprodutivas }\end{array}$ & & $X$ & & $\mathrm{X}$ & $\mathrm{X}$ & & & & $\mathrm{X}$ & $X$ \\
\hline $\begin{array}{l}\text { b7 Funções } \\
\text { neuromusculoesqueléticas } \\
\text { e relacionadas ao } \\
\text { movimento }\end{array}$ & X & $\mathrm{X}$ & $\mathrm{X}$ & $\mathrm{X}$ & $\mathrm{X}$ & $\mathrm{X}$ & $X$ & $X$ & $\mathrm{X}$ & $\mathrm{X}$ \\
\hline $\begin{array}{l}\text { b8 Funções da pele e } \\
\text { estruturas relacionadas }\end{array}$ & & $\mathrm{X}$ & & & & & & & $\mathrm{X}$ & $\mathrm{X}$ \\
\hline $\begin{array}{l}\text { s1 Estruturas do sistema } \\
\text { nervoso }\end{array}$ & $\mathrm{X}$ & $X$ & $\mathrm{X}$ & $\mathrm{X}$ & $X$ & $\mathrm{X}$ & $X$ & & $X$ & $\mathrm{X}$ \\
\hline $\begin{array}{l}\text { s2 Olho, ouvido e } \\
\text { estruturas relacionadas }\end{array}$ & & $X$ & & & & & & & $\mathrm{X}$ & \\
\hline $\begin{array}{l}\text { s3 Estruturas } \\
\text { relacionadas à voz e fala }\end{array}$ & $\mathrm{X}$ & $X$ & & & & & & & $X$ & $\mathrm{X}$ \\
\hline $\begin{array}{l}\text { s4 Estruturas do sistema } \\
\text { cardiovascular, }\end{array}$ & $\mathrm{X}$ & $X$ & & $\mathrm{X}$ & $\mathrm{X}$ & $\mathrm{X}$ & $X$ & & $X$ & $X$ \\
\hline
\end{tabular}




\begin{tabular}{|c|c|c|c|c|c|c|c|c|c|c|}
\hline $\begin{array}{l}\text { hematológico e } \\
\text { respiratório }\end{array}$ & & & & & & & & & & \\
\hline $\begin{array}{l}\text { s5 Estruturas relaciondas } \\
\text { ao aparelho digestivo, } \\
\text { metabólico e endócrino }\end{array}$ & $X$ & $\mathrm{X}$ & & $X$ & $X$ & $X$ & & & $\mathrm{X}$ & \\
\hline $\begin{array}{l}\text { s6 Estruturas } \\
\text { relacionadas ao sistema } \\
\text { geniturinário e } \\
\text { reprodutivo }\end{array}$ & & $\mathrm{X}$ & & $\mathrm{X}$ & $X$ & & & & $\mathrm{X}$ & $\mathrm{X}$ \\
\hline $\begin{array}{l}\text { s7 Estruturas relaciondas } \\
\text { ao movimento }\end{array}$ & $\mathrm{X}$ & $\mathrm{X}$ & $\mathrm{X}$ & $\mathrm{X}$ & $X$ & $X$ & $\mathrm{X}$ & $\mathrm{X}$ & $\mathrm{X}$ & $\mathrm{X}$ \\
\hline $\begin{array}{l}\text { s8 Pele e estruturas } \\
\text { relacionadas }\end{array}$ & & $\mathrm{X}$ & & & & & & & $\mathrm{X}$ & $X$ \\
\hline $\begin{array}{l}\text { d1 Aprendizagem e } \\
\text { aplicação do } \\
\text { conhecimento }\end{array}$ & $X$ & $\mathrm{X}$ & $X$ & $\mathrm{X}$ & $X$ & & $\mathrm{X}$ & & & \\
\hline $\begin{array}{l}\text { d2 Tarefas e demandas } \\
\text { gerais }\end{array}$ & $X$ & $\mathrm{X}$ & & $\mathrm{X}$ & $X$ & $\mathrm{X}$ & $X$ & & $\mathrm{X}$ & $\mathrm{X}$ \\
\hline d3 Comunicação & & $\mathrm{X}$ & $\mathrm{X}$ & & & & $X$ & & & \\
\hline d4 Mobilidade & $X$ & $\mathrm{X}$ & $\mathrm{X}$ & $\mathrm{X}$ & $\mathrm{X}$ & $X$ & $\mathrm{X}$ & $\mathrm{X}$ & $\mathrm{X}$ & $\mathrm{X}$ \\
\hline d5 Cuidados pessoais & & $\mathrm{X}$ & $\mathrm{X}$ & $X$ & $X$ & $X$ & $X$ & & $\mathrm{X}$ & $X$ \\
\hline d6 Vida doméstica & & $\mathrm{X}$ & $\mathrm{X}$ & $\mathrm{X}$ & $\mathrm{X}$ & $X$ & $X$ & $\mathrm{X}$ & $\mathrm{X}$ & $\mathrm{X}$ \\
\hline $\begin{array}{l}\text { d7 Interações e relações } \\
\text { pessoais }\end{array}$ & & $\mathrm{X}$ & & & & $X$ & $\mathrm{X}$ & & $\mathrm{X}$ & \\
\hline $\begin{array}{l}\text { d8 Áreas principais da } \\
\text { vida }\end{array}$ & & $X$ & & $\mathrm{X}$ & $X$ & & $\mathrm{X}$ & $\mathrm{X}$ & $X$ & \\
\hline $\begin{array}{l}\text { d9 Vida comunitária, } \\
\text { social e cívica }\end{array}$ & & $X$ & & & & $X$ & & $X$ & $X$ & $X$ \\
\hline
\end{tabular}


Quadro 2 - Categorias de Fatores Ambientais, segundo consenso das especialidades

\begin{tabular}{|l|l|l|l|l|l|l|l|l|l|l|}
\hline & FA & FE & FN & FO & FQ & FR & FT & FTO & ONCO & SP \\
\hline $\begin{array}{l}\text { e1 Produtos e } \\
\text { tecnologia }\end{array}$ & & $\mathrm{X}$ & $\mathrm{X}$ & & $\mathrm{X}$ & $\mathrm{X}$ & $\mathrm{X}$ & $\mathrm{X}$ & & $\mathrm{X}$ \\
\hline $\begin{array}{l}\text { e2 Ambiente } \\
\text { natural e } \\
\text { mudanças feitas } \\
\text { pelo homem }\end{array}$ & & $\mathrm{X}$ & & $\mathrm{X}$ & $\mathrm{X}$ & $\mathrm{X}$ & $\mathrm{X}$ & $\mathrm{X}$ & & \\
\hline $\begin{array}{l}\text { e3 Apoio e } \\
\text { relacionamentos }\end{array}$ & & $\mathrm{X}$ & $\mathrm{X}$ & $\mathrm{X}$ & $\mathrm{X}$ & & $\mathrm{X}$ & $\mathrm{X}$ & $\mathrm{X}$ & $\mathrm{X}$ \\
\hline $\begin{array}{l}\text { e4 Atitudes } \\
\text { e5 Serviços, } \\
\text { sistemas e } \\
\text { políticas }\end{array}$ & $\mathrm{X}$ & $\mathrm{X}$ & $\mathrm{X}$ & $\mathrm{X}$ & $\mathrm{X}$ & $\mathrm{X}$ & $\mathrm{X}$ & $\mathrm{X}$ & $\mathrm{X}$ & $\mathrm{X}$ \\
\hline
\end{tabular}

Dentre as categorias de funcionalidade, b7 (funções neuromusculoesqueléticas e relacionadas ao movimento), s7 (estruturas relacionadas ao movimento) e d4 (mobilidade) aparecem em todas as especialidades demonstrando que podem ser as categorias essenciais para Fisioterapia. Na lista complementar, e4 (atitudes) também aparece como consenso geral.

Segundo a descrição do uso dos qualificadores da CIF (números que dão a magnitude de alteração em determinada categoria), é possível o uso do número "8" que indica "alteração de nível não especificado" e do " 0 " que indica "nenhum problema". Assim, um instrumento que contenha as categorias selecionadas e as opções de uso de "0" ou " 8 " como qualificadores pode determinar uma forma rápida e operacional para transferências de dados relativos à funcionalidade dentro da área de Fisioterapia. 


\section{Discussão}

A seleção de categorias por meio de consenso entre especialistas foi a maneira mais apropriada, principalmente, pela falta de comunicação direta entre os participantes, já que todos preencheram os formulários e questionários diretamente na rede mundial de computadores. Os resultados obtidos apontam para o objeto de estudo das respectivas especialidades, ou seja, as categorias selecionadas se relacionam diretamente com o objetivo de cada uma das áreas envolvidas.

Juntando as duas possibilidades citadas anteriormente (seleção de categorias mais relevantes e uso de categorias de primeiro nível), foi possível estruturar tal forma de avaliação para uso em Fisioterapia, mesmo com a amostra desenhada aleatoriamente, composta por profissionais conhecedores das bases teóricas da CIF.

Pouco mais da metade dos voluntários participaram da pesquisa. Esse resultado é superior à outras pesquisas do mesmo tipo e se deve, inicialmente, ao fato de que a amostra inicial foi formada por profissionais interessados no tema. No entanto, ao considerar-se as regiões do país de onde são tais participantes, não há representatividade da Região Norte. Mesmo assim, a amostra tem potencial para definir um consenso da área de Fisioterapia brasileira, já que mais da metade dos fisioterapeutas brasileiros estão entre as Regiões Sul e Sudeste.

A especialidade mais interessada foi a Neurofuncional. Provavelmente, esse fato se deu pela proximidade que a especialidade tem com a matriz da informação da CIF: Atividades e Participação. Outro ponto importante é a íntima relação com pacientes com deficiências graves e grandes incapacitados. Possivelmente, esse grupo populacional será o maior beneficiado com a implantação da CIF, mesmo apesar dela estar baseada em conceitos universais. Outras especialidades, apesar de não estarem relacionadas na CBO, apareceram como áreas específicas e foram incluídas neste estudo: Fisioterapia Oncofuncional e Saúde Pública. No caso da segunda, temos uma área de conhecimento abrangente, que pode ser excluída, pois, para que se determine um consenso para a área, será necessária uma amostra mais fidedigna.

A união dos resultados de cada especialidade resulta em categorias utilizadas em

todas as especialidades. Considerando as listas de funcionalidade, temos b7 (funções neuromusculoesqueléticas e relacionadas ao movimento), s7 (estruturas relacionadas ao 
movimento) e d4 (mobilidade) aparecendo em todas as especialidades indo de encontro com a definição de Fisioterapia enquanto área do conhecimento: ciência voltada à prevenção, diagnóstico e tratamento de distúrbios cinesiológicos-funcionais.

O uso das 3 categorias selecionadas em todas as especialidades da Fisioterapia em sistemas de informação é capaz de gerar indicadores sobre a qualidade da funcionalidade humana em relação ao movimento. Por outro lado, a lista complementar chamada de fatores ambientais, poderia ser composta, principalmente, pela categoria e1 (produtos e tecnologia), considerando a existência e a utilização de dispositivos que auxiliam o movimento humano, tais como próteses e dispositivos ortopédicos. O consenso levou à escolha da categoria e4 (atitudes), que se refere às atitudes da sociedade em relação ao paciente, como a mais importante da lista complementar. Considera-se, portanto, que a falta de interação social é um dos fatores mais relevantes na geração de problemas de desempenho.

Com dados gerados pelo uso da classificação, estudos sobre prevalência, coeficientes de incidência, comparação de coeficientes, estudos de riscos ambientais, entre outros, poderão ser desenvolvidos para conhecimento do estado de funcionalidade, assim como já se faz em relação aos dados de morbidade e mortalidade.

A lista criada gera um instrumento de fácil uso, que pode ser adaptado aos prontuários físicos ou, até mesmo, aos prontuários eletrônicos, em serviços e sistemas de saúde. Assim, determina-se uma forma rápida e viável de aplicação da classificação por meio de um instrumento de rápido uso, capaz de gerar informações sobre a funcionalidade, mesmo que de forma superficial. É importante salientar que dados essenciais para o conhecimento da evolução, da incidência e prevalência de incapacidades nas populações, ou seja, o estado de saúde funcional, ficam numa situação de invisibilidade atualmente no Brasil apenas com o uso da CID. Essa forma pode ser denominada Avaliação Baseada nos Componentes, Domínios e Adaptações da CIF. 
Conclusão

A primeira versão de um instrumento de classificação de funcionalidade em Fisioterapia e suas respectivas especialidades foi definida e pode ser denominada “Avaliação Baseada nos Componentes, Domínios e Adaptações da CIF (ABCDACIF)".

$\mathrm{O}$ uso recomendado pelo ABCDACIF, que inclui o uso das categorias de primeiro nível associado ao uso dos dois principais qualificadores (" 0 " e " 8 "), parece ser a forma mais adequada para iniciar a adoção e implantação da CIF como ferramenta geradora de informações epidemiológicas de funcionalidade. 


\section{Referências:}

- Bossmann T, et al.Validation of the Comprehensive ICF Core Set for Osteoarthritis: the perspective of physical therapists. Physiotherapy, 201; 97: 3-16

- Brasileiro IC, Moreira TMM, Jorge MSB. Interveniência dos fatores ambientais na vida de crianças com paralisia cerebral. Acta Fisiátrica, 2009; 16(3): 132-37.

- Escorpizo R, Stucki G, Cieza A, et al. Creating an interface between the International Classification of Functioning, Disability and Health and physical therapist practice. Phys Ther. 2010;90:1053-1063.

- Finger ME, Cieza A, Stoll J, Stucki G, Huber EO. Identification of intervention categories for physical therapy, based on the International Classification of Functioning, Disability and Health: a Delphi exercise. Physical Therapy. 2006; 86 (9): 1203-20.

- Herold CJ. A systematic review of outcomes assessed in randomized controlled trials of surgical intervention for carpal tunnel syndrome using the International Classifications of Functioning, Disability and Health (ICF) as a reference tool. BMC Musculoskeletal Disorders. 2006; 7:96.

- Kirchberger I, Glaessel A, Stucki G, Cieza A. Validation of the comprehensive International Classification of Functioning, Disability and Health Core Set for Rheumatoid Arthritis: the perspective of physical therapists. Physical Therapy. 2007; 87:368-84.

- Martins EF, et al. A Brazilian experience to describe functioning and disability profiles provided by combined use of ICD and ICF in chronic stroke patientsat homecare. Disability and Rehabilitation, 2011; Early Online, 1-11

- Neubert S, et al. Development of an ICF-based patient education program. Patient Educ Couns (2010), doi:10.1016/j.pec.2010.07.021

- OMS. Classificação Internacional de Funcionalidade, Incapacidade e Saúde. EDUSP. São Paulo; 2003.

- Palisano RJ. A collaborative model of service delivery for children with movement disorders: a framework for evidence-based decision making. Physical Therapy. 2006; 86 (9): 1295-305.

- Rauch A, et al. Using a case report of a patient with spinal cord injury to illustrate the application of the International Classification of Functioning, Disability and Health during a multidisciplinary patient management. Phisycal Therapy, 2010; 90: 1039-52 - Rauch A, Cieza A, Stucki G. How to apply the International Classification of 
Functioning, Disability and Health (ICF) for rehabilitation management in clinical practice. Eur J Phys Rehabil Med, 2008; 44: 329-42

- Sampaio RF, Mancini MC, Gonçalves GGP, Bittencourt NFN, Miranda AD, Fonseca ST. Aplicação da Classificação Internacional de Funcionalidade, Incapacidade e Saúde (CIF) na prática clínica do fisioterapeuta. Revista Brasileira de Fisioterapia. 2005; 9: 129-36.

- Starrost K, Geih S, Trautwein A, et al. Interrater Reliability of the Extended ICF Core Set for Stroke applied by Physical Therapists. Physical Therapy. 2008; 88: 841-851.

- Weigl Martin, Cieza A, Andersen C, Kollerits B, Amann E, Stucki G. Identification of relevant ICF categories in patients with chronic health conditions: a Delphi exercise. Journal of Rehabilitation Medicine. 2004; 44: 12-21.

- WHO.Towards a Common Language for Functioning, Disability and Health- ICF. Geneva; 2002. 
4.2 - Estudo 2: a ser submetido para publicação na Revista Acta Fisiátrica

Utilização da CIF em Fisioterapia do Trabalho: uma contribuição para coleta de dados sobre funcionalidade

\section{Eduardo Santana Araujo}

Departamento de Epidemiologia da Faculdade de Saúde Pública da Universidade de São Paulo.

edusantana@usp.br

Endereço para correspondência: Rua Maracatu, 102 - casa 1. Cotia/SP.

\section{Cassia Maria Buchalla}

Departamento de Epidemiologia da Faculdade de Saúde Pública da Universidade de São Paulo.

\section{cmbuchal@usp.br}

Endereço para correspondência: Av. Dr. Arnaldo, 715. São Paulo/SP. 


\section{Resumo}

Introdução. Embora conhecer a funcionalidade e incapacidade no Trabalho seja importante, a notificação sobre saúde do trabalhador no Brasil ainda é feita apenas por meio da Classificação Internacional de Doenças. A Classificação Internacional de Funcionalidade, Incapacidade e Saúde (CIF) é uma ferramenta capaz de gerar dados sobre a funcionalidade humana no trabalho e sobre a influência do ambiente no desempenho das atividades ocupacionais. Este trabalho tem como objetivo o desenvolvimento de uma ficha de coleta de dados para uso em Fisioterapia do Trabalho como intuito de facilitar a notificação de incapacidades ou de riscos à funcionalidade. Métodos. Por meio de um consenso com especialistas, baseado na técnica Delphi, foram escolhidas categorias relevantes da CIF e estruturado um instrumento de coleta de dados que, ao final, foi remetido aos participantes desse processo de seleção para avaliação de sua aplicabilidade. Resultados. Um instrumento de coleta de dados contendo 26 categorias da CIF e a possibilidade de uso de três qualificadores foi criado. Ele foi considerado de fácil exequibilidade segundo avaliação dos participantes. Conclusões. Uma ferramenta baseada na CIF foi desenvolvida e está pronta para ser testada como geradora de dados sobre funcionalidade humana.

Palavras-chave: consenso, fisioterapia, coleta de dados, funcionalidade, CIF, questionários 


\begin{abstract}
Introduction. While it is important to generate data about functioning and disability at Occupational Health, reporting in Brazil is still made only by ICD ways. The ICF is a capable tool of generating data on human functioning at work and on the environmental influence on the performance of occupational activities. This study aims to develop a form to collect data by Physiotherapy Labour Specialty to facilitate the reporting of disabilities or functioning risks. Methods. We developed a consensus with experts based Delphi Technique to choose relevant categories of ICF and made a data collection instrument that was sent to the participants of the process for evaluating about its applicability. Results. A data collection instrument based on ICF, containing 26 categories of the classification and three possible qualifications was created. It was approved by participants due its easy form. Conclusions. The classifier tool for Physical Therapists use is developed and ready to be tested as a data generator about functioning.
\end{abstract}

Descriptors: consensus, physiotherapy, data collection, functionality, ICF, questionnaires 


\section{Introdução}

O uso da CIF como ferramenta estatística que permita a obtenção de informações sobre funcionalidade humana pode ser considerado a sua mais importante aplicação. Apesar de transcorridos 11 anos de sua publicação, ainda não existem dados sobre funcionalidade no Trabalho baseados na linguagem comum e padronizada oferecida pela classificação. Os sistemas de informação sobre saúde do trabalhador contém apenas dados da Classificação Estatística Internacional de Doenças e Problemas Relacionados à Saúde (CID), ou seja, o código da doença ou condição/lesão. O foco da CID é a morbidade e a mortalidade. Portanto, os sistemas de informação sobre saúde do trabalhador geram informações importantes do ponto de vista clinico, porém, incompletas do ponto de vista dos determinantes das condições de funcionalidade. $\mathrm{O}$ uso da CIF poderá trazer dados mais amplos tanto sobre a funcionalidade, como em relação ao ambiente de trabalho e ao desempenho das atividades relacionadas à ele.

Muito mais do que estabelecer uma linguagem comum, e de estabelecer um padrão para a área, a CIF pode servir como ferramenta norteadora de ações estratégicas que melhorem a produtividade, a eficiência do trabalho e o direcionamento dos recursos financeiros.

O conhecimento do estado geral de saúde pode partir de dados gerados pela avaliação da população economicamente ativa, visto que as leis do país exigem, por exemplo, exames admissionais, demissionais e periódicos, que podem alimentar sistemas de informação em saúde. Assim, de maneira relevante, a falta de informações sobre funcionalidade, que poderiam ser fornecidas, por exemplo, por fisioterapeutas, afeta drasticamente a área de Saúde do Trabalhador.

Os fisioterapeutas brasileiros ainda não têm contato diário e efetivo com a classificação, tampouco conhecem o modelo de funcionalidade que a CIF propõe (Sampaio e Madel, 2009). Segundo os trabalhos publicados desde o lançamento dessa classificação pela OMS, o modelo multidirecional, publicado na classificação, deve ser absorvido para que ela seja efetivamente utilizada. A Fisioterapia é uma das principais áreas que vem tentando usar a CIF em todo mundo. Isto se dá, principalmente, pela necessidade de se unificar a linguagem diagnóstica destes profissionais (Palisano, 2006). 
A CIF possui mais de 1400 categorias. Isso significa que podem ser gerados, para uma mesma pessoa, mais de 1400 códigos. Cada categoria é transformada em código ao ser completada por qualificadores (que são números que dão a magnitude de um problema dentro de uma categoria específica). Em regras gerais, o classificador deve selecionar as categorias e os qualificadores que identificam e expressam cada caso (OMS, 2003).

Uma sub-categoria da CIF, como, por exemplo, d4500 (andar distâncias curtas menos que $1 \mathrm{Km}$ ) sempre faz parte de uma "categoria-mãe", do nível mais simples, mais geral, (ou de $1^{\circ}$ nível), que, neste caso é d4 (mobilidade). Se considerarmos apenas o primeiro nível, a CIF em 30 categorias apenas, que se referem à soma dos capítulos de todos os componentes. Cada categoria da CIF tem até quatro níveis de. Assim, é possível diminuir o número de categorias por meio do uso das de menor complexidade.

Além disso, a utilização dos qualificadores também pode ser simplificada. Uma categoria sem alterações (ou sem problemas) é completada com o qualificador " 0 " (zero). Já magnitude de um problema é definida com o uso dos qualificadores de " 1 " a “4", sendo "4" a identificação de um problema completo (ou de magnitude máxima). Porém, a CIF também propõe o uso do qualificador "8" (não especificado), que significa a existência de alguma alteração, sem que seu grau de magnitude esteja especificado. Assim, pode-se propor o uso de apenas dois qualificadores : "0" para ausência e o " 8 " para presença de determinado problema numa categoria específica.

Esse recurso pode evitar a calibração necessária entre os qualificadores da CIF e os instrumentos de medida (Cieza, 2002). Assim, torna-se possível a criação de um instrumento classificatório de fácil uso e de grande serventia na geração de dados sobre funcionalidade e incapacidade.

Este estudo visa estruturar um instrumento de classificação para uso na especialidade de Fisioterapia do Trabalho, norteado pelos domínios da CIF, que seja capaz de apresentar dados de forma que se permita a análise e a geração de informações sobre funcionalidade humana. 


\section{Método}

Foi realizado um estudo de consenso nacional com uma amostra composta por 24 profissionais indicados pela Associação Brasileira de Fisioterapia do Trabalho ABRAFIT, para construção de uma lista mínima de categorias da CIF referentes às condições dos pacientes atendidos por essa área. A ABRAFIT possui cerca de 120 profissionais titulados nas cinco regiões do pais. A participação na pesquisa ocorreu após convite e aceite, tendo sido preenchido um consentimento livre e informado pelos profissionais convidados.

$\mathrm{Na}$ primeira fase, todos receberam um convite por meio eletrônico, com os detalhes da pesquisa e a declaração de aceite em relação à participação no estudo. Foilhes enviado um material descritivo sobre a CIF, testado previamente em um estudo piloto. Um questionário ficou disponibilizado, também por meio eletrônico, no sítio do Laboratório de Estudos Populacionais (LEP) da Faculdade de Saúde Pública da Universidade de São Paulo para que cada participante indicasse as categorias da CIF aplicáveis à sua especialidade. Os formulários encontram-se no link http://www.fsp.usp.br/site/paginas/mostrar/556 e no Anexo 1.

O material descritivo disponibilizado continha dois arquivos, o primeiro para leitura obrigatória e o segundo para leitura complementar. O primeiro arquivo tratava-se da tradução de um documento feito por grupos de trabalho da OMS, para ser disponibilizado em página eletrônica da OMS, denominado ICF Overview. O segundo arquivo foi a versão integral da CIF em Português. O acesso ao questionário só foi possível após a declaração de entendimento acerca do material proposto. A leitura do material era imprescindível para que o convidado/profissional tivesse condições de participar do consenso. A declaração pode ser visualizada no Formulário B do Anexo 1.

Na segunda fase, os participantes foram urgidos a responderem ao questionário. O prazo para resposta foi de 30 dias após a disponibilização do material. Na metade do período, todos receberam uma mensagem de alerta sobre o prazo de entrega.

O questionário solicitava aos participantes que selecionassem categorias da CIF aplicáveis para a sua especialidade e as respostas foram computadas pelo LEP, automaticamente, formando um banco de dados no sistema. 
Cada categoria da CIF indicada por pelo menos $80 \%$ dos participantes foi considerada como consenso, segundo método utilizado por Finger (2006). A partir das categorias selecionadas, foi estruturado um instrumento para uso pela especialidade. $\mathrm{Na}$ terceira fase, essa ferramenta foi reenviada aos participantes para nova análise.

Resumindo, o processo de consenso foi realizado em três fases:

\begin{tabular}{|c|c|c|}
\hline FASE 1: convite e aceite & $\begin{array}{l}\text { FASE 2: Identificação das } \\
\text { categorias mais } \\
\text { importantes }\end{array}$ & FASE 3 Elaboração da lista \\
\hline - envio material didático & $\begin{array}{l}\text { - } \quad \text { apresentação } \mathrm{da} \\
\text { classificação }\end{array}$ & - analise das respostas \\
\hline \multirow[t]{3}{*}{$\begin{array}{l}\text {-identificação por meio } \\
\text { eletrônico }\end{array}$} & $\begin{array}{llll} & \text { respostas } & \text { com } & \text { as } \\
\text { categorias } & & & \text { mais } \\
\text { importantes da } & \text { área do } & \text { do } \\
\text { participante } & & & \end{array}$ & $\begin{array}{l}\text { - seleção das categorias } \\
\text { indicadas por } 80 \% \text { ou mais } \\
\text { dos participantes }\end{array}$ \\
\hline & & $\begin{array}{l}\text { - envio da lista para os } \\
\text { participantes }\end{array}$ \\
\hline & & $\begin{array}{lcc}\text { analise } & \text { de } & \text { sua } \\
\text { aplicabilidade } & & \end{array}$ \\
\hline
\end{tabular}

- Fase 1: convite aos profissionais e envio do material didático sobre a CIF.

O material didático enviado foi previamente testado num estudo-piloto quanto a sua potencialidade de apresentar os conceitos básicos da CIF, suficientes para que cada participante pudesse selecionar, com segurança, as categorias mais relevantes para sua especialidade.

O envio do material didático e da documentação de identificação necessária foi feito por meio eletrônico. 
- Fase 2: apresentação de todas as categorias da CIF (níveis 1 e 2) para seleção das mais utilizadas pela especialidade, por meio do sistema eletrônico do LEP;

O participante selecionou as categorias da CIF aplicáveis na sua área de atuação e intervenção, indicando SIM ou NÃO ao lado de cada uma delas. Um item foi considerado aplicável se indispensável para uso nas atividades do especialista na sua prática profissional diária.

- Fase 3: análise das respostas, elaboração da lista mínima de categorias da CIF, com base nas informações obtidas na fase anterior, envio do instrumento final aos participantes para validação e análise sobre a aplicabilidade;

Após a resposta de todos os participantes, foram listadas as categorias consideradas aplicáveis.A partir das categorias selecionadas pelo consenso, foi criado um instrumento para uso da classificação, obedecendo às regras de uso dos qualificadores da CIF, expostas no início de cada componente da classificação. Este foi reenviado aos participantes para conhecimento das categorias selecionadas. Cada participante, nesta fase 3, reavaliou o instrumento e não houve novas sugestões. Assim, foram convidados a responder a um novo questionário, desta vez sobre a aplicação do instrumento (Anexo 2). 


\section{Resultados}

O Quadro 1 apresenta as categorias da CIF selecionadas por pelo menos $80 \%$ dos participantes.

Quadro 1 - Relação das categorias da CIF (níveis 1 e 2 ) selecionadas pelos participantes como importantes para a área de fisioterapia do trabalhador

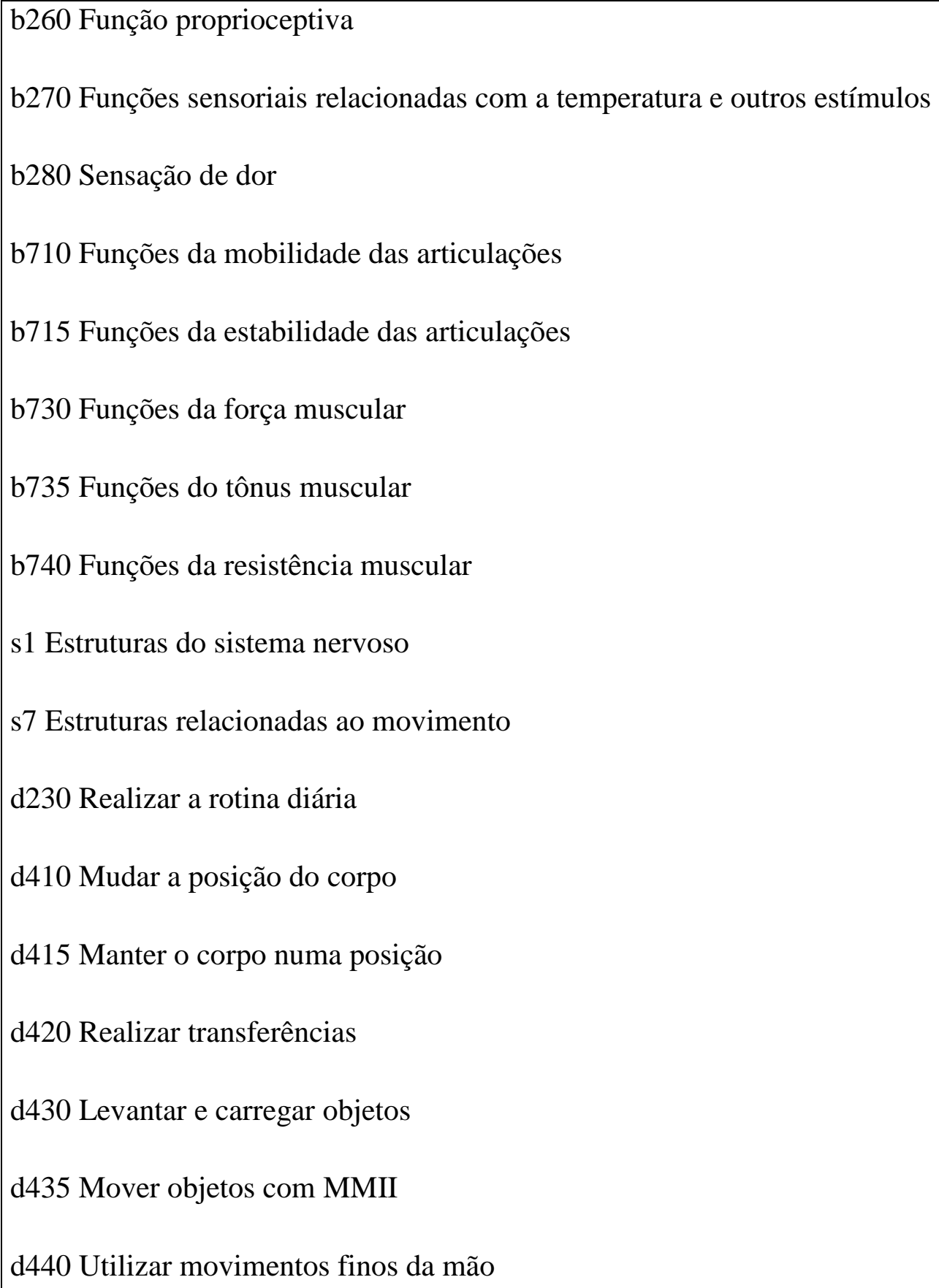


d450 Andar

d470 Utilizar transporte público

d475 Dirigir

d7 Interações e relacionamentos interpessoais

e1 Produtos e tecnologias disponíveis ao indivíduo

e2 Ambiente natural do local de trabalho e entorno

e4 Atitudes de pessoas próximas no trabalho

e5 Serviços, sistemas e políticas disponíveis no país

A partir das categorias selecionadas, foi estruturado um instrumento de coleta de dados e classificação simplificado (Quadro 2), pois contém as categorias mais relevantes até o $2^{\circ}$ nível de complexidade, de um total de quatro níveis possíveis. A ferramenta ainda simplifica o uso dos qualificadores, pois as respostas usam, no máximo, três possibilidades: perda completa (qualificador “4”), perda parcial (qualificador “8”, em substituição ao 1, 2 ou 3) e sem perda (qualificador “0”).

No instrumento final apresentado acima, o usuário marca cada resposta referente ao resultado de sua avaliação. Cada uma delas equivale a um qualificador da CIF. Por exemplo, se a primeira questão for anotada como "perda completa da função", tem-se o código b710.4. Ao marcar que existe completa dificuldade/lesão/perda da função/alteração, ler-se-á o qualificador “4”, ao se marcar parcial dificuldade/lesão/perda da função/alteração, ler-se-á o qualificador "8" e ao se marcar que não há dificuldade/lesão/perda da função/alteração, ler-se-á o qualificador “ 0 ”. Na parte de fatores ambientais, a palavra "atrapalham" deverá ser lida como qualificador ".8" e a palavra "facilitam" como qualificador "+8".

Quadro 2 - Sugestão para instrumento de avaliação do trabalhador

\section{Instrumento de coleta de dados sobre funcionalidade $e$ incapacidade}

Especialidade: Fisioterapia do Trabalho 
Nome:

Idade:

Sexo:

Raça/Cor:

Antecedentes pessoais:

CID (se houver):

$\begin{array}{ccc}\text { Perda } & \text { Perda } & \\ \text { completa da } & \text { parcial da } & \text { Função } \\ \text { função } & \text { função } & \text { preservada }\end{array}$

b260 Função proprioceptiva

b270 Funções sensoriais relacionadas com a temperatura e outros estímulos

b280 Sensação de dor Presente ( ) Ausente ( )

Perda Perda completa da parcial da função função

b710 Funções da mobilidade das articulações

b715 Funções da estabilidade das articulações

b730 Funções da força muscular

b735 Funções do tônus muscular

b740 Funções da resistência muscular

$\begin{array}{cc}\text { Existe } & \text { Não existe } \\ \text { lesão/alteração } & \text { lesão/alt. }\end{array}$

s1 Estruturas do sistema nervoso

s7 Estrutura

Desempenho (o profissional pergunta ao paciente sobre sua vida habitual)

NÃO FAZ

FAZ com
dificuldade

FAZ sem

dificuldade 
parcial

d230 Realizar a rotina diária

d3 Comunicação

d470 Utilizar transporte público

d475 Dirigir

d7 Interações e relacionamentos interpessoais

$\begin{array}{cccc}\text { Capacidade (o profissional avalia a } & \text { Dificuldade } \\ \text { condição física do paciente) } & \text { completa } & \begin{array}{c}\text { Dificuldade } \\ \text { parcial }\end{array} & \begin{array}{c}\mathrm{S} / \\ \text { dificuld. }\end{array}\end{array}$

d410 Mudar a posição do corpo

d415 Manter o corpo numa posição

d420 Realizar transferências

d430 Levantar e carregar objetos

d435 Mover objetos com MMII

d440 Utilizar movimentos finos da mão

d450 Andar

\section{Fatores ambientais (informações adicionais/complementares)}

Atrapalham Facilitam

Sobre os produtos e tecnologias disponíveis

ao indivíduo

Sobre os itens do ambiente natural do local de

trabalho e entorno

Sobre as atitudes de pessoas próximas no

trabalho, segundo a impressão do paciente

Sobre serviços, sistemas e políticas

disponíveis no país

As respostas referentes à aplicabilidade do instrumento foram as seguintes:

- 91,67\% consideraram aceitável a aplicação do instrumento na prática profissional;

- 91,67\% acreditavam que os conceitos da CIF propiciam unificação da linguagem na 
especialidade;

- $100 \%$ entenderam que o uso do instrumento é capaz de gerar dados sobre funcionalidade humana;

- 66,67\% apontaram que o instrumento desenvolvido a partir da CIF é capaz de alimentar sistemas de informação como ocorre com a CID;

- 58,33\% informaram que o instrumento é completamente ou muito aplicável;

- 91,67\% consideraram como imprescindível ou muito importante.

Gráfico 1 - Aplicabilidade, segundo opinião dos participantes

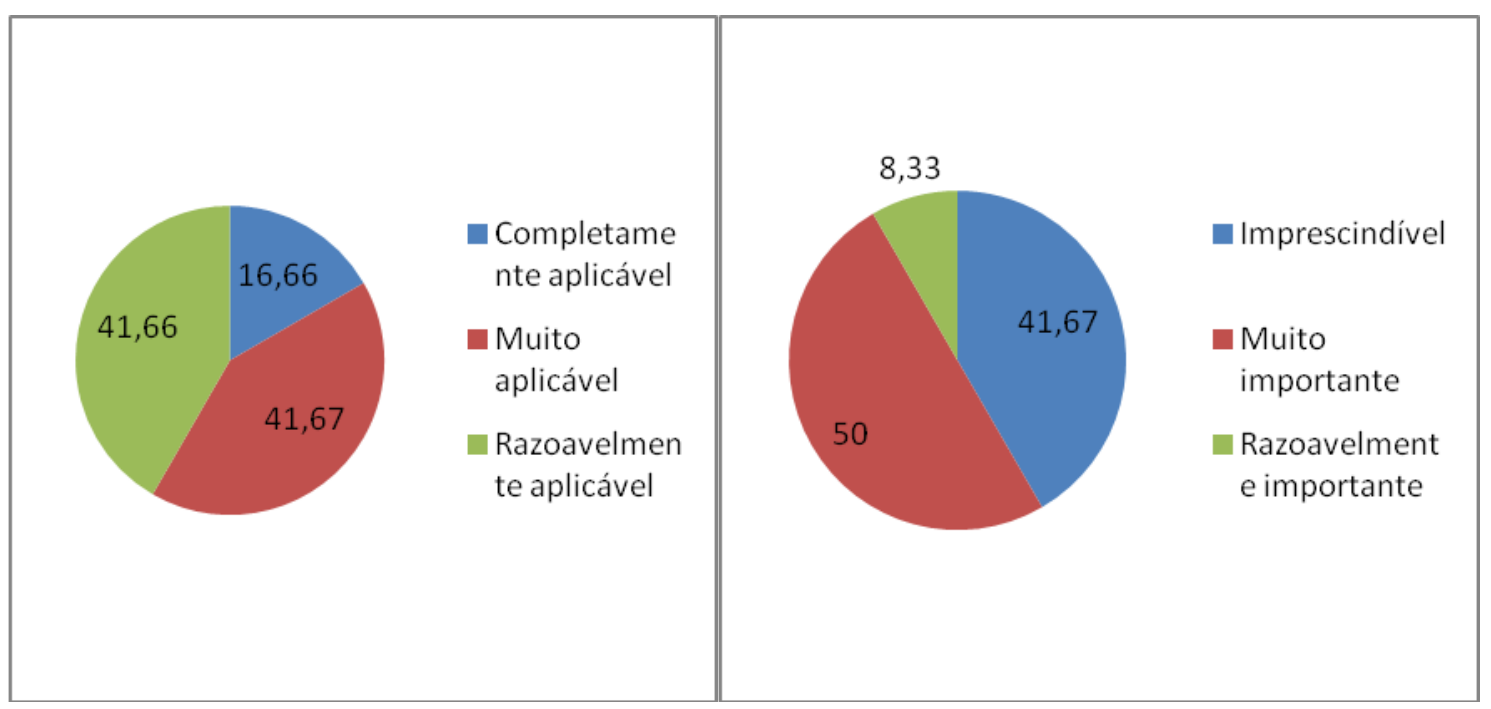

Gráfico 2 - Relevância, segundo opinião dos participantes

Ainda, segundo $83,33 \%$ dos profissionais consultados, o instrumento classificatório poderá trazer benefícios e vantagens para o trabalhador por gerar informações sobre sua funcionalidade. 


\section{Discussão}

Para utilização da CIF a partir de listas específicas, tem sido usual a execução de um processo de consenso entre especialistas. Essa parece ser a forma mais apropriada, sendo o método Delphi o mais utilizado desde o início do processo de elaboração dessas listas (Weigl M, AC, CA, BK, et al. 2004) até a atualidade (Kalay L, Fujimori S, Suzuki H, Minamoto K, et al., 2010).

Neste trabalho, o processo foi conduzido por meio da rede mundial de computadores, num sistema sofisticado de aplicação de questionários. As categorias selecionadas representam a especificidade da área e apontam os aspectos de funcionalidade e incapacidade que os especialistas consideram mais importantes. $\mathrm{O}$ instrumento elaborado a partir do consenso se baseia no uso dos qualificadores da CIF, porém, de forma simplificada: o uso do "8" (problema de magnitude não especificada) substitui o uso do "1" (problema de magnitude leve), do "2" (problema de magnitude moderada) e do "3" (problema de magnitude grave). Excluímos assim, a necessidade de calibrar instrumentos de avaliação com os qualificadores da CIF, o que poderia demandar mais tempo para uso e dificultar a execução da classificação. Como a CIF tem um padrão único, ela deve ser constantemente calibrada sob a perspectiva das ferramentas de avaliação existentes (Cieza A et al, 2005).

A ferramenta criada deve ser submetida a validação. Os resultados obtidos neste trabalho dão conta da qualidade prática da ferramenta e da importância dos dados que ela coleta, tendo sido aprovada para uso pelos participantes, incluindo a forma baseada na especialidade e não baseada em uma condição de saúde. Esse tipo de "core set" busca informações de funcionalidade para determinada área de atuação, gerando dados relevantes sobre a situação das pessoas avaliadas (Finger et al, 2012).

Há “core sets" para condições de saúde específicas que foram revistos sob novos olhares (Starrost K et al, 2008), o que pode indicar que, mesmo após um consenso de profissionais de diferentes áreas, o olhar de determinada especialidade ainda leva à mudanças relevantes, pois, cada área profissional tende a escolher categorias que se refiram a possíveis alterações tratadas em sua especialidade. Isso leva a crer que a base por área é mais segura que por uma condição de saúde. Muitos "core sets" por condições de saúde foram desenvolvidos como parte de um projeto multicêntrico, envolvendo especialistas do mundo todo e utilizando diferentes níveis de complexidade 
da CIF, incluindo os mais robustos. Alguns foram validados sob a perspectiva de determinada área (Bossmann $\mathrm{T}$ et al, 2011) e podem ser instrumentos de extrema utilidade na coleta de dados sobre funcionalidade de um grupo de pacientes com a mesma condição de saúde. No entanto, no caso de um instrumento de coleta de dados para uso por determinada especialidade, é possível abranger um maior número de condições de saúde (como as mais comuns da área) com o uso mais simplificado das categorias da CIF. Mesmo assim, é possível levantar dados relevantes sobre a funcionalidade.

As atividades do especialista em Fisioterapia do Trabalho envolve prevenção e tratamento. É importante que uma ficha de notificação seja amigável, que o tempo de preenchimento seja curto e suficiente para atingir os objetivos propostos na geração de informações. Assim, verificar a aceitabilidade de quem efetivamente a usará é um dos principais passos para garantir sua adoção . A ferramenta criada foi aceita por mais de $90 \%$ dos entrevistados.

Araujo e Buchalla (2011), em estudo de revisão verificaram que a unificação da linguagem é uma das necessidades atuais da área de Fisioterapia. Há uma contribuição neste sentido com a criação da ferramenta, segundo a maioria dos profissionais entrevistados, o que confirma que realmente existe uma necessidade de padronização conceitual.

O envolvimento dos profissionais da Fisioterapia com sistemas de informação de saúde ainda é pequeno, pois parece haver falta de entendimento sobre a importância das informações geradas por eles para a Saúde Pública. O reconhecimento da importância, aplicabilidade e vantagens do uso da CIF depende de diversos fatores, como a clareza sobre o que essas informações podem gerar de retorno para a atividade da área. O que defendemos é que o instrumento que facilita o uso da CIF em Fisioterapia do Trabalho tenha uso amplo e que possa ser utilizado com segurança, garantindo o esclarecimento da verdade sobre o estado de funcionalidade de determinada população.

Com dados gerados pelo uso da classificação, estudos sobre prevalência, incidência, comparação de coeficientes, estudos de riscos ambientais, entre outros, poderão ser desenvolvidos para conhecimento do estado de funcionalidade, assim como já se faz em relação aos dados de morbidade e mortalidade. 
A lista criada gera um instrumento de fácil uso, que pode ser adaptado aos prontuários físicos ou até mesmo aos prontuários eletrônicos, em serviços e sistemas de saúde. Assim, determina-se uma forma rápida e viável de aplicação da classificação por meio de um instrumento prático, capaz de gerar informações sobre a funcionalidade, mesmo que de forma superficial. É importante salientar que dados essenciais para o conhecimento da evolução, da incidência e da prevalência de incapacidades nas populações, estão numa situação de invisibilidade atualmente no Brasil, apenas com o uso da CID. Sendo CIF e CID complementares entre si, existe a necessidade clara de um sistema de informação mais completo. 
Conclusão

A primeira versão de um instrumento de classificação baseado na CIF, para uso em Fisioterapia do Trabalho, estruturado pela seleção de categorias mais relevantes e pelo uso do qualificador "não especificado", foi desenvolvida e está pronta para ser testada como geradora de dados sobre funcionalidade humana. 


\section{Referências:.}

1. Cieza A, Brockow T, Ewert T, Amman E, Kollerits B, Chatterji S, Ustun TB, Stucki G. Linking health-status measurements to the International Classification of Functioning, Disability and Health. Journal of Rehabilitation Medicine 2002; 34: 205-10.

2. de Pedro-Cuesta J, Comin Comin M, Virues-Ortega J, Almazan Isla J, et al. ICF-based disability survey in a rural population of adults and older adults living in Cinco Villas, Northeastern Spain: design, methods and population characteristics. Neuroepidemiology. 2010; 35(1):72-82.

3. Fernandez-Lopez JA, Fernandez-Fidalgo M, Cieza A. Quality of life, health and well-being conceptualizations from the perspective of the International Classification of Functioning, disability and health (ICF). Revista Espanola de Salud Publica. 2010; 84(2):169-84.

4. Finger ME, Escorpizo R, Glassel A, Gmunder HP, Luckenkemper M, Chan C, Fritz J, Studer U, Ekholm J, Kostanisek N, Stucki G, Cieza A. ICF Core Set for vocational rehabilitation: results of an international consensus conference. Disabilility and Rehabilitation. 2012; 34(5): 429-38.

5. Hinsch KD, Zick . International classification of function, disability and health (ICF): Basis for cutaneous rehabilitation management. Hautarzt 2010; 61(4):294-301.

6. Kalay L, Fujimori S, Suzuki H, Minamoto K, et al. Description of environmental determinants of quality of life in children with intellectual disability in Japan using the Delphi technique. Environmental Health and Preventive Medicine. 2010; 15(2):73-83. 
7. McDougall $\mathrm{J}$, Wright $\mathrm{V}$, Rosenbaum $\mathrm{P}$. The ICF model of functioning and disability: Incorporating quality of life and human development. Developmental Neurorehabilitation. 2012; 13(3):204-211.

8. Palisano RJ. A collaborative model of service delivery for children with movement disorders: a framework for evidence-based decision making. Physical Therapy. 2006; 86 (9): 1295-305.

9. Pollard B, Dixon D, Dieppe P, Johnston M. Measuring the ICF components of impairment, activity limitation and participation restriction: an item analysis using classical test theory and item response theory. Health and Quality of Life Outcomes. 2009; 7(41).

10. Sampaio RF, Madel TL. Funcionalidade e Incapacidade humana: explorando o escopo da classificação internacional da Organização Mundial da Saúde. Cad. Saúde Pública. 2009; 25 (3): 475-83.

11. Weigl M, AC, CA, BK, et al. Identification of relevant ICF categories in patient with chronic health conditions: A Delphi exercise. Journal of Rehabilitation Medicine. 2004; Supplement (44):12-21 
Anexo 1 - Formulários A, B, C e D

A) CONVITE e DETALHES DA PESQUISA

Prezado Especialista em Fisioterapia do Trabalho, reconhecido pela ABRAFIT, Eu, Eduardo Santana de Araujo, aluno do programa de doutorado em Saúde Pública da Faculdade de Saúde Pública da USP, concentrado em Epidemiologia, sob orientação da Profa. Dra. Cássia M. Buchalla, tenho como projeto a criação de um instrumento baseado na Classificação Internacional de Funcionalidade, Incapacidade e Saúde (CIF) para uso em sua especialidade. Este instrumento visa aumentar a viabilidade do uso da classificação.

Minha proposição será baseada na metodologia Delphi (maiores detalhes abaixo) e será avaliada por uma comissão de especialistas na área de Fisioterapia do Trabalho.

Assim, considerando sua experiência acadêmica, profissional e seu vasto conhecimento sobre a área, gostaria de convidá-lo a fazer parte de tal comissão. Havendo o aceite de participação, informações complementares serão enviadas em breve.

Será uma enorme honra poder contar com sua valiosa colaboração.

Saudações acadêmicas,

Eduardo Santana de Araujo

\section{Técnica Delphi:}

A técnica Delphi tem por objetivo obter o consenso de um painel de pessoas com 
conhecimento do assunto a ser investigado - os chamados especialistas. Ela inclui uma série de rodadas para reunir e fornecer informações sobre o assunto a ser examinado. As principais características desta técnica são o anonimato para evitar o domínio dos indivíduos isolados do grupo; iteração, o que permite que os membros do painel possam mudar suas opiniões nas rodadas subseqüentes, e feedback controlado, mostrando a distribuição das respostas do grupo, bem como cada resposta anterior do indivíduo.

A técnica Delphi respeita os seguintes passos:

Rodada 1: Indivíduos envolvidos na causa e especialistas são selecionados, sendo convidados a opinar sobre um assunto específico, com base em seus conhecimentos e experiências sobre o tema.

Obs: Estas opiniões são agrupadas sob um número limitado de posições e declarações e colocadas em circulação para todos os participantes.

Rodada 2: Os participantes classificam (ranqueiam) a sua concordância com cada item do construto.

Obs: As classificações são sumarizadas e incluídas em um versão secundária do construto.

Rodada 3: Os participantes re-classificam (re-ranqueiam) sua concordância com cada item do construto, com a oportunidade para mudar a sua pontuação, tendo em vista as respostas do grupo.

Obs: As reclassificações são sumarizadas e avaliadas pelo grau de consenso: se um grau aceitável de consenso é obtido, o processo finaliza-se, com feedback dos resultados finais obtidos aos participantes; se não, o terceiro passo é repetido.

Uma concordância mínima de $80 \%$ dos especialistas será o critério adotado para a retenção do item. 
B) DECLARAÇÃO DE ACEITE

$\mathrm{Eu}$

CREFITO

especialista profissional em Fisioterapia do Trabalho, declaro que aceito participar da pesquisa intitulada "Utilização da Classificação Internacional de Funcionalidade na prática da Fisioterapia: uma contribuição para coleta de dados epidemiológicos sobre funcionalidade", a ser desenvolvida como tese de Doutorado do aluno Eduardo Santana de Araujo, da Faculdade de Saúde Pública da Universidade de São Paulo.

Declaro ainda ter lido o material didático enviado sobre a Classificação Internacional de Funcionalidade, Incapacidade e Saúde - CIF, da Organização Mundial da Saúde.

\section{C) MATERIAL DESCRITIVO OBRIGATÓRIO}

\section{CIF: uma abordagem ampla.}

\section{INTRODUÇÃO}

A Classificação Internacional de Funcionalidade, Incapacidade e Saúde (CIF) é uma ferramenta para descrição e organização de informações sobre a funcionalidade e a incapacidade. Ele fornece uma linguagem padrão, uma base conceitual para a definição e a classificação da saúde e da incapacidade.

A CIF foi aprovada para uso pela Assembléia Mundial da Saúde, em 2001, após testes extensivos em todo o mundo envolvendo as pessoas com incapacidades e profissionais de uma variedade de disciplinas e áreas relevantes. Uma classificação secundária, para crianças e jovens (CIF-CJ), foi publicada em 2007.

A CIF integra os principais modelos de incapacidade. Reconhece o papel de fatores ambientais na criação das limitações, bem como, a relevância das condições de saúde 
associadas e seus efeitos.

Este documento é uma visão geral que fornece uma breve introdução sobre a CIF, sua estrutura, conteúdo, efeitos e aplicações.

\section{Pontos importantes}

Trata-se de um sistema de classificação multiuso, projetado para atender a diversas disciplinas e setores, por exemplo, na educação e transporte, bem como nos serviços de saúde, serviços sociais e entre diferentes países e culturas. Os objetivos da CIF, segundo a Organização Mundial da Saúde, são: fornecer uma base científica para compreender e estudar a saúde e estados relacionados, os resultados de intervenções, determinantes e alterações no nível de saúde e funcionalidade.

A classificação estabelece uma linguagem comum para descrever a saúde com o intuito de melhorar a comunicação entre usuários diferentes, como profissionais de saúde, pesquisadores, decisores políticos e o público em geral. Também permite a comparação de dados entre países, disciplinas de cuidados de saúde, serviços e durante o tempo de tratamento. Fornece ainda um esquema de codificação sistemático para sistemas de informação de saúde.

A CIF foi aceita como uma das classificações sociais das Nações Unidas, tendo sido considerada um instrumento adequado para a implementação dos mandatos em declarações internacionais de direitos humanos, bem como em legislações nacionais. Assim, a CIF fornece um valioso quadro para monitoramento de aspectos da Convenção da ONU sobre os direitos das pessoas em geral, bem como para a formulação de políticas nacionais e internacionais.

\section{Princípios}


Quatro princípios gerais orientaram o desenvolvimento da CIF e são essenciais para a sua aplicação.

Universalidade - uma classificação de funcionalidade e incapacidade deve ser aplicável a

todas as pessoas, independentemente da condição de saúde e em todos os contextos físicos, sociais e culturais. A CIF consegue isso e reconhece que qualquer um pode experimentar alguma incapacidade. Ela diz respeito a funcionalidade e incapacidade de todos e não foi concebida, nem deve ser usada como rótulo de pessoas com deficiência, como um grupo separado da sociedade.

Paridade e neutralidade etiológica - na classificação de funcionalidade e incapacidade, não há uma explícita ou implícita distinção entre saúde e diferentes condições, sejam 'mentais' ou 'físicas'. Em outras palavras, a incapacidade não é diferenciada por etiologia.

Deslocando o foco da condição de saúde para funcionalidade, ela coloca todas as condições de saúde em pé de igualdade, permitindo-lhes serem comparadas usando uma métrica comum. Esclarece ainda que não se pode inferir a participação na vida cotidiana por determinado diagnóstico etiológico sozinho.

Neutralidade - as definições de domínio são redigidas em linguagem neutra, sempre que possível, para que a classificação possa ser usada para gravar os aspectos positivos e negativos da funcionalidade e incapacidade.

Influência ambiental - a CIF inclui uma lista de fatores ambientais em reconhecimento do

importante papel do ambiente na funcionalidade das pessoas. Estes fatores variam de fatores físicos (tais como o clima, terreno ou arquitetura) a fatores sociais (como as 
atitudes, instituições e leis). A interação com o ambiente é um aspecto essencial do entendimento científico da funcionalidade e incapacidade.

\section{O MODELO DA CIF}

$\mathrm{Na}$ CIF, funcionalidade e incapacidade são conceitos multi-dimensionais, relativos

a:

- funções e estruturas do corpo e suas alterações;

- atividades das pessoas e as suas limitações;

- participação ou envolvimento de pessoas em todas as áreas da vida e as restrições de participação;

- fatores ambientais que afetam essas experiências (e se estes fatores são facilitadores ou barreiras).

A CIF conceitua o nível de uma pessoa funcionar como uma interação dinâmica entre sua saúde, fatores ambientais e fatores pessoais. É um modelo biopsicossocial, com base em uma integração dos modelos sociais e biológicos da incapacidade.

Conforme ilustrado na Figura 1, a incapacidade é multidimensional e interativa.

Todos os componentes de incapacidade são igualmente importantes e qualquer um pode interagir com o outro. Fatores ambientais devem ser tomados como essenciais, pois, sempre afetam todos os outros componentes.

Embora os fatores pessoais sejam reconhecidos no modelo interativo, mostrado na Figura 1, ainda não são classificados na CIF. Tais fatores influenciam sobre como incapacidade é vivida pelo indivíduo e alguns, tais como idade e gênero, geralmente são incluídos em conjuntos de dados. 
Figura 1 - Interação entre os componentes da CIF.

CONDIÇÃO DE SAÚDE (transtorno ou doença)

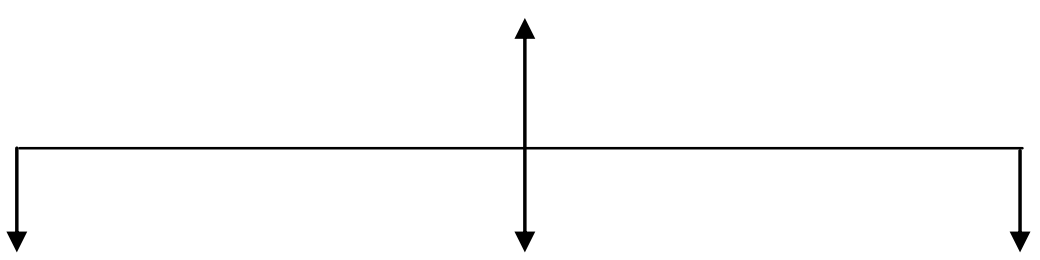

FUNÇÃO E ESTRUTURA

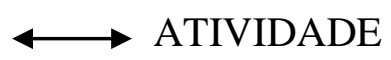

PARTICIPAÇÃO

DO CORPO

(deficiência)

(limitação)

(restrição)

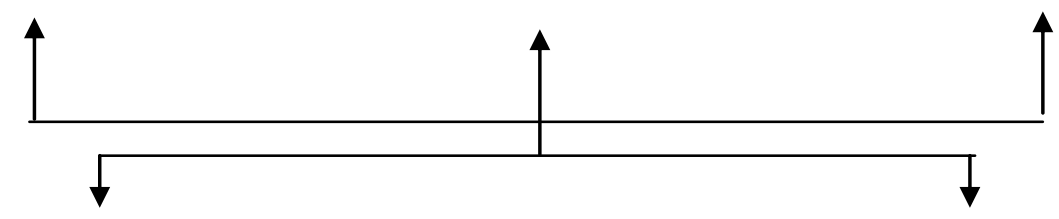

FATORES AMBIENTAIS

FATORES PESSOAIS

Fonte: OMS (2001)

A CIF pode fornecer ou sustentar um perfil descritivo de padrão de funcionalidade de um indivíduo, não apenas um "sim" ou "não" como resposta sobre se ele está incapacitado. Uma decisão sobre onde desenhar uma linha entre estar ou não incapacitado depende de efeitos para fazê-lo. Medidas individuais, pesquisas e outras aplicações devem ser baseadas nesta compreensão, bem como o conhecimento de que existem várias dimensões da incapacidade e potencialmente múltiplas perspectivas a considerar. Medições diferentes em nível individual ou populacional podem resultar em diferentes ações nesses diferentes níveis, bem como, determinar os referidos limites. Portanto, há diferentes medidas em nível individual e populacional. 


\section{Componentes da CIF e seu conteúdo:}

Os principais componentes da funcionalidade e da incapacidade são estabelecidos

e definidos no Quadro 1; Estes são entendidos 'no contexto da saúde' que esclarece que as restrições de participação estão relacionadas a outros fatores, por exemplo, o prejuízo racial, que não está dentro do escopo da CIF.

Quadro 1:

Definições: funcionalidade, incapacidade e os componentes da CIF

I - funções do corpo: são as funções fisiológicas dos sistemas orgânicos, incluindo as funções psicológicas;

II - estruturas do corpo: são as partes estruturais topográficas ou anatômicas do corpo, tais como, órgãos, membros e seus componentes, classificados de acordo com os sistemas orgânicos;

III - deficiências ou alterações: são problemas nas funções ou nas estruturas do corpo, tais como, um desvio importante ou uma perda;

IV - atividade: é a execução de uma tarefa ou ação por um indivíduo, representando a perspectiva individual da funcionalidade;

V - limitações de atividades: são dificuldades que um indivíduo pode ter na execução de atividades de vida diária;

VI - participação: é o envolvimento de um indivíduo numa situação de vida real e corresponde à perspectiva social da funcionalidade;

VII - restrições da participação: são problemas que um indivíduo pode enfrentar quando está envolvido em situações da vida real, sendo determinadas pela comparação entre sua participação e a esperada de um indivíduo sem deficiência, na mesma cultura ou 
sociedade;

VIII - capacidade: refere-se à aptidão de um indivíduo para executar uma tarefa ou ação em um ambiente considerado uniforme ou padrão, de modo a neutralizar impactos externos sobre a avaliação;

IX - desempenho: refere-se ao que o indivíduo faz em seu ambiente de vida habitual, incluídos neste conceito os aspectos do mundo físico, social e atitudinal, descritos na CIF

como fatores ambientais. Comparando-se as avaliações de capacidade e de desempenho na execução das atividades de vida diária, pode-se perceber o que pode ser modificado no ambiente para melhorar o desempenho de um indivíduo.

$\mathrm{X}$ - funcionalidade: é um termo genérico envolvendo as funções do corpo, estruturas do corpo, assim como as atividades e participação, indicando os aspectos positivos da interação entre um indivíduo e os fatores ambientais e pessoais;

XI - incapacidade: é um termo genérico envolvendo mudanças nas funções ou nas estruturas do corpo, limitação de atividades e restrição da participação, indicando os aspectos negativos da interação entre um indivíduo e seus fatores ambientais e pessoais; XII - fatores pessoais: representam o histórico particular da vida e estilo de vida de um indivíduo e englobam características próprias que não são parte de uma condição de saúde ou de um estado de saúde, os quais não são classificados na CIF, mas podem influenciar os resultados das várias intervenções;

XIII - fatores ambientais: constituem o ambiente físico, social e atitudinal no qual as pessoas vivem e conduzem sua vida, são externos ao indivíduo e podem atuar como facilitadores ou barreiras sobre a função e/ou estrutura de seu corpo e sobre seu 
desempenho e/ou capacidade para executar ações ou tarefas.

Cada componente contém domínios hierarquicamente organizados. Estes são conjuntos relacionados à funções, estruturas, ações, tarefas, áreas da vida e às influências externas. A CIF tem um capítulo para cada um dos domínios conforme listado

na tabela 1 .

Tabela 1: Componentes ICF e domínios/capítulos

Fonte: OMS 2001: 29-30

\section{Qualificação}

A CIF é um sistema de classificação e enquadramento sobre o qual as ferramentas de avaliação individual de funcionalidade podem ser baseadas. O quadro geral coloca o contexto de funcionalidade e fornece o foco para a seleção de aspectos relevantes de avaliação.

Qualificadores são complementos das categorias, tranformando-as em códigos, usados para registrar a extensão da funcionalidade ou incapacidade em um domínio ou uma categoria, ou a medida em que um fator ambiental é um facilitador ou barreira. É uma escala uniforme e genérica para registrar a extensão do problema, em relação à deficiência, mudança estrutural, limitação de atividade ou restrição de participação social, como mostrado no quadro 2. O qualificador de fatores ambientais usa tanto uma escala positiva quanto uma negativa, para indicar a extensão a que um fator ambiental atua como um facilitador ou barreira para funcionalidade.

O qualificador é uma tema para desenvolvimento e é reconhecido que ele requer 
calibração ao relacionar-se uma escala de ferramentas de medição existentes.

\section{Quadro 1}

Função do corpo:

Funções mentais

Funções sensoriais e dor

Funções de voz e da fala

Funções dos sistemas cardiovascular, hematológico, imunológico e respiratório

Funções dos sistemas digestivos, metabólico, endócrino

Funções geniturinárias e reprodutivas

Funções neuromusculoesqueléticas e relacionadas ao movimento

Funções da pele e estruturas relacionadas

Estrutura do corpo:

Estruturas do sistema nervoso

Olho, ouvido e estruturas relacionadas

Estruturas relacionadas à voz e à fala

Estruturas dos sistemas cardiovascular, imunológico e respiratório

Estruturas relacionadas aos sistemas digestório, metabólico e endócrino

Estruturas relacionadas aos sistemas geniturinário e reprodutivo

Estruturas relacionadas ao movimento

Pele e estruturas relacionadas

Atividades e participação:

Aprendizagem e aplicação do conhecimento

Tarefas e demandas gerais 
Comunicação

Mobilidade

Cuidados pessoais

Vida doméstica

Relações e interações interpessoais

Áreas principais da vida

Vida comunitária social e cívica

Fatores ambientais:

Produtos e tecnologia

Ambiente natural e mudanças ambientais feitas pelo ser humano

Apoio e relacionamentos

Atitudes

Serviços, sistemas e políticas

Quadro 2:

Qualificadores

Qualificador genérico:

0 Nenhum problema

1 Problema leve

2 Problema moderado

3 Problema grave

4 Problema completo

8 Não especificado

9 Não aplicável 
Qualificador de fatores ambientais:

.0 Nenhuma barreira +0 Nenhum facilitador

.1 Barreira leve +1 Facilitador leve

.2 Barreira moderada +2 Facilitador moderado

.3 Barreira grave +3 Facilitador considerável

.4 Barreira completa +4 Facilitador completo

.8 Barreira não especificada +8 Facilitador não especificado

.9 Não aplicável

Dois qualificadores, chamados 'desempenho' e 'capacidade', podem ser usados na operacionalização para atividades e participação. Esses qualificadores fornecem uma maneira de indicar como o ambiente impactou nas atividades e na participação, e como mudança ambiental pode melhorar a funcionalidade.

"Capacidade" refere-se a que um indivíduo pode fazer em um ambiente 'padrão' (isso muitas vezes envolve alguns tipos de avaliação clínica). 'Desempenho' refere-se a que a pessoa realmente faz no seu ambiente atual (habitual), ou seja, sob a influência ambiental. Então, o qualificador de desempenho em atividades e participação depende do conteúdo de qualificadores de fatores ambientais e da influência dos fatores pessoais não classificados.

A diferença entre a capacidade e o desempenho reflete a diferença entre os impactos de ambientes e, portanto, fornece um guia útil para o que pode ser feito para ambientes individuais e coletivos, a fim de melhorar o desempenho. (OMS 2001:15) Há uma variedade de qualificadores adicionais e opcionais que podem ser úteis, incluindo indicações para desempenho sem assistência e capacidade de assistência, que 
são particularmente úteis em casos específicos. Um qualificador de envolvimento ou satisfação subjetiva para o componente de atividades e participação é uma possibilidade futura (WHO 2001:230-231).

\section{APLICANDO A CIF}

Em sistemas de informações e estatísticas:

No desenvolvimento de coleta de informações sobre a funcionalidade e incapacidade é importante considerar todos os componentes da CIF. Uma definição comum de incapacidade é fundamental para entender e melhorar as políticas e resultados para pessoas com incapacidades, bem como para aumentar o poder da informação através da capacidade de relacionar dados de fontes diferentes, como configurações de serviço e o nível da população. Quando linguagem e conceitos consistentes são usados, facilitam comparações, informações complementares e conhecimento concreto. A sinergia é ativada entre sistemas de informação diferentes, como registro de estudos, investigação e saúde.

Sistemas de classificação têm sido descritos como blocos de construção de informação estatística.

A família de classificações internacionais da Organização Mundial da Saúde fornece uma estrutura para uma ampla gama de informações sobre a saúde. Assim, as pessoas podem se comunicar sobre saúde e cuidados de saúde em termos comuns, entre diferentes disciplinas e diferentes países (OMS 2001:3).

A CIF é reconhecida como membro de referência da família de classificações internacionais, assim como sua complementar, a Classificação Estatística Internacional de Doenças e Problemas relacionados à Saúde (CID). As condições de saúde são 
classificadas usando a CID (a versão mais atual é CID-10), que fornece códigos para doenças, enfermidades, lesões ou outros problemas de saúde.

Como a funcionalidade e a incapacidade podem estar associadas com alguma enfermidade, o uso da CID-10 e da CIF juntas fornece uma imagem mais significativa e completa das necessidades de saúde das pessoas e populações, mesmo sendo possível o uso individual de cada uma delas (WHO 2001:4).

Os exemplos na Figura 2 ilustram incapacidades que podem ser associadas a algumas condições de saúde e fatores ambientais.

Quando dados de população utilizam os mesmos conceitos e ferramentas como dados administrativos e de serviços, uma matriz de informações nacional forte e integrada pode ser desenvolvida. Por exemplo, normas de dados nacionais australianos (baseadas na CIF) são projetadas para promover uniformidade e normalização de definição e coleta de dados, sem ditar o conteúdo preciso das coletas. O grupo de Washington em Estatísticas de deficiência tem trabalhado para criar, testar e adotar um conjunto pequeno de seis perguntas para uso nos censos e pesquisas, seguindo os princípios fundamentais das estatísticas oficiais de forma coerente com a CIF.

\section{Figura 2 - exemplos}

Lesão da medula espinhal (transtorno ou doença)

Dificuldade de andar (atividades)

Problemas musculares (funções)

Perda de funções de energia (funções)

Alteração estrutural da medula espinhal. (estrutura) Participação restrita no emprego e na utilização de transportes públicos (participação) 
Masculinos, 30 anos (fatores pessoais)

Lesão da medula espinhal (transtorno ou doença)

Dificuldade de andar (atividades)

Problemas musculares (funções)

Perda de funções de energia (funções)

Alteração estrutural da medula espinhal (estruturas)

Participação no emprego, esporte e lazer: sem problemas (participação)

Sistema de ensino, produtos e tecnologia, arquitetura, família: facilitadores (fatores ambientais)

Masculinos, 35 anos, casado, um filho (fatores pessoais)

Notas:

1. Os exemplos acima não se destinam a representar um quadro completo das limitações de atividades, restrições de participação ou deficiências, mas sim representam alguns domínios de cada componente que pode ser relacionado a uma condição de saúde particular e a alguns factores ambientais. Cada exemplo é baseado no pressuposto de que as atividades e a participação podem ser distinguidas por domínios.

2. Para situações específicas e/ou pessoas a direção ou a magnitude das setas pode ser diferente, no entanto o bidireccional as setas são mantidas na Figura 2 para ilustrar a influência multidireccional habitual.

A CIF fornece uma estrutura para a descrição da funcionalidade humana, em uma continuidade. É importante lembrar que ela classifica a funcionalidade, não as pessoas. $\mathrm{O}$ 
desenvolvimento e testes da CIF envolveu pessoas de uma ampla gama de disciplinas, incluindo pessoas com deficiência. A CIF tem uma vasta gama de aplicações potenciais. As pessoas usam a CIF em vastos setores, incluindo saúde, deficiência, recuperação funcional, cuidados comunitários, seguro, segurança social, emprego, educação, economia, política social, legislação e ambiente.

\section{Desenho e modificações.}

A CIF oferece uma ferramenta internacional, científica, para estudar a incapacidade, em todas as suas dimensões. Ela pode ser usada por pessoas e profissionais, através de diferentes setores, rede de cuidados (por exemplo, comunidade, serviços e suporte, cuidados de saúde primários, hospitais, centros de recuperação funcional, lares de idosos) e populações.

Exemplos de aplicação:

Algumas das aplicações da CIF que demonstram sua versatilidade e utilidade como um modelo de funcionalidade e incapacidade, como uma língua comum, são os seguintes:

- A CIF e o seu modelo foram introduzidos na legislação e política social em alguns países. Por exemplo, é usada na segurança social e sistemas de registo na América Latina. Países ratificaram-na na Convenção da ONU sobre os direitos das pessoas com deficiência, esperando que a CIF será padrão mundial para dados de deficiência e a política social para todos os países. Ela fornece um quadro de informações valiosas e mecanismos para que países construam seu relatório de acompanhamento do para as

Nações Unidas sobre os progressos contra alvos da Convenção.

- Em configurações clínicas a CIF pode ser usada em sua gama completa, como num 
programa de recuperação funcional segundo Martinuzzi et al (2010). Para condições de doenças específicas, em vez de usar toda a CIF (com mais de 1400 categorias), pode ser útil ter uma pequena lista, que são essenciais para descrever a experiência de incapacidade da pessoa. Para conseguir isso, os Core Sets da CIF têm sido desenvolvidos com os profissionais e pessoas que sofrem da doença, em uma sistemática abordagemde consenso (ver www.icf-researchbranch.org/publications/publications ).

- A CIF pode ser usada para apoiar reformas na educação, de emprego ou de bem-estar social, e garantir aplicação coerente em diferentes níveis e setores. Por exemplo, na Suíça, a CIF é usada na educação como um modelo e uma classificação para determinar a elegibilidade (ver www.sav-pes.ch ) e organização de apoio escolar (Hollenweger, Lienhard 2007). Na Itália, uma experiência nacional do setor do emprego e experiências locais em educação têm mostrado grande potencial (ver www.reteclassificazioni.it/).

- Serviços de atendimento à pessoas com incapacidade oferecem consulta aos valores utilizando a CIF (ver www.novita.org.au/Content.aspx?p=573).

- A definição de deficiência pode influenciar a casos de defesa judicial e a CIF pode ser usada para oferecer suporte. Este valor potencial da CIF foi reconhecido por advogados envolvidos no seu desenvolvimento (Hurst 2003).

- A CIF é adequada para uso na comunidade e cuidados, através de atendimento multidisciplinar. O modelo pode ser usado para apoiar o processo de planejamento, monitoramento de progresso e avaliação de resultados. É coerente com uma abordagem de cuidados e tratamento que é centrada na pessoa. Por conseguinte, tem sido defendido o seu uso em cuidados de saúde primários (por exemplo, Veitch et al 2009). 
- A CIF é valiosa como um modelo unificador na prática de Saúde Funcional, investigação

e educação segundo Stucki et al (2007). Ela auxilia profissionais a olhar para além das suas próprias áreas de prática, comunicar disciplinas e pensar numa perspectiva de funcionalidade, em vez das perspectivas de uma condição de saúde.

-Há um crescente corpo de investigação centrada sobre a utilização da CIF, não só para a identificação das pessoas, cuidados de saúde, recuperação funcional e necessidades de suporte, mas também para identificar e medir o efeito do ambiente físico, social e político em suas vidas.

\section{Uso ético:}

Cada ferramenta científica pode ser mal utilizada, a CIF não é nenhuma exceção.

Para todos os usos da CIF, seja em pesquisa clínica, epidemiológica, saúde e política social, é essencial que as informações recolhidas e analisadas respeitem o valor inerente e autonomia dos indivíduos de quem a informação é recolhida.

Aplicam normas sobre consentimento informado, mas mais importante, as pessoas cukas situações estão sendo classificadas, devem participar em todos os aspectos da utilização da CIF e da aplicação dos dados.

Plena participação e transparência de uso são os itens mais importantes em aplicações sociais da CIF e, em especial, com a utilização prevista da CIF para o desenvolvimento de indicadores de acompanhamento da implementação da Convenção da ONU sobre os direitos das pessoas com deficiência.

A CIF é a bússola moral para o desenvolvimento da política social e mudança política necessária para alcançar a plena participação das pessoas com incapacidades. $\mathrm{O}$ 
aplicativo ético da CIF visa apoiar esse objetivo futuro.

\section{Referências e links}

American Psychological Association Procedural Manual and Guide for the Standardized Application of the ICF: http://www.apa.org/monitor/jan06/changing.aspx

Australian ICF-related data standards:

http://meteor.aihw.gov.au/content/index.phtml/itemId/320319

Hollenweger, J., Lienhard, P. (2007). Schulische Standortgespräche. EinVerfahren zur Förderplanung und Zuweisung von sonderpädagogischen Massnahmen.

Bildungsdirektion des Kantons Zürich. Zürich: Lehrmittelverlag des Kantons Zürich.

Hurst R 2003. The international disability rights movement and the ICF. Disability and Rehabilitation Vol 25, No, 11-12, 572-576

ICF checklist: http://www.who.int/classifications/icf/training/icfchecklist.pdf

Martinuzzi, A, Salghetti, A, Betto, S, et al. (2010). The international classification of functioning disability and health, version for children and youth as a road-map for projecting and programming rehabilitation in a neuropaediatric hospital unit. J Rehabil Med 42: 49-55

Stucki G, Reinhardt JD, Grimby G, Melvin J 2007. Developing 'human functioning and rehabilitation research' from the comprehensive perspective. J Rehabil Med 2007; 39: $665-671$

United Nations 2006. Convention on the Rights of Persons with Disabilities. http://www.un.org/disabilities/default.asp?navid=12\&pid=150

Veitch C, Madden R, Britt H, Kuipers P, Brentnall J, Madden R, Georgiou A, Llewellyn G 
2009. Using ICF and ICPC in primary health care provision and evaluation: http://www.who.int/classifications/network/WHOFIC2009_D009p_Veitch.pdf

Washington Group on Disability Statistics

http://unstats.un.org/unsd/methods/citygroup/washington.htm

WHODAS2 http://www.who.int/classifications/icf/whodasii/en/index.html

WHO Family of International Classifications http://www.who.int/classifications/en/

WHO Family of International Classifications Network (including a list of Collaborating

Centres): http://www.who.int/classifications/network/en/

World Health Organization 2001. ICF browser:

http://apps.who.int/classifications/icfbrowser/

World Health Organization 2001. The International Classification of Functioning, Disability

and Health (ICF). Geneva: WHO. http://www.who.int/classifications/icf/en/

World Health Organization (2007) The International Classification of Functioning,

Disability and Health, Children and Youth version Geneva: WHO.

http://www.who.int/classifications/icf/en/

Para mais informações, contate:

Dr. T.B. Üstün

World Health Organization

Coordinator, Classification, Terminology and Standards

20 Avenue Appia

CH-1211 Geneva 27 
Switzerland

Tel: 4122791.36 .09

Fax: 4122791.48 .85

E-mail: ustunb@who.int

\section{D) QUESTIONÁRIO 1: CATEGORIAS}

Especialidade: Fisioterapia do Trabalho.

Selecione as categorias aplicáveis em sua especialidade.

\section{FUNÇÕES DO CORPO}

\section{Capítulo 1 Funções Mentais}

Funções mentais globais (b110-b139)

b110 Funções da consciência

b114 Funções da orientação

b117 Funções intelectuais

b122 Funções psicossociais globais

b126 Funções do temperamento e da personalidade

b130 Funções da energia e dos impulsos

b134 Funções do sono

b139 Funções mentais globais, outras especificas e não especificadas

Funções mentais específicas (b140-b189) 
b140 Funções da atenção

b144 Funções da memória

b147 Funções psicomotoras

b152 Funções emocionais

b156 Funções da percepção

b160 Funções do pensamento

b164 Funções cognitivas de nível superior

b167 Funções mentais da linguagem

b172 Funções de cálculo

b176 Funções mentais para a sequência de movimentos complexos

b180 Funções de experiência pessoal e do tempo

b189 Funções mentais específicas, outras especificadas (...)

b198 Funções mentais, outras especificadas

b199 Funções mentais, não especificadas

Capítulo 2 Funções sensoriais e dor

Visão e funções relacionadas (b210-229)

b210 Funções da visão

b215 Funções dos anexos do olho

b220 Sensações associadas ao olho e anexos

b229 Visão e funções relacionadas, outras especificadas e não (...) 
Funções auditivas e vestibulares (b230-b249)

b230 Funções auditivas

b235 Funções vestibulares

b240 Sensações associadas à audição e à função vestibular

b249 Funções auditivas e vestibulares, outras especificadas e não (...)

Funções sensoriais adicionais (b250-b279)

b250 Função gustativa

b255 Função olfactiva

b260 Função proprioceptiva

b265 Função táctil

b270 Funções sensoriais relacionadas com a temperatura e outros (...)

b279 Funções sensoriais adicionais, outras especificadas e não (...)

Dor (b280-b289)

b280 Sensação de dor

b289 Sensação de dor, outras especificadas e não especificadas

b298 Funções sensoriais e dor, outras especificadas

b299 Funções sensoriais e dor, não especificadas

\section{Capítulo 3 Funções da voz e da fala}

b310 Funções da voz

b320 Funções da articulação 
b330 Funções da fluência e do ritmo da fala

b340 Funções de outras formas de vocalização

b398 Funções da voz e da fala, outras especificadas

b399 Funções da voz e da fala, não especificadas

Capítulo 4 Funções do aparelho cardiovascular, dos sistemas hematológico e imunológico e do aparelho respiratório

Funções do aparelho cardiovascular (b410-b429)

b410 Funções cardíacas

b415 Funções dos vasos sanguíneos

b420 Funções da pressão arterial

b429 Funções do aparelho cardiovascular, outras especificadas e (...)

Funções dos sistemas hematológico e imunológico (b430-b439)

b430 Funções do sistema hematológico

b435 Funções do sistema imunológico

b439 Funções dos sistemas hematológico e imunológico, outras (...)

Funções do aparelho respiratório (b440-b449)

b440 Funções da respiração

b445 Funções dos músculos respiratórios

b449 Funções do aparelho respiratório, outras especificadas e não (...)

Funções e sensações adicionais dos aparelhos cardiovascular e respiratório (b450-b469) 
b450 Funções respiratórias adicionais

b455 Funções de tolerância ao exercício

b460 Sensações associadas às funções cardiovasculares e respiratórias

b469 Funções e sensações adicionais dos aparelhos cardiovascular (...)

b498 Funções do aparelho cardiovascular, dos sistemas hemat. (...)

b499 Funções do aparelho cardiovascular, dos sistemas hemat. (...)

\section{Capítulo 5 Funções do aparelho digestivo e dos sistemas metabólico e endócrino}

\section{Funções relacionadas com o aparelho digestivo (b510-b539)}

b510 Funções de ingestão

b515 Funções digestivas

b520 Funções de assimilação

b525 Funções de defecação

b530 Funções de manutenção do peso

b535 Sensações associadas ao aparelho digestivo

b539 Funções relacionadas com o aparelho digestivo, outras (...)

Funções relacionadas com os sistemas metabólicos e endócrino (b540-b559)

b540 Funções metabólicas gerais

b545 Funções de equilíbrio hídrico, mineral e electrolítico

b550 Funções termo reguladoras

b555 Funções das glândulas endócrinas 
b559 Funções relacionadas com os sistemas metabólico e end. (...)

b598 Funções do aparelho digestivo e dos sistemas metabólico e (...)

b599 Funções do aparelho digestivo e dos sistemas metabólico e (...)

\section{Capítulo 6 Funções geniturinárias e reprodutivas}

\section{Funções urinárias (b610-639)}

b610 Funções de excreção urinária

b620 Funções miccionais

b630 Sensações associadas às funções urinárias

b639 Funções urinárias, outras especificadas e não especificadas

Funções genitais e reprodutivas (b640-b679)

b640 Funções sexuais

b650 Funções relacionadas com a menstruação

b660 Funções de procriação

b670 Sensações associadas às funções genitais e reprodutivas

b679 Funções genitais e reprodutivas, outras especificadas e não (...)

b698 Funções geniturinárias e reprodutivas, outras especificadas

b699 Funções geniturinárias e reprodutivas, não especificadas

Capítulo 7 Funções neuromusculoesqueléticas e relacionadas com o movimento

Funções das articulações e dos ossos (b710-b729)

b710 Funções da mobilidade das articulações 
b715 Funções da estabilidade das articulações

b720 Funções da mobilidade dos ossos

b729 Funções das articulações e dos ossos, outras especificadas e (...)

\section{Funções musculares (b730-b749)}

b730 Funções da força muscular

b735 Funções do tônus muscular

b740 Funções da resistência muscular

b749 Funções musculares, outras especificadas e não especificadas

\section{Funções relacionadas com o movimento (b750-b789)}

b750 Funções de reflexos motores

b755 Funções de reações motoras involuntárias

b760 Funções de controlo do movimento voluntário

b765 Funções dos movimentos involuntários

b770 Funções relacionadas com o padrão de marcha

b780 Sensações relacionadas com os músculos e as funções do (...)

b789 Funções do movimento, outras especificadas e não especificadas

b798 Funções neuromusculoesqueléticas e relacionadas com o (...)

b799 Funções neuromusculoesqueléticas e relacionadas com o (...)

Capítulo 8 Funções da pele e estruturas relacionadas

Funções da pele (b810-b849) 
b810 Funções protetoras da pele

b820 Funções reparadoras da pele

b830 Outras funções da pele

b840 Sensação relacionada com a pele

b849 Funções da pele, outras especificadas e não especificadas

Funções dos pêlos e das unhas (b850-b869)

b850 Funções dos pêlos

b860 Funções das unhas

b869 Funções dos pelos e das unhas, outras especificadas e não (...)

b898 Funções da pele e estruturas relacionadas, outras especificadas

b899 Funções da pele e estruturas relacionadas, não especificadas

\section{ESTRUTURAS DO CORPO}

\section{Capítulo 1 Estruturas do sistema nervoso}

s110 Estrutura do cérebro

s120 Medula espinhal e estruturas relacionadas

s130 Estrutura das meninges

s140 Estrutura do sistema nervoso simpático

s150 Estrutura do sistema nervoso parassimpático

s198 Estrutura do sistema nervoso, outra especificada

s199 Estrutura do sistema nervoso, não especificada 


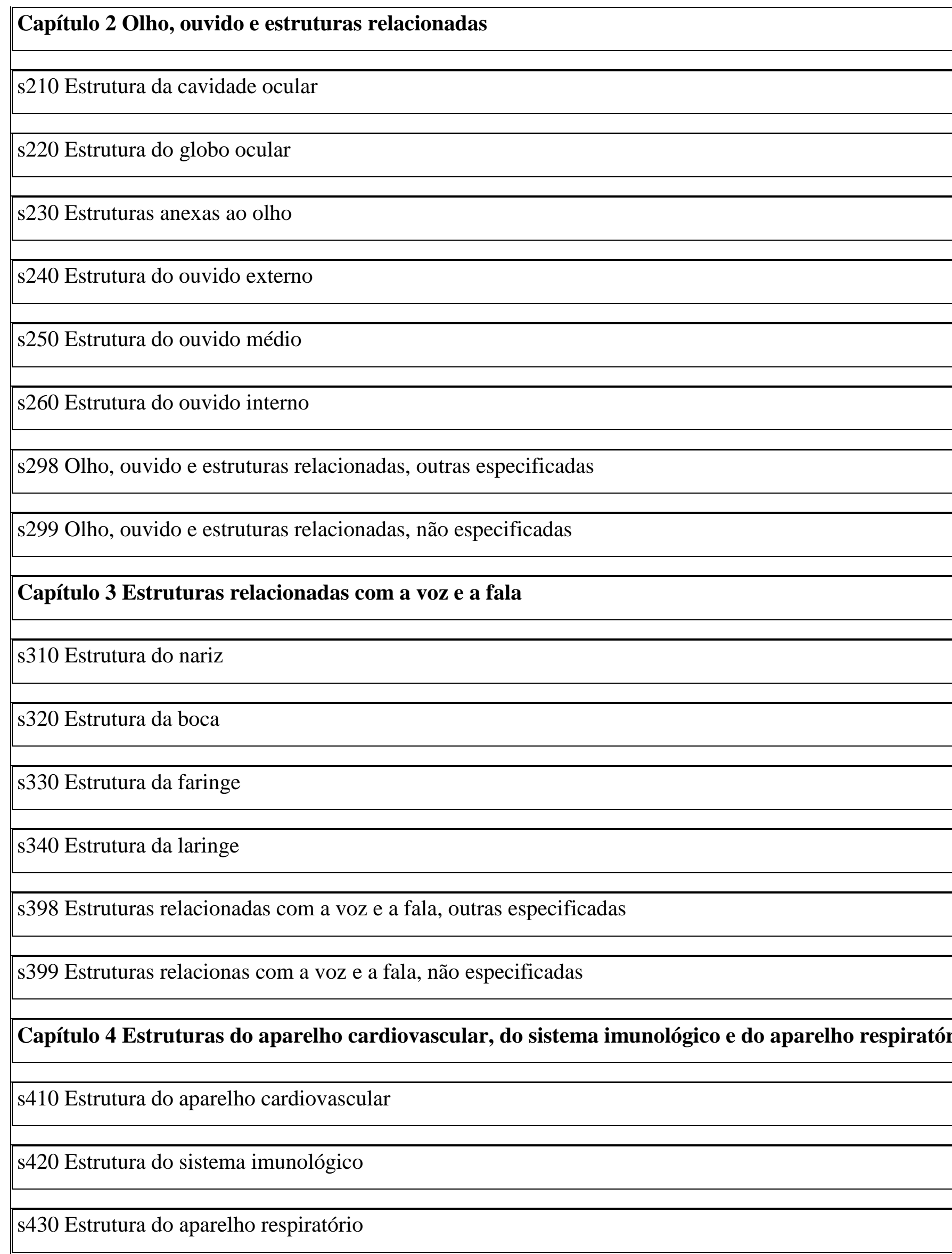


s498 Estruturas do aparelho cardiovascular, do sistema imunol. (...)

s499 Estruturas do aparelho cardiovascular, do sistema imunol. (...)

Capítulo 5 Estruturas relacionadas com o aparelho digestivo e com os sistemas metabólico e endócr

s510 Estrutura das glândulas salivares

s520 Estrutura do esôfago

s530 Estrutura do estômago

s540 Estrutura dos intestinos

s550 Estrutura do pâncreas

s560 Estrutura do fígado

s570 Estrutura da vesícula e vias biliares

s580 Estrutura das glândulas endócrinas

s598 Estruturas relacionadas com o aparelho digestivo e com os (...)

s599 Estruturas relacionadas com o aparelho digestivo e com os (...)

\section{Capítulo 6 Estruturas relacionadas com os aparelhos geniturinário e reprodutivo}

s610 Estrutura do aparelho urinário

s620 Estrutura do pavimento pélvico

s630 Estrutura do aparelho reprodutivo

s698 Estruturas relacionadas com os aparelhos geniturinário e (...)

s699 Estruturas relacionadas com os aparelhos geniturinário e (...)

Capítulo 7 Estruturas relacionadas com o movimento 
s710 Estrutura da região da cabeça e do pescoço

s720 Estrutura da região do ombro

s730 Estrutura do membro superior

s740 Estrutura da região pélvica

s750 Estrutura do membro inferior

s760 Estrutura do tronco

\$770 Estruturas musculoesqueléticas adicionais relacionadas ao (...)

s798 Estruturas relacionadas com o movimento, outras especificadas

s799 Estruturas relacionadas com o movimento, não especificadas

\section{Capítulo 8 Pele e estruturas relacionadas}

s810 Estrutura das áreas da pele

s820 Estrutura das glândulas da pele

s830 Estrutura das unhas

s840 Estrutura dos pelos

s898 Pele e estruturas relacionadas, outras especificadas

s899 Pele e estruturas relacionadas, não especificadas

ATIVIDADES E PARTICIPAÇÃO

Capítulo 1 Aprendizagem e aplicação de conhecimentos

Experiências sensoriais intencionais (d110-d129)

d110 Observar 


\section{d115 Ouvir}

d120 Outras percepções sensoriais intencionais

d129 Experiências sensoriais intencionais, outras especificadas e (...)

\section{Aprendizagem básica (d130-d159)}

d130 Imitar

d135 Ensaiar (Repetir)

d140 Aprender a ler

d145 Aprender a escrever

d150 Aprender a calcular

d155 Adquirir competências

d159 Aprendizagem básica, outra especificada e não especificada

\section{Aplicação do conhecimento (d160-d179)}

d160 Concentrar a atenção

d163 Pensar

d166 Ler

d170 Escrever

d172 Calcular

d175 Resolver problemas

d177 Tomar decisões

d179 Aplicação do conhecimento, outra especificada 
d198 Aprendizagem e aplicação do conhecimento, outras especificadas

d199 Aprendizagem e aplicação do conhecimento, não especificadas

\section{Capítulo 2 Tarefas e exigências gerais}

d210 Realizar uma única tarefa

d220 Realizar tarefas múltiplas

d230 Realizar a rotina diária

d240 Lidar com o stresse e outras exigências psicológicas

d298 Tarefas e exigências gerais, outras especificadas

d299 Tarefas e exigências gerais, não especificadas

\section{Capítulo 3 Comunicação}

Comunicar e receber mensagens (d310-d329)

d310 Comunicar e receber mensagens orais

d315 Comunicar e receber mensagens não verbais

d320 Comunicar e receber mensagens usando linguagem gestual

d325 Comunicar e receber mensagens escritas

d329 Comunicar e receber mensagens, outras especificadas e não (...)

Comunicar e produzir mensagens(d330-d349)

d330 Falar

d335 Produzir mensagens não verbais

d340 Produzir mensagens usando linguagem gestual 


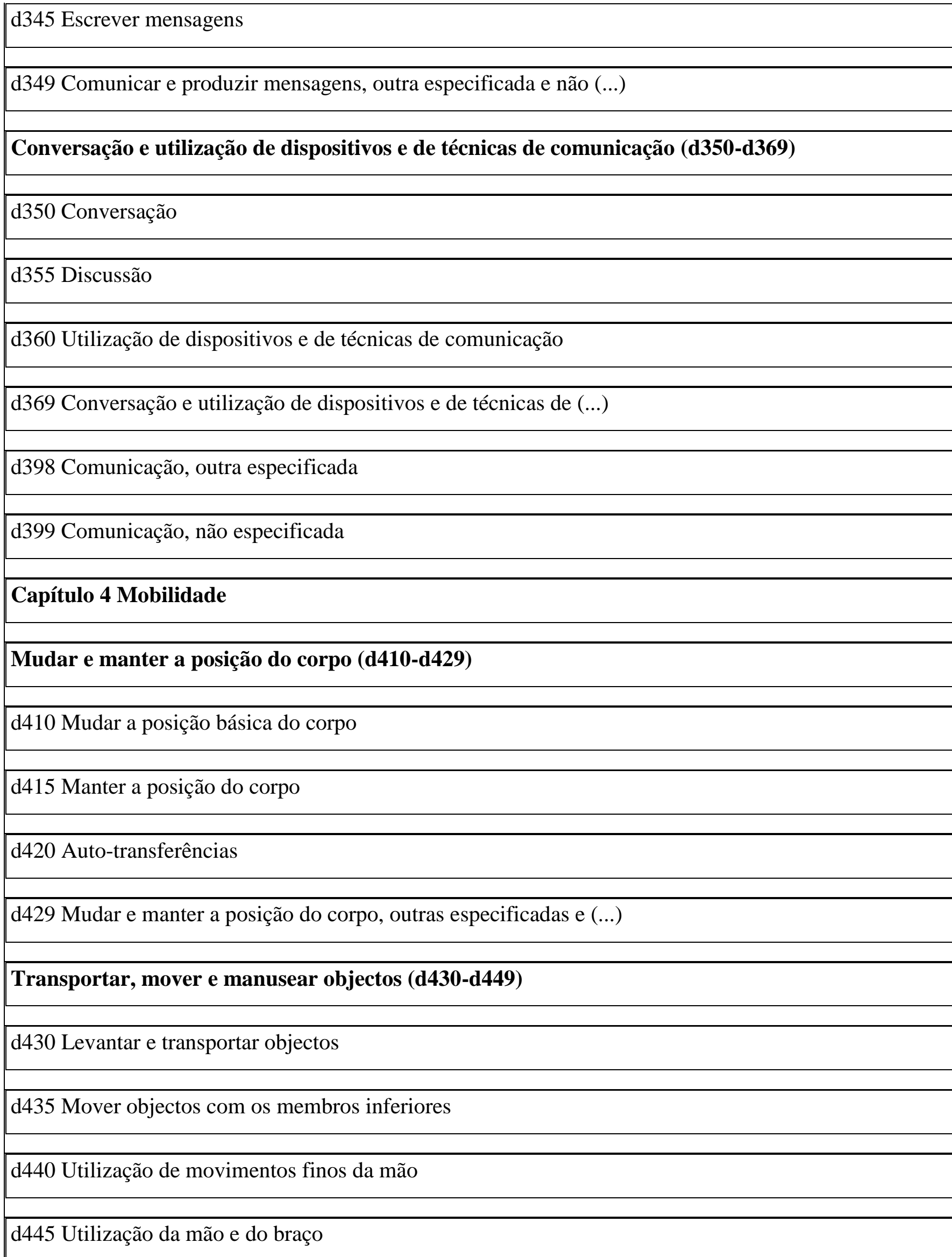


d449 Transportar, mover e manusear objectos, outros (...)

\section{Andar e deslocar-se (d450-d469)}

d450 Andar

d455 Deslocar-se

d460 Deslocar-se por diferentes locais

d465 Deslocar-se utilizando algum tipo de equipamento

d469 Andar e mover-se, outros especificados e não especificados

\section{Deslocar-se utilizando transporte (d470-d489)}

d470 Utilização de transporte

d475 Dirigir

d480 Montar animais como meio transporte

d489 Deslocar-se utilizando transporte, outros especificados e (...)

d498 Mobilidade, outra especificada

d499 Mobilidade, não especificada

\section{Capítulo 5 Cuidados Pessoais}

d510 Lavar-se

d520 Cuidar de partes do corpo

d530 Cuidados relacionados com os processos de excreção

d540 Vestir-se

d550 Comer 
d560 Beber

d570 Cuidar da própria saúde

d598 Auto cuidados, outros especificados

d599 Auto cuidados, não especificados

\section{Capítulo 6 Vida doméstica}

Aquisição do necessário para viver (d610-d629)

d610 Aquisição de um lugar para morar

d620 Aquisição de bens e serviços

d629 Aquisição do necessário para viver, outro especificado e não (...)

\section{Tarefas domésticas (d630-d649)}

d630 Preparar refeições

d640 Realizar as tarefas domésticas

d649 Tarefas domésticas, outras especificadas e não especificadas

\section{Cuidar dos objectos da casa e ajudar os outros (d650-d669)}

d650 Cuidar dos objectos da casa

d660 Ajudar os outros

d669 Cuidar dos objectos da casa e ajudar os outros, outros (...)

d698 Vida doméstica, outra especificada

d699 Vida doméstica, não especificada

Capítulo 7 Interações e relacionamentos interpessoais 


\section{Interacções interpessoais gerais (d710-d729)}

d710 Interações interpessoais básicas

d720 Interações interpessoais complexas

d729 Interações interpessoais gerais, outras especificadas e não (...)

\section{Relacionamentos interpessoais particulares (d730-d779)}

d730 Relacionamento com estranhos

d740 Relacionamento formal

d750 Relacionamentos sociais informais

d760 Relacionamentos familiares

d770 Relacionamentos íntimos

d779 Relacionamentos interpessoais particulares, outros (...)

d798 Interações e relacionamentos interpessoais, outros especificados

d799 Interações e relacionamentos interpessoais, não especificados

\section{Capítulo 8 Áreas principais da vida}

\section{Educação (d810-d839)}

d810 Educação informal

d815 Educação pré-escolar

d820 Educação escolar

d825 Formação profissional

d830 Educação de nível superior 
d839 Educação, outra especificada e não especificada

\section{Trabalho e emprego (d840-d859)}

d840 Estágio (preparação para o trabalho)

d845 Obter, manter e sair de um emprego

d850 Trabalho remunerado

d855 Trabalho não remunerado

d859 Trabalho e emprego, outros especificados e não especificados

\section{Vida econômica (d860-d879)}

d860 Transações econômicas básicas

d865 Transações econômicas complexas

d870 Auto-suficiência económica

d879 Vida econômica, outra especificada e não especificada

d898 Áreas principais da vida, outras especificadas

d899 Áreas principais da vida, não especificadas

\section{Capítulo 9 Vida comunitária, social e cívica}

d910 Vida comunitária

d920 Recreação e lazer

d930 Religião e espiritualidade

d940 Direitos Humanos

d950 Vida política e cidadania 
d998 Vida comunitária, social e cívica, outra especificada

d999 Vida comunitária, social e cívica, não especificada

\section{FATORES AMBIENTAIS}

\section{Capítulo 1 Produtos e tecnologia}

e110 Produtos ou substâncias para consumo pessoal

e115 Produtos e tecnologias para uso pessoal na vida diária

e120 Produtos e tecnologias destinados a facilitar a mobilidade (...)

e125 Produtos e tecnologias para a comunicação

e130 Produtos e tecnologias para a educação

e135 Produtos e tecnologias para o trabalho

e140 Produtos e tecnologias para a cultura, atividades (...)

e145 Produtos e tecnologias para a prática religiosa e espiritualidade

e150 Arquitectura, construção, materiais e tecnologias (...)

e155 Arquitectura, construção, materiais e tecnologias (...)

e160 Produtos e tecnologias relacionados com a utilização (...)

e165 Bens

e198 Produtos e tecnologias, outros especificados

e199 Produtos e tecnologias, não especificados

Capítulo 2 Ambiente natural e mudanças ambientais feitas pelo homem

e210 Geografia física 


\begin{tabular}{|l|l}
\hline e215 População \\
\hline e220 Flora e fauna \\
\hline e225 Clima \\
\hline e230 Desastres naturais \\
\hline e235 Desastres causados pelo homem \\
\hline e240 Luz \\
\hline e245 Mudanças relacionadas com o tempo \\
\hline e250 Som \\
\hline e340 Prestadores de cuidados pessoais e assistentes pessoais \\
\hline e255 Vibração \\
\hline e260 Qualidade do ar \\
\hline e330 Pessoas em posição de autoridade \\
\hline e298 Ambiente natural e mudanças ambientais feitas (...) \\
\hline e299 Ambiente natural e mudanças ambientais feitas pelo (...) \\
\hline
\end{tabular}




\begin{tabular}{|l|l}
\hline e345 Estranhos \\
\hline e350 Animais domesticados \\
\hline e355 Profissionais de saúde \\
\hline e360 Outros profissionais \\
\hline e398 Apoio e relacionamentos, outros especificados \\
\hline e399 Apoio e relacionamentos, não especificados
\end{tabular}

\section{Capítulo 4 Atitudes}

e410 Atitudes individuais de membros da família próxima

e415 Atitudes individuais de membros da família alargada

e420 Atitudes individuais de amigos

e425 Atitudes individuais de conhecidos, pares, colegas, vizinhos (...)

e430 Atitudes individuais de pessoas em posições de autoridade

e435 Atitudes individuais de pessoas em posições subordinadas

e440 Atitudes individuais de prestadores de cuidados pessoais e (...)

e445 Atitudes individuais de estranhos

e450 Atitudes individuais de profissionais de saúde

e455 Atitudes individuais de outros profissionais

e460 Atitudes sociais

e465 Normas, práticas e ideologias sociais

e498 Atitudes, outras especificadas 
e499 Atitudes, não especificadas

\section{Capítulo 5 Serviços, sistemas e políticas}

e510 Serviços, sistemas e políticas relacionados com a produção (...)

e515 Serviços, sistemas e políticas relacionados com arquitetura (...)

e520 Serviços, sistemas e políticas relacionados com o (...)

e525 Serviços, sistemas e políticas relacionados com a habitação

e530 Serviços, sistemas e políticas relacionados com os serviços (...)

e535 Serviços, sistemas e políticas relacionados com a área da (...)

e540 Serviços, sistemas e políticas relacionados com os transportes

e545 Serviços, sistemas e políticas relacionados com a protecção civil

e550 Serviços, sistemas e políticas relacionados com a área (...)

e555 Serviços, sistemas e políticas relacionados com associações (...)

e560 Serviços, sistemas e políticas relacionados com os meios (...)

e565 Serviços, sistemas e políticas relacionados com a economia

e570 Serviços, sistemas e políticas relacionados com a segurança social

e575 Serviços, sistemas e políticas relacionados com o apoio (...)

e580 Serviços, sistemas e políticas relacionados com a saúde

e585 Serviços, sistemas e políticas relacionados com a educação (...)

e590 Serviços, sistemas e políticas relacionados com o trabalho (...)

e595 Serviços, sistemas e políticas relacionados com o sistema político 
e598 Serviços, sistemas e políticas, outros especificados

e599 Serviços, sistemas e políticas, não especificados 


\section{Anexo 2 - Aplicabilidade}

NOME:

CREFITO:

ABRAFIT:

REGIÃO DO PAÍS: ( ) Centro-Oeste ( ) Nordeste ( ) Norte ( ) Sudeste ( ) Sul

1. É aceitável utilizar o instrumento criado na sua prática profissional?

( ) SIM

( ) NÃO

Comentários (opcional):

2. A utilização dos conceitos da CIF propicia uma unificação da linguagem na sua área de atuação?

( ) SIM

( ) NÃO

Comentários (opcional):

3. O instrumento contribui para geração de dados sobre funcionalidade humana no trabalho?

( ) SIM

( ) NÃO

Comentários (opcional):

4. Pode-se considerar que a CIF tem potencialidade para suprir os sistemas de informação em saúde com dados epidemiológicos, assim como a CID-10?

( ) SIM

( ) NÃO

Comentários (opcional):

5. O uso do instrumento contribui para proporcionar vantagens para o trabalhador?
( ) SIM
( ) NÃO

Comentários (opcional):

6. Como você avalia a aplicabilidade do instrumento?

( ) não aplicável

( ) pouco aplicável

( )razoavelmente aplicável

( ) muito aplicável

( ) completamente aplicável

7. Como você avalia a importância do instrumento criado?

( ) sem importância

( ) pouco importante

( ) razoavelmente importante

( ) muito importante

( ) imprescindível 


\section{3 - Estudo 3: submetido à Revista Cadernos de Saúde Pública}

\section{A CIF e o inquérito de saúde ISA-Capital}

\section{Eduardo Santana Araujo}

Departamento de Epidemiologia da Faculdade de Saúde Pública da Universidade de São Paulo.

edusantana@usp.br

Endereço para correspondência: Rua Maracatu, 102 - casa 1. Cotia/SP.

\section{Cassia Maria Buchalla}

Departamento de Epidemiologia da Faculdade de Saúde Pública da Universidade de São Paulo.

\section{cmbuchal@usp.br}

Endereço para correspondência: Av. Dr. Arnaldo, 715. São Paulo/SP.

\section{Chester Luiz Galvão Cesar}

Departamento de Epidemiologia da Faculdade de Saúde Pública da Universidade de São Paulo.

\section{clcesar@usp.br}

Endereço para correspondência: Av. Dr. Arnaldo, 715. São Paulo/SP. 


\section{Resumo}

Os inquéritos de saúde têm alguns objetivos em comum com a Classificação Internacional de Funcionalidade, Incapacidade e Saúde (CIF). Em tese, a CIF pode fornecer uma base teórica para a criação de inquéritos com a intenção de conhecer condições de saúde da população, para além das informações sobre morbidade e mortalidade, coletadas de rotina pelos sistemas de informação. Este trabalho relacionou os dados coletados no bloco de deficiências, pelo ISA Capital 2003, com os domínios da CIF. Verificamos uma grande intersecção de conteúdos do questionário com os domínios da classificação, mostrando que ela pode ser utilizada como base para de formulários de inquéritos populacionais. Além das vantagens do uso de uma ferramenta internacional, a CIF permitirá a obtenção de dados sobre funcionalidade humana e o efeito do ambiente na qualidade de vida da população estudada.

Palavras-chave: CIF, inquéritos de saúde, pessoas com incapacidade 


\begin{abstract}
Health surveys and the International Classification of Functioning, Disability and Health (ICF) have some common goals. But ICF content can be a helpful tool to creat surveys that intent to meet the population's health conditions, include that wich are different from information on morbidity and mortality, collected by routine information systems. This study collected data related to deficiencies in the block by "ISA Capital 2003", with the ICF domains. We found a great intersection of contents of the questionnaire with the fields of classification, showing that it can be used as the basis for forms of surveys. Besides the advantages of using an international tool, ICF will allow to obtain data on human functioning and the effect of environment on quality of life of the population studied.
\end{abstract}

Descriptors: ICF, heatlh surveys, disability, disabled persons 


\section{INTRODUÇÃO}

A CIF pode ser usada para levantamentos populacionais sobre saúde e incapacidade, além do uso clínico, epidemiológico, em políticas sociais e em pesquisa. ${ }^{1}$ Ela propõe um modelo conceitual de funcionalidade e incapacidade que admite uma influência multidirecional entre os elementos que o compõem, representados pelos constructos da classificação. Desta forma, tanto os fatores contextuais (pessoais e ambientais) quanto às condições de saúde podem influenciar o estado de funcionalidade de determinado indivíduo ou população, ou serem por ele afetados. O novo modelo é chamado de integrador e deve estar em constante revisão e aprimoramento. ${ }^{2}$

Essa classificação é indicada pela Organização Mundial da Saúde (OMS) ${ }^{3}$ para mensurar a saúde e a incapacidade em ambas as escalas, individual e populacional, sendo capaz de facilitar a análise estatística e a criação de novos indicadores. Uma das formas de aplicá-la pode ser por meio dos inquéritos populacionais.

Os inquéritos de saúde, como o ISA, de maneira geral, foram desenhados para identificar as relações existentes entre condições sociais e saúde. Um dos diferenciais dos inquéritos é a possibilidade de se avaliar as condições de saúde das pessoas, incluindo aquelas que não são tratadas em serviços de saúde e, portanto, estão fora das estatísticas habituais do sistema. ${ }^{4}$

Esses inquéritos contribuem para o planejamento e avaliação de serviços ${ }^{5}$ podendo constituir elementos importantes para sistemas de informação e formulação de políticas públicas. ${ }^{6}$ A coleta de dados relativos à funcionalidade e incapacidade por meio de um sistema de códigos alimentado pelo uso de inquéritos de saúde poderia facilitar a análise dos resultados, o que pode ser possível com o uso da CIF.

Este trabalho pretende determinar os domínios e códigos da CIF abordados pelo questionário ISA, verificando se todas as dimensões do processo incapacitante estão sendo contempladas na coleta de dados do ISA, segundo o modelo de funcionalidade proposto na CIF. 


\section{MATERIAL E MÉTODO}

Esta pesquisa, inicialmente, relaciona as categorias da CIF com questões e dados de formulário do ISA - Capital 2003. Numa segunda fase, relaciona a possibilidade de qualificação dos resultados por meio da classificação. O estudo foi baseado em um dos questionários do Inquérito de Saúde no Município de São Paulo, o ISA - Capital 2003, elaborado antes do lançamento da CIF em Português e publicado na página eletrônica http://hygeia.fsp.usp.br/isa-sp/index_arquivos/Page3157.htm

Selecionamos a seção do questionário voltada à deficiência física (Bloco E), cujas questões foram comparadas com as categorias existentes na CIF.

As questões do Bloco E do ISA - Capital 2003 foram estruturadas para o conhecimento das alterações nas funções do corpo, na estrutura do corpo, nas atividades funcionais, na participação social e no ambiente.

Há três diferentes grupos para conhecimento sobre deficiências: aquele com deficiência visual, o segundo com deficiência auditiva e o terceiro com deficiência física. O grupo de deficiência visual inclui cegueira de um olho e cegueira dos dois olhos. O grupo de deficiência auditiva inclui surdez de um ouvido e surdez dos dois ouvidos. Já o grupo de deficiência física inclui paralisia parcial ou total de membros e perda parcial ou total de membros. A parte sobre as limitações de atividades e restrições de participação social avaliadas pelo inquérito abrange: dificuldades na educação escolar, dificuldades na execução do trabalho, dificuldades na recreação e lazer, dificuldades na vida doméstica e dificuldades no cuidado pessoal.

Já a parte sobre as condições ambientais avaliadas pelo questionário identifica: condições de moradia e de entorno. Um domicílio foi considerado adequado quando a habitação fosse casa ou apartamento, com abastecimento de água e esgoto, que apresentasse instalação sanitária interna e iluminação elétrica. Já o entorno foi considerado como adequado quando a rua da habitação fosse pavimentada, com guia e sarjeta, iluminação pública e abastecimento público de esgoto.

Considerando que funções/estruturas do corpo, atividades/participação, fatores ambientais são componentes da CIF, relacionamos as questões do inquérito com as possíveis categorias de cada componente da classificação. ${ }^{7}$ 
Numa segunda etapa desta pesquisa, as possibilidades de respostas ao inquérito das categorias relacionadas foram classificadas segundo as categorias da classificação com o objetivo de analisar a possibilidade de transformá-las em códigos completos, da maneira prevista pela CIF.

Aplicamos uma análise detalhada para discutir a aplicação e as possibilidades de contribuição da CIF para inquéritos de saúde. 


\section{RESULTADOS}

A análise do questionário do inquérito mostrou que as categorias da CIF contemplam todas as questões do Bloco E do ISA - Capital 2003, exceto a questão E04 (O que provocou o seu problema?). O Quadro 1 apresenta as questões nas quais o pareamento foi possível e quais as categorias da CIF que se aplicam em cada uma delas.

\section{Quadro 1 - Pareamento das questões do Bloco E com categorias da CIF}

Questões do Inquérito

Categorias/capítulos da CIF

\begin{tabular}{|c|l|}
\hline $\begin{array}{l}\text { E } 02 . \text { O(a) Sr.(a.) tem algum desses } \\
\text { problemas? }\end{array}$ & \\
Dificuldade de enxergar c/ óculos & d110, e1250 \\
Cegueira de um olho & b210 \\
Cegueira de dois olhos & b210 \\
Dificuldade de ouvir & d115 \\
Surdez de um ouvido & b230 \\
Surdez de dois ouvidos & b230 \\
Paralisia total ou parcial de membros & b730 \\
Perda de membros ou parte deles & s720 até s750 \\
\hline $\begin{array}{l}\text { E 03c - Dificulta(ou) a realização de suas } \\
\text { atividades de trabalho? }\end{array}$ & d920 \\
\hline atividades escolares?
\end{tabular}




\begin{tabular}{|l|l|}
\hline filhos? & \\
\hline $\begin{array}{l}\text { E 03e - Faz com que o(a) Sr.(a) necessite } \\
\text { de ajuda para suas atividades de rotina? }\end{array}$ & d230, d610 até d650, e3 \\
\hline $\begin{array}{l}\text { E 03f - Faz com que o(a) Sr.(a.) necessite } \\
\text { de ajuda para seus cuidados pessoais? }\end{array}$ & d510 até d570, e3 \\
\hline $\begin{array}{l}\text { E 05 - Esse problema requer algum tipo } \\
\text { de assistência? }\end{array}$ & e1, e2, e3, e4, e5 \\
\hline $\begin{array}{l}\text { E 06 - O Sr.(a.) recebe a assistência que } \\
\text { precisa? }\end{array}$ & e1, e2, e3, e4, e5 \\
\hline
\end{tabular}

As questões de E04 (O que provocou o seu problema?) e de E07 (Senão recebe a assistência que precisa, por quê?) não puderam ser categorizadas na CIF. A descrição de cada categoria selecionada encontra-se no Anexo 1.

Apesar de parte das questões do ISA-Capital 2003 poderem ser referenciadas com categorias da CIF, as possibilidades de resposta não dão informações suficientes para uso de todos os qualificadores que a classificação oferece.

O Quadro 2 apresenta as formas de qualificação, pela CIF, das respostas do inquérito, segundo as possibilidades oferecidas pelas alternativas do questionário.

\section{Quadro 2 - Categorias de respostas classificáveis pela CIF}

\begin{tabular}{|l|c|}
\hline \multicolumn{1}{|c|}{ Descrição das categorias de resposta } & Codificação pela CIF \\
\hline Dificuldade de observar & $\mathrm{d} 110.8$ \\
\hline Deficiência visual completa (um olho) & $\mathrm{b} 210.2$ \\
\hline Deficiência visual completa (dois olhos) & $\mathrm{b} 210.4$ \\
\hline Dificuldade de ouvir & $\mathrm{d} 115.8$ \\
\hline
\end{tabular}




\begin{tabular}{|l|c|}
\hline Deficiência auditiva completa (um ouvido) & $\mathrm{b} 230.2$ \\
\hline Deficiência auditiva completa (dois ouvidos) & $\mathrm{b} 230.4$ \\
\hline Deficiência de força muscular & $\mathrm{b} 730.8$ \\
\hline Alteração estrutural de MMSS & $\mathrm{s} 730.98$ \\
\hline Dificuldade na educação escolar & $\mathrm{d} 820.88$ \\
\hline Dificuldade no trabalho & $\mathrm{d} 850.88$ \\
\hline Dificuldade na recreação e lazer & $\mathrm{d} 920.88$ \\
\hline Dificuldade na vida doméstica & $\mathrm{d} 6.88$ \\
\hline Dificuldade no cuidado pessoal & $\mathrm{d} 5.88$ \\
\hline Barreira para conseguir acesso aos serviços, \\
sistema e políticas de saúde
\end{tabular}

Cada conjunto de letra e números na coluna 2 representa a categoria e a qualificação, ou seja, a questão e a sua respectiva resposta, ambas traduzidas por meio de um sistema de códigos. 


\section{DISCUSSÃO}

A existência de categorias da CIF para quase todo conteúdo de questões do Bloco E do ISA - Capital 2003 reafirma a interação entre as ferramentas. Apenas a questões de E04 e E07 não puderam ser categorizadas na CIF. Para se obter os benefícios do uso da CIF, se faz necessário estabelecer relações entre as ferramentas existentes com seu conteúdo. ${ }^{8}$

Ambas as ferramentas tentam esclarecer aspectos de saúde que vão além do conhecimento das doenças. Por outro lado, há uma importante diferença entre elas: a primeira (CIF) é uma ferramenta de classificação da situação das pessoas e a segunda (ISA) é um instrumento de coleta de dados auto-referidos. Essa diferença faz com que as duas sejam necessárias, apontando para um uso em conjunto, complementar e não para uma absoluta substituição. Usualmente, a CIF não substitui as ferramentas comumente utilizadas, mas notifica a situação de funcionalidade, diagnosticada por diversos meios, numa linguagem comum. ${ }^{9}$

Há de se considerar que a interação de objetivos não resulta numa aplicação imediata de códigos em inquéritos já existentes, pois a CIF, de forma abrangente e completa, considera o estudo da funcionalidade humana em seus diversos aspectos. Nos inquéritos, por sua vez, conforme apresentado nos resultados, mesmo que a formulação das questões seja ótima, como é o caso do Bloco E do ISA-Capital 2003, ainda não há a abrangência que a CIF permitiria. Para que isso ocorra, é necessário que a criação do inquérito seja baseada nas categorias da CIF. A classificação pode servir como um guia para criação das questões. ${ }^{10}$

A qualificação das categorias da CIF permite que se conheçam as dificuldades das pessoas tanto como conseqüência dos problemas nas funções e estruturas do corpo como de forma resultante da interação do indivíduo e seus fatores pessoais com o ambiente a sua volta, além da possibilidade de estabelecer o grau de comprometimento, o que não ocorre com o inquérito analisado, na forma que está.

As questões do ISA-Capital 2003, de maneira geral, acabam não trazendo subsídios para o conhecimento de tal situação, mostrando mais uma vez que, o uso da CIF como norteadora da formulação de inquéritos populacionais pode contribuir para 
uma ferramenta de coleta de dados mais robusta e completa. Há um exemplo numa versão para coleta de dados em inquéritos de saúde disponível no anexo 9 da CIF. ${ }^{3}$

Considerando o bloco do questionário tomado como exemplo neste estudo, percebe-se que, ao elaborar as questões, não se levou em consideração que os problemas de desempenho, avaliados no ambiente habitual, não são gerados apenas pela presença de deficiências graves, o que, na verdade, tem relação mais próxima com os problemas de capacidade. Assim, a complexidade inerente aos aspectos da funcionalidade humana é tão alta que se fazem necessárias revisões sobre a aplicabilidade da CIF e de outros instrumentos que se comunicam com ela, periodicamente. Pessoas com as mesmas deficiências e com os mesmos problemas de capacidade podem ter problemas de desempenho extremamente diferentes, principalmente, graças à influência dos fatores contextuais (ambientais e pessoais). Assim, um dos maiores determinantes da incapacidade é o contexto. ${ }^{11}$

As condições de moradia e de entorno influenciam na limitação de atividades escolares, de lazer e de trabalho de pessoas com deficiências graves (visual, auditiva ou física). Um conhecimento mais aprofundado do ambiente, incluindo a influência tecnológica, geográfica, social e política, permitiria o esclarecimento potencial das causas das limitações das atividades e da restrição da participação social da população envolvida. Os resultados, se mais detalhados por meio da CIF, seriam capazes de mostrar que é possível melhorar a vida das pessoas e diminuir suas limitações com estratégias que visem adequar a moradia e o entorno, pois, o ambiente é um dos principais geradores da incapacidade humana, devendo ser o foco das políticas públicas voltadas à funcionalidade humana. ${ }^{12}$

O modelo conceitual da CIF considera a incapacidade como decorrente da interação entre as condições de saúde, condições ambientais e pessoais. Como o ISACapital 2003 apenas avalia condições de entorno e moradia, não existe subsídio para estabelecer, com segurança, uma relação entre os fatores contextuais e o estado de funcionalidade das pessoas. Dentro do escopo da CIF, vários fatores ambientais, tais como, tecnologias de acessibilidade, de transporte público, de mobilidade, acesso a serviços e sistema que facilitem a funcionalidade humana são listados no componente complementar da classificação, denominado Fatores Ambientais. ${ }^{13,14}$ 
Embora este trabalho tenha tomado como ponto de partida o bloco de um inquérito especifico, seus resultados podem ser extrapolados para outros inquéritos, como a indicação do uso das categorias da CIF e seus conceitos na Rede Inteagencial de Informações para a Saúde (RIPSA), disponível em www.ripsa.org.br/lildbi/docsonline/get.php?id=227. Há muitas similaridades entre investigações da funcionalidade humana, especialmente, nos domínios de limitações de atividades e participação social. O uso das categorias da CIF pode ser uma forma de estruturar as questões dos inquéritos de saúde, incluindo os fatores que influenciam na funcionalidade, tais como, os fatores ambientais. 


\section{CONCLUSÕES}

É possível identificar categorias e códigos da CIF a partir dos componentes abordados pelo ISA-Capital 2003. No entanto, considerando o modelo biopsicossocial proposto pela Organização Mundial da Saúde na CIF, há uma deficiência na abordagem do processo incapacitante pelo ISA, visto que poucos dados referentes aos fatores ambientais são coletados.

O uso da CIF como ferramenta de base para construção de inquéritos contribuirá para facilitar a coleta de dados dos fenômenos relacionados às limitações de atividades e restrições da participação social, bem como, facilitarão a comparação da situação de funcionalidade entre regiões. Esse uso pode contribuir tanto para melhorar a abrangência e interpretação de dados de inquéritos quanto para o desenvolvimento da própria classificação em versões futuras. 


\section{BIBLIOGRAFIA}

1. Francescutti C, Martinuzzi A, Leonardi M, Kostanjsek NFI. Eight years of ICF in Italy: Principles, results and future perspectives. Disability and Rehabilitation 2009; 31(SUPPL. 1):S4-S7

2. McDougall J, Wright V, Rosenbaum P. The ICF model of functioning and disability: Incorporating quality of life and human development. Developmental Neurorehabilitation 2010; 13(3):204-211.

3. OMS. Classificação Internacional de Funcionalidade, Incapacidade e Saúde. EDUSP 2003.

4. Campos, CEA. Health Surveys from a Planning Perspective. Cad. Saúde Públ. 1993; 9(2):190-200.

5. Krieger N. Theories for social epidemiology in the $21^{\text {st }}$ century: an ecosocial perspective. Int J Epidemiol 2001; 30:668-77.

6. Viacava E. Informações em Saúde: a importância dos inquéritos populacionais. Ciência e Saúde Coletiva 2002; 7(4):607-21.

7. Cieza A, Geih A, Chatterji S, Kostanjsek N, Ustun B, Stucki G. ICF Linking rules: an update based on lessons learned. J Rehabil Med 2005; 37:212-8

8. Escorpizo R, Stucki G, Cieza A, Davis K, Stumbo T, Riddle D. Creating an interface between the International Classification of Functioning, Disability and Health and Physical Therapist Practice. Physical Therapy 2010; 90(7): 1053-63.

9. Rauch A, Cieza A, Stucki G. How to apply the International Classification of Functioning, Disabilty and Health (ICF) for rehabilitation management in clinical practice. Europe Journal of Phys Rehabil Medicine 2008; 44: 329-42.

10. Madans et al.: Measuring disability and monitoring the UN Convention on the Rights of Persons with Disabilities: the work of the Washington Group on Disability Statistics. BMC Public Health 2011. 11(Suppl 4):S4. 
11. Francescutti C, Gongolo F, Simoncello A, Frattura L. Description of the personenvironment interaction: methodological issues and empirical results of an Italian large-scale disability assessment study using an ICF-based protocol. BMC Public Health 2011; 11(Suppl 4):S11.

12. Vall J, Costa CMC, Pereira LF, Friesen TT.Application of International Classification of Functioning, Disability and Health (ICF) in individuals with spinal Cord injury. Arq Neuropsiquiatr 2011; 69(3):513-8

13. Brasileiro IC, Moreira TMM, Jorge MSB. Interveniência dos fatores ambientais na vida de crianças com paralisia cerebral. Acta Fisiátrica 2009; 16(3): 132-7.

14. Riberto M. Core sets da Classificação Internacional de Funcionalidade, Incapacidade e Saúde. Rev. bras. enferm. 2011; 64(5): 938-46. 
Anexo 1 - Descrição das categorias da CIF até $2^{\circ}$ nível

\section{FUNÇÕES DO CORPO}

\section{Capítulo 1 Funções Mentais}

\section{Funções mentais globais (b110-b139)}

b110 Funções da consciência

b114 Funções da orientação

b117 Funções intelectuais

b122 Funções psicossociais globais

b126 Funções do temperamento e da personalidade

b130 Funções da energia e dos impulsos

b134 Funções do sono

b139 Funções mentais globais, outras especificas e não especificadas

\section{Funções mentais específicas (b140-b189)}

b140 Funções da atenção

b144 Funções da memória

b147 Funções psicomotoras

b152 Funções emocionais

b156 Funções da percepção

b160 Funções do pensamento

b164 Funções cognitivas de nível superior

b167 Funções mentais da linguagem

b172 Funções de cálculo

b176 Funções mentais para a sequência de movimentos complexos

b180 Funções de experiência pessoal e do tempo

b189 Funções mentais específicas, outras especificadas e não especificadas

b198 Funções mentais, outras especificadas

b199 Funções mentais, não especificadas

\section{Capítulo 2 Funções sensoriais e dor}




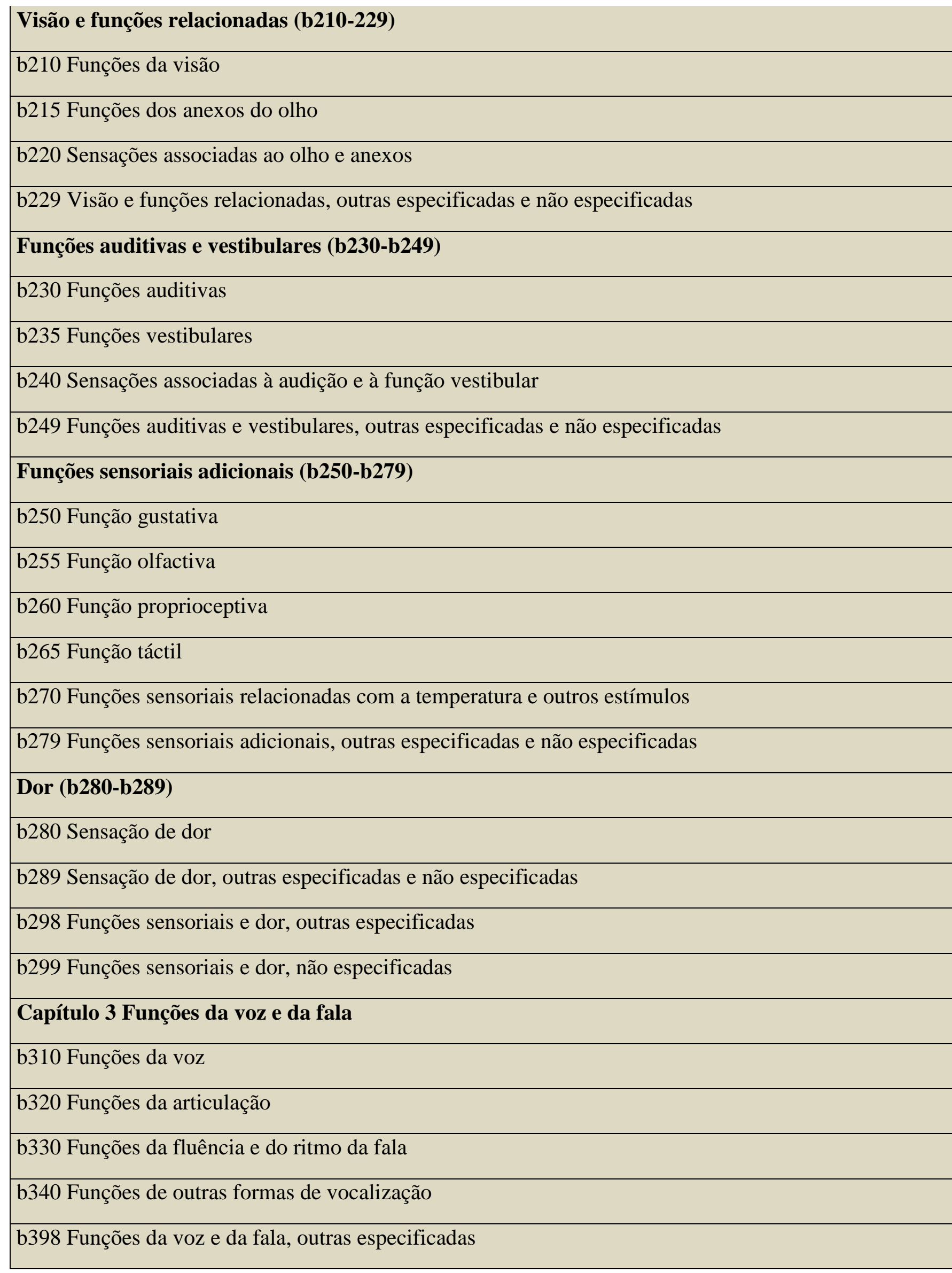


b399 Funções da voz e da fala, não especificadas

Capítulo 4 Funções do aparelho cardiovascular, dos sistemas hematológico e imunológico e do apar Funções do aparelho cardiovascular (b410-b429)

b410 Funções cardíacas

b415 Funções dos vasos sanguíneos

b420 Funções da pressão arterial

b429 Funções do aparelho cardiovascular, outras especificadas e não especificadas

\section{Funções dos sistemas hematológico e imunológico (b430-b439)}

b430 Funções do sistema hematológico

b435 Funções do sistema imunológico

b439 Funções dos sistemas hematológico e imunológico, outras especificadas e não especificadas

Funções do aparelho respiratório (b440-b449)

b440 Funções da respiração

b445 Funções dos músculos respiratórios

b449 Funções do aparelho respiratório, outras especificadas e não especificadas

Funções e sensações adicionais dos aparelhos cardiovascular e respiratório (b450-b469)

b450 Funções respiratórias adicionais

b455 Funções de tolerância ao exercício

b460 Sensações associadas às funções cardiovasculares e respiratórias

b469 Funções e sensações adicionais dos aparelhos cardiovascular e respiratório, outras especificadas e nå

b498 Funções do aparelho cardiovascular, sist. hematológico e imunológico e do aparelho respiratório, ou

b499 Funções do aparelho cardiovascular, sist. hematológico e imunológico e do aparelho respiratório, nã

Capítulo 5 Funções do aparelho digestivo e dos sistemas metabólico e endócrino

Funções relacionadas com o aparelho digestivo (b510-b539)

b510 Funções de ingestão

b515 Funções digestivas

b520 Funções de assimilação

b525 Funções de defecação 
b530 Funções de manutenção do peso

b535 Sensações associadas ao aparelho digestivo

b539 Funções relacionadas com o aparelho digestivo, outras especificadas e não especificadas

\section{Funções relacionadas com os sistemas metabólicos e endócrino (b540-b559)}

b540 Funções metabólicas gerais

b545 Funções de equilíbrio hídrico, mineral e electrolítico

b550 Funções termo reguladoras

b555 Funções das glândulas endócrinas

b559 Funções relacionadas com os sistemas metabólico e endócrino, outras especificadas e não especifica

b598 Funções do aparelho digestivo e dos sistemas metabólico e endócrino, outras especificadas

b599 Funções do aparelho digestivo e dos sistemas metabólico e endócrino, não especificadas

\section{Capítulo 6 Funções geniturinárias e reprodutivas}

\section{Funções urinárias (b610-639)}

b610 Funções de excreção urinária

b620 Funções miccionais

b630 Sensações associadas às funções urinárias

b639 Funções urinárias, outras especificadas e não especificadas

Funções genitais e reprodutivas (b640-b679)

b640 Funções sexuais

b650 Funções relacionadas com a menstruação

b660 Funções de procriação

b670 Sensações associadas às funções genitais e reprodutivas

b679 Funções genitais e reprodutivas, outras especificadas e não especificadas

b698 Funções geniturinárias e reprodutivas, outras especificadas

b699 Funções geniturinárias e reprodutivas, não especificadas

Capítulo 7 Funções neuromusculoesqueléticas e relacionadas com o movimento

Funções das articulações e dos ossos (b710-b729)

b710 Funções da mobilidade das articulações 
b715 Funções da estabilidade das articulações

b720 Funções da mobilidade dos ossos

b729 Funções das articulações e dos ossos, outras especificadas e não especificadas

\section{Funções musculares (b730-b749)}

b730 Funções da força muscular

b735 Funções do tônus muscular

b740 Funções da resistência muscular

b749 Funções musculares, outras especificadas e não especificadas

Funções relacionadas com o movimento (b750-b789)

b750 Funções de reflexos motores

b755 Funções de reações motoras involuntárias

b760 Funções de controlo do movimento voluntário

b765 Funções dos movimentos involuntários

b770 Funções relacionadas com o padrão de marcha

b780 Sensações relacionadas com os músculos e as funções do movimento

b789 Funções do movimento, outras especificadas e não especificadas

b798 Funções neuromusculoesqueléticas e relacionadas com o movimento, outras especificadas

b799 Funções neuromusculoesqueléticas e relacionadas com o movimento, não especificadas

\section{Capítulo 8 Funções da pele e estruturas relacionadas}

\section{Funções da pele (b810-b849)}

b810 Funções protetoras da pele

b820 Funções reparadoras da pele

b830 Outras funções da pele

b840 Sensação relacionada com a pele

b849 Funções da pele, outras especificadas e não especificadas

\section{Funções dos pêlos e das unhas (b850-b869)}

b850 Funções dos pelos

b860 Funções das unhas 
b869 Funções dos pelos e das unhas, outras especificadas e não especificadas b898 Funções da pele e estruturas relacionadas, outras especificadas b899 Funções da pele e estruturas relacionadas, não especificadas ESTRUTURAS DO CORPO

\section{Capítulo 1 Estruturas do sistema nervoso}

s110 Estrutura do cérebro

s120 Medula espinhal e estruturas relacionadas

s130 Estrutura das meninges

s140 Estrutura do sistema nervoso simpático

s150 Estrutura do sistema nervoso parassimpático

s198 Estrutura do sistema nervoso, outra especificada

s199 Estrutura do sistema nervoso, não especificada

Capítulo 2 Olho, ouvido e estruturas relacionadas

s210 Estrutura da cavidade ocular

s220 Estrutura do globo ocular

s230 Estruturas anexas ao olho

s240 Estrutura do ouvido externo

s250 Estrutura do ouvido médio

s260 Estrutura do ouvido interno

s298 Olho, ouvido e estruturas relacionadas, outras especificadas

s299 Olho, ouvido e estruturas relacionadas, não especificadas

Capítulo 3 Estruturas relacionadas com a voz e a fala

s310 Estrutura do nariz

s320 Estrutura da boca

s330 Estrutura da faringe

s340 Estrutura da laringe

s398 Estruturas relacionadas com a voz e a fala, outras especificadas

s399 Estruturas relacionas com a voz e a fala, não especificadas 
Capítulo 4 Estruturas do aparelho cardiovascular, do sistema imunológico e do aparelho respiratór s410 Estrutura do aparelho cardiovascular

s420 Estrutura do sistema imunológico s430 Estrutura do aparelho respiratório s498 Estruturas do aparelho cardiovascular, do sistema imunológico e do aparelho respiratório, outras esp s499 Estruturas do aparelho cardiovascular, do sistema imunológico e do aparelho respiratório, não especi

Capítulo 5 Estruturas relacionadas com o aparelho digestivo e com os sistemas metabólico e endócr s510 Estrutura das glândulas salivares

s520 Estrutura do esôfago

s530 Estrutura do estômago

s540 Estrutura dos intestinos

s550 Estrutura do pâncreas

s560 Estrutura do fígado

s570 Estrutura da vesícula e vias biliares

s580 Estrutura das glândulas endócrinas

s598 Estruturas relacionadas com o aparelho digestivo e com os sistemas metabólico e endócrino, outras s599 Estruturas relacionadas com o aparelho digestivo e com os sistemas metabólico e endócrino, não esp

Capítulo 6 Estruturas relacionadas com os aparelhos geniturinário e reprodutivo

s610 Estrutura do aparelho urinário

s620 Estrutura do pavimento pélvico

s630 Estrutura do aparelho reprodutivo

s698 Estruturas relacionadas com os aparelhos geniturinário e reprodutivo, outras especificadas

s699 Estruturas relacionadas com os aparelhos geniturinário e reprodutivo, não especificadas

\section{Capítulo 7 Estruturas relacionadas com o movimento}

s710 Estrutura da região da cabeça e do pescoço

s720 Estrutura da região do ombro

s730 Estrutura do membro superior

s740 Estrutura da região pélvica 


\begin{tabular}{|l} 
s750 Estrutura do membro inferior \\
\hline s760 Estrutura do tronco \\
\hline s770 Estruturas musculoesqueléticas adicionais relacionadas ao movimento \\
\hline s798 Estruturas relacionadas com o movimento, outras especificadas \\
\hline s799 Estruturas relacionadas com o movimento, não especificadas
\end{tabular}

\section{Capítulo 8 Pele e estruturas relacionadas}

s810 Estrutura das áreas da pele

s820 Estrutura das glândulas da pele

s830 Estrutura das unhas

s840 Estrutura dos pelos

s898 Pele e estruturas relacionadas, outras especificadas

s899 Pele e estruturas relacionadas, não especificadas

\section{ATIVIDADES E PARTICIPAÇÃO}

\section{Capítulo 1 Aprendizagem e aplicação de conhecimentos}

\section{Experiências sensoriais intencionais (d110-d129)}

\section{d110 Observar}

d115 Ouvir

d120 Outras percepções sensoriais intencionais

d129 Experiências sensoriais intencionais, outras especificadas e não especificadas

\section{Aprendizagem básica (d130-d159)}

d130 Imitar

d135 Ensaiar (Repetir)

d140 Aprender a ler

d145 Aprender a escrever

d150 Aprender a calcular

d155 Adquirir competências

d159 Aprendizagem básica, outra especificada e não especificada

\section{Aplicação do conhecimento (d160-d179)}




\begin{tabular}{|l} 
d160 Concentrar a atenção \\
\hline d163 Pensar \\
\hline d166 Ler \\
\hline d170 Escrever \\
\hline d172 Calcular \\
\hline d175 Resolver problemas \\
\hline d177 Tomar decisões \\
\hline d179 Aplicação do conhecimento, outra especificada \\
\hline d198 Aprendizagem e aplicação do conhecimento, outras especificadas \\
\hline d199 Aprendizagem e aplicação do conhecimento, não especificadas
\end{tabular}

\section{Capítulo 2 Tarefas e exigências gerais}

d210 Realizar uma única tarefa

d220 Realizar tarefas múltiplas

d230 Realizar a rotina diária

d240 Lidar com o stresse e outras exigências psicológicas

d298 Tarefas e exigências gerais, outras especificadas

d299 Tarefas e exigências gerais, não especificadas

\section{Capítulo 3 Comunicação}

\section{Comunicar e receber mensagens (d310-d329)}

d310 Comunicar e receber mensagens orais

d315 Comunicar e receber mensagens não verbais

d320 Comunicar e receber mensagens usando linguagem gestual

d325 Comunicar e receber mensagens escritas

d329 Comunicar e receber mensagens, outras especificadas e não especificadas

Comunicar e produzir mensagens(d330-d349)

d330 Falar

d335 Produzir mensagens não verbais

d340 Produzir mensagens usando linguagem gestual 
\begin{tabular}{|l} 
d345 Escrever mensagens \\
\hline d349 Comunicar e produzir mensagens, outra especificada e não especificada
\end{tabular}

Conversação e utilização de dispositivos e de técnicas de comunicação (d350-d369)

d350 Conversação

d355 Discussão

d360 Utilização de dispositivos e de técnicas de comunicação

d369 Conversação e utilização de dispositivos e de técnicas de comunicação, outros especificados e não e

d398 Comunicação, outra especificada

d399 Comunicação, não especificada

\section{Capítulo 4 Mobilidade}

\section{Mudar e manter a posição do corpo (d410-d429)}

d410 Mudar a posição básica do corpo

d415 Manter a posição do corpo

d420 Auto-transferências

d429 Mudar e manter a posição do corpo, outras especificadas e não especificadas

\section{Transportar, mover e manusear objectos (d430-d449)}

d430 Levantar e transportar objectos

d435 Mover objectos com os membros inferiores

d440 Utilização de movimentos finos da mão

d445 Utilização da mão e do braço

d449 Transportar, mover e manusear objectos, outros especificados e não especificados

\section{Andar e deslocar-se (d450-d469)}

d450 Andar

d455 Deslocar-se

d460 Deslocar-se por diferentes locais

d465 Deslocar-se utilizando algum tipo de equipamento

d469 Andar e mover-se, outros especificados e não especificados

\section{Deslocar-se utilizando transporte (d470-d489)}




\begin{tabular}{|l} 
d470 Utilização de transporte \\
\hline d475 Dirigir \\
\hline d480 Montar animais como meio transporte \\
\hline d489 Deslocar-se utilizando transporte, outros especificados e não especificados \\
\hline d498 Mobilidade, outra especificada \\
\hline d499 Mobilidade, não especificada
\end{tabular}

\section{Capítulo 5 Cuidados Pessoais}

\begin{tabular}{|l}
\hline d510 Lavar-se \\
\hline d520 Cuidar de partes do corpo \\
\hline d530 Cuidados relacionados com os processos de excreção \\
\hline d540 Vestir-se \\
\hline d550 Comer \\
\hline d560 Beber \\
\hline d570 Cuidar da própria saúde \\
\hline d598 Auto cuidados, outros especificados \\
\hline d599 Auto cuidados, não especificados
\end{tabular}

\section{Capítulo 6 Vida doméstica}

\section{Aquisição do necessário para viver (d610-d629)}

d610 Aquisição de um lugar para morar d620 Aquisição de bens e serviços

d629 Aquisição do necessário para viver, outro especificado e não especificado

\section{Tarefas domésticas (d630-d649)}

d630 Preparar refeições

d640 Realizar as tarefas domésticas

d649 Tarefas domésticas, outras especificadas e não especificadas

Cuidar dos objectos da casa e ajudar os outros (d650-d669)

d650 Cuidar dos objectos da casa

d660 Ajudar os outros 
d669 Cuidar dos objectos da casa e ajudar os outros, outros especificados e não especificados d698 Vida doméstica, outra especificada

d699 Vida doméstica, não especificada

Capítulo 7 Interações e relacionamentos interpessoais

Interacções interpessoais gerais (d710-d729)

d710 Interações interpessoais básicas

d720 Interações interpessoais complexas

d729 Interações interpessoais gerais, outras especificadas e não especificadas

Relacionamentos interpessoais particulares (d730-d779)

d730 Relacionamento com estranhos

d740 Relacionamento formal

d750 Relacionamentos sociais informais

d760 Relacionamentos familiares

d770 Relacionamentos íntimos

d779 Relacionamentos interpessoais particulares, outros especificados e não especificados

d798 Interações e relacionamentos interpessoais, outros especificados

d799 Interações e relacionamentos interpessoais, não especificados

Capítulo 8 Áreas principais da vida

Educação (d810-d839)

d810 Educação informal

d815 Educação pré-escolar

d820 Educação escolar

d825 Formação profissional

d830 Educação de nível superior

d839 Educação, outra especificada e não especificada

\section{Trabalho e emprego (d840-d859)}

d840 Estágio (preparação para o trabalho)

d845 Obter, manter e sair de um emprego 


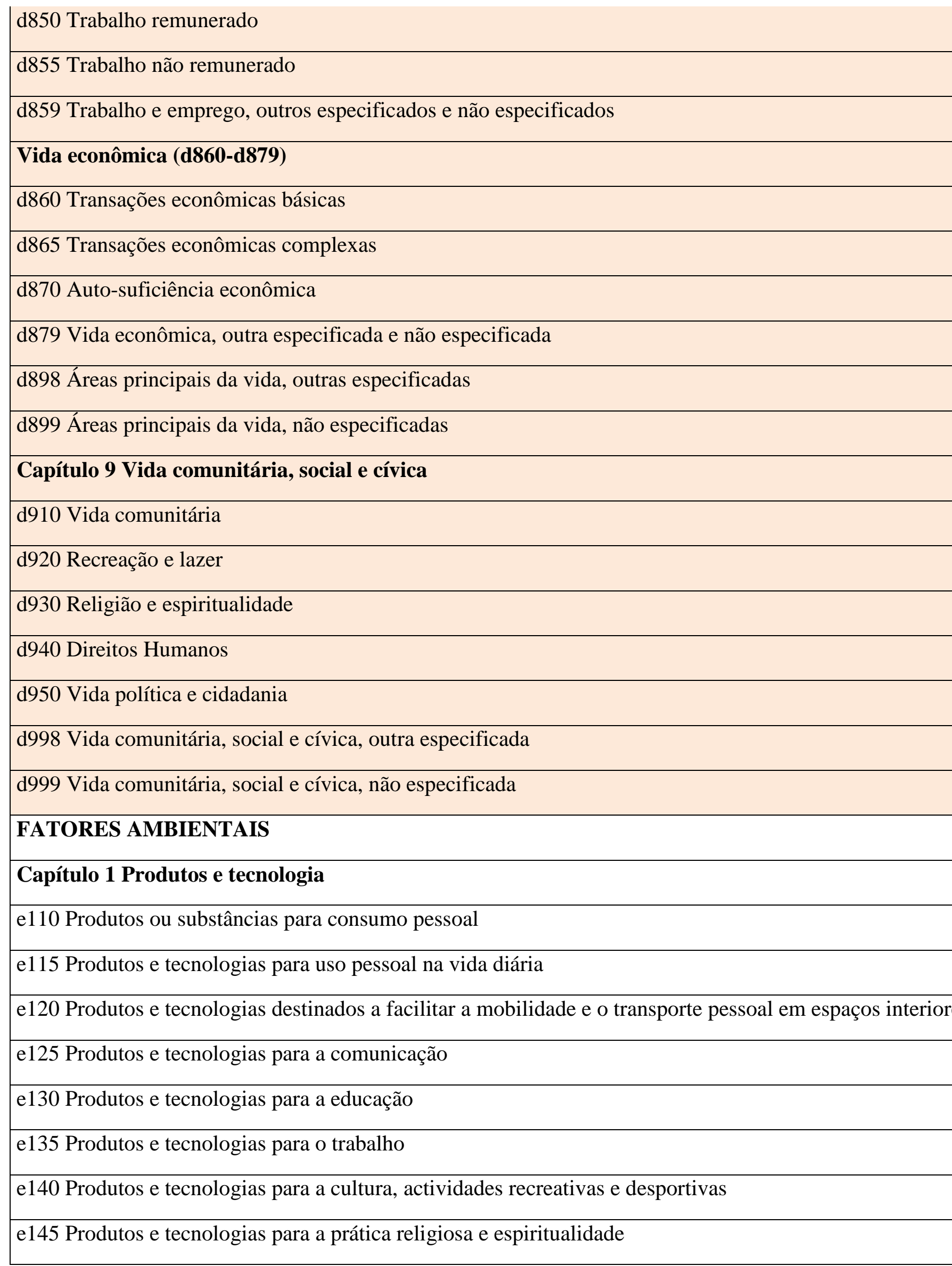


e150 Arquitectura, construção, materiais e tecnologias arquitectónicas em prédios para uso público e155 Arquitectura, construção, materiais e tecnologias arquitectónicas em prédios para uso privado e160 Produtos e tecnologias relacionados com a utilização e a exploração dos solos e165 Bens

e198 Produtos e tecnologias, outros especificados

e199 Produtos e tecnologias, não especificados

\section{Capítulo 2 Ambiente natural e mudanças ambientais feitas pelo homem}

e210 Geografia física

e215 População

e220 Flora e fauna

e225 Clima

e230 Desastres naturais

e235 Desastres causados pelo homem

e240 Luz

e245 Mudanças relacionadas com o tempo

e250 Som

e255 Vibração

e260 Qualidade do ar

e298 Ambiente natural e mudanças ambientais feitas pelo homem, outro especificado

e299 Ambiente natural e mudanças ambientais feitas pelo homem, não especificado

\section{Capítulo 3 Apoio e relacionamentos}

e310 Família próxima

e315 Família alargada

e320 Amigos

e325 Conhecidos, pares, colegas, vizinhos e membros da comunidade

e330 Pessoas em posição de autoridade

e335 Pessoas em posição subordinada

e340 Prestadores de cuidados pessoais e assistentes pessoais 


\begin{tabular}{|l} 
e345 Estranhos \\
\hline e350 Animais domesticados \\
\hline e355 Profissionais de saúde \\
\hline e360 Outros profissionais \\
\hline e398 Apoio e relacionamentos, outros especificados \\
\hline e399 Apoio e relacionamentos, não especificados
\end{tabular}

\section{Capítulo 4 Atitudes}

e410 Atitudes individuais de membros da família próxima

e415 Atitudes individuais de membros da família alargada

e420 Atitudes individuais de amigos

e425 Atitudes individuais de conhecidos, pares, colegas, vizinhos e membros da comunidade

e430 Atitudes individuais de pessoas em posições de autoridade

e435 Atitudes individuais de pessoas em posições subordinadas

e440 Atitudes individuais de prestadores de cuidados pessoais e dos assistentes pessoais

e445 Atitudes individuais de estranhos

e450 Atitudes individuais de profissionais de saúde

e455 Atitudes individuais de outros profissionais

e460 Atitudes sociais

e465 Normas, práticas e ideologias sociais

e498 Atitudes, outras especificadas

e499 Atitudes, não especificadas

\section{Capítulo 5 Serviços, sistemas e políticas}

e510 Serviços, sistemas e políticas relacionados com a produção de bens de consumo

e515 Serviços, sistemas e políticas relacionados com a arquitectura e a construção

e520 Serviços, sistemas e políticas relacionados com o planeamento de espaços abertos

e525 Serviços, sistemas e políticas relacionados com a habitação

e530 Serviços, sistemas e políticas relacionados com os serviços de utilidade pública

e535 Serviços, sistemas e políticas relacionados com a área da comunicação 
e540 Serviços, sistemas e políticas relacionados com os transportes

e545 Serviços, sistemas e políticas relacionados com a protecção civil

e550 Serviços, sistemas e políticas relacionados com a área jurídico-legal

e555 Serviços, sistemas e políticas relacionados com associações e organizações

e560 Serviços, sistemas e políticas relacionados com os meios de comunicação

e565 Serviços, sistemas e políticas relacionados com a economia

e570 Serviços, sistemas e políticas relacionados com a segurança social

e575 Serviços, sistemas e políticas relacionados com o apoio social geral

e580 Serviços, sistemas e políticas relacionados com a saúde

e585 Serviços, sistemas e políticas relacionados com a educação e a formação profissional

e590 Serviços, sistemas e políticas relacionados com o trabalho e o emprego

e595 Serviços, sistemas e políticas relacionados com o sistema político

e598 Serviços, sistemas e políticas, outros especificados

e599 Serviços, sistemas e políticas, não especificados 


\section{CONSIDERAÇÕES FINAIS}

Os estudos desta tese apontam a CIF como uma ferramenta adequada para coletar dados sobre funcionalidade humana. Mostram também que é possível facilitar seu uso, de forma a torná-la operacional, deixando claro que nem todas as categorias da classificação precisam fazer parte da prática diária dos profissionais de determinada área. Ainda que o ideal seja usá-la integralmente, em uma equipe multidisciplinar, isso nem sempre é possível. Este trabalho estuda as formas de uso da CIF conhecidas e publicadas e propõe um novo modelo de lista simplificada como uma outra forma para seu uso.

Conforme a necessidade de gerar conhecimento sobre a funcionalidade aumenta, instrumentos mais detalhados, e desenvolvidos a partir de categorias mais específicas da CIF, devem ser construídos. No entanto, o uso de categorias menos complexas também pode permitir a operacionalização de dados. Essa diferença é perceptível entre os estudos 1 e 2. O segundo, por ser mais específico, tornou necessário o uso de categorias de $2^{\circ}$ nível da CIF. O estudo 1 foi baseado apenas no uso de categorias de $1^{\circ}$ nível, limitado aos capítulos.

A CIF se mostrou como uma ferramenta completa, capaz, inclusive, de servir como um parâmetro na criação de inquéritos de saúde. O uso do sistema de códigos da classificação torna mais tangível a visualização da situação de funcionalidade e incapacidade.

A CIF tem, como um dos seus principais objetivos, dar visibilidade ao estado de funcionalidade e incapacidade de populações, quando aplicada como uma ferramenta estatística. O conhecimento dessa situação pode ser capaz de embasar políticas de saúde. No entanto, para que isso seja possível, é necessário que os profissionais estejam aptos a utilizá-la com segurança e de forma assertiva, levando-se em consideração que, para isso existem etapas a serem vencidas. A primeira etapa a ser transposta, conforme a literatura apresenta claramente, é a inserção do modelo conceitual de funcionalidade e incapacidade da OMS na prática profissional, na prática política e na prática acadêmica. O modelo multidimensional não nega a existência pontual e limitada de um modelo linear, mas o inverso é verdadeiro. Se assumirmos a linearidade, dificilmente executaremos a multidirecionalidade. Atualmente, as instituições formadoras dos profissionais de saúde ainda ensinam a execução do modelo linear para a prática clínica 
e para determinação das diretrizes político-sociais. Araujo e Buchalla (2011) concluíram que a utilização da CIF na área de Fisioterapia só ocorrerá após a inclusão desse tema nos cursos de graduação e pós-graduação da área.

Mesmo após 11 anos da publicação da CIF e do modelo integrador de funcionalidade e incapacidade, alguns exemplos da força do modelo linear na prática clínica persistem, como no caso da publicação dos "core sets" segundo doenças. Esses "core sets" consideram a influência dos fatores contextuais, portanto, são diferentes da linearidade proposta pela versão anterior: a "ICIDH". Mas, há outra característica presente no modelo linear: a doença como o evento que precede todos os outros. Essa característica permanece quando se cria "core sets" por doenças. Esse instrumento permite que se conheça como o contexto e sua influência repercutem na funcionalidade e, por consequência dessa repercussão, geram doenças como um resultado final. Assim, os "core sets" por doenças não permitem que se conheça um fator contextual como evento que preceda todos os outros, incluindo a geração de uma incapacidade ou, até mesmo, o aparecimento de uma enfermidade.

Nos "core sets" por doenças, mesmo que os fatores contextuais sejam considerados, o ponto de partida nesses casos continua sendo determinada doença e as incapacidades continuam sendo consideradas como conseqüências de doenças. De outro lado, do ponto de vista estatístico, os "core sets" representam outra dificuldade, pois levam o classificador a utilizar diferentes categorias da CIF, de acordo com a doença relacionada. Isso possibilita a comparação de dados apenas de pessoas com as mesmas doenças, impedindo a comparação do estado de funcionalidade de pessoas com doenças diferentes, tornando um possível sistema de informação incompleto.

Um sistema de informação que permita a comparação do estado de funcionalidade, independentemente da condição de saúde, é muito importante. Um paciente com tetraparesia com fatores contextuais facilitadores pode desempenhar suas atividades com menos dificuldade que um paciente com diabetes dentro de um contexto repleto de barreiras. A adaptação de carros, cadeira de rodas e vias públicas pode garantir, por exemplo, o desempenho ocupacional de um paciente com tetraparesia. $\mathrm{Na}$ mesma cidade, se não houver um sistema/serviço que garanta o acesso a medicamentos e ao controle da saúde, o paciente com diabetes pode se ver impedido de desempenhar suas atividades laborais. 
A execução do modelo multidimencional permite que possamos partir do conhecimento do ambiente (em sua visão ampla) como determinante do estado da funcionalidade e não, meramente, do contexto biológico experimentado por cada indivíduo. Portanto, as listas resumidas criadas para aplicação em pessoas com determinada condição de saúde ainda se mostram com grandes limitações no que se refere ao conhecimento real do estado de funcionalidade e de seus determinantes.

Esse tipo de limitação existe em menor grau nas listas (ou “core sets") por áreas, justamente porque elas conseguirão abranger um grande número de condições de saúde. Apenas um "core set" genérico, como apresentado da introdução do presente trabalho, ou uma intersecção entre os "core sets" por área poderiam resolver melhor a questão, o que já está em andamento e pode ser visualizado em www.cihiconferences.ca/icf conference/20.pdf.

A divulgação da classificação e o ensino do modelo de funcionalidade proposto pela OMS configuram, então, o primeiro passo para que a CIF se torne uma ferramenta estatística para geração de informações sobre funcionalidade e incapacidade.

Em segundo lugar, outra etapa a ser transposta é a complexidade da classificação. Muitos pesquisadores têm se ocupado em desenvolver formas de operacionalização do instrumento (Lima ET AL, 2008). A alta complexidade da classificação é, ao mesmo tempo, algo essencial para geração das informações de forma consistente e um complicador para seu uso por demandar muito tempo do classificador.

Esse segundo obstáculo parece ser incompatível com o primeiro. Em princípio, abrir mão da resolução de um deles poderia ser uma forma viável. Porém, existe a possibilidade de facilitar o uso da CIF sem fugir fortemente do modelo multidirecional de funcionalidade. Um dos objetivos deste trabalho foi mostrar como instrumentos de classificação criados a partir da CIF podem ser um meio de transpor as duas barreiras e propiciar a coleta de dados para um sistema de informação.

Outras formas de utilização da CIF foram propostas por autores de diferentes países, como utilizar apenas as categorias alteradas (OMS, 2001), criar resumos da CIF por doenças, por áreas, por profissões, por objetivos, aplicação por meio do "CheckList" ou por meio de instrumentos de avaliação existentes (Eliyara Ikehara E et $a l, 2010)$. 
Apesar do grande número de publicações sobre a CIF, ainda pouco se discute sobre o uso epidemiológico dessa classificação, apesar deste ser um dos grandes benefícios de sua implantação mundial. O Estudo 2 busca justamente suprir a dificuldade da operacionalização sem romper fortemente com o modelo multidimensional.

O Estudo 2 mostrou uma ferramenta de coleta de dados de funcionalidade baseada na CIF. O objetivo do trabalho era criar uma ferramenta que, além de fácil uso, pudesse facilitar a disponibilização de dados sobre funcionalidade e incapacidade. A ferramenta criada simplifica o uso e permite gerar informações que sirvam como base para indicadores de saúde.

O Estudo 3 mostrou como a abordagem de um inquérito pode ser feita a partir da CIF, para que se conheça o processo incapacitante. A CIF pode ser a estrutura adequada para a coleta de dados sobre o estado de funcionalidade e incapacidade de determinada população.

Quando se transforma os resultados de um inquérito numa linguagem codificada dá-se visibilidade estatística às necessidades e aos detalhes que não são vistos por meio dos indicadores de morbidade e mortalidade.

Indicadores de funcionalidade, obtidos por meio de categorias da CIF, podem nortear políticas públicas voltadas à prevenção de incapacidades. Indicadores estruturados a partir de categorias da CIF podem apresentar a frequiência de códigos que indiquem alteração ou preservação do estado de funcionalidade em populações segundo variáveis epidemiológicas. 


\section{REFERÊNCIAS}

1. Araujo ES, Buchalla CM. Uso da Classificação Internacional de Funcionalidade, Incapacidade e Saúde em Fisioterapia: uma revisão bibliográfica. Terapia Manual. 2011; 40(8): 548-54.

2. Bossmanna T, Kirchberger A, Glaessel A, Stucki G, Cieza A. Validation of the comprehensive ICF Core Set for Osteoarthritis. Physiotherapy 2011; 97: 3-16.

3. Brockow T, Cieza A, Kuhlow H, Sigl T, Franke T, Harder M, Stucki G. Identifying the concepts contained in outcome measures of clinical trials on musculoskeletal disorders and chronic widespread pain using the international classification of functioning, disability and health as a reference. Journal of Rehabilitation Medicine. 2004; 44: 30-6.

4. Buchalla CM. A Classificação Internacional de Funcionalidade, Incapacidade e Saúde. Acta Fisiátrica. 2003; 10(1): 29-31.

5. Cieza A, Geyh S, Chatterji S, Kostanjsek N, Ustun B. ICF linking rules: an update based on lessons learned. Journal of Rehabilitation Medicine 2005; 37:212-18.

6. Di Nubila H, Paula AR, Marcelino MA, Maior IL. Evaluating the model of classification and valuation of disabilities used in Brazil and defining the elaboration and adoption of a unique model for all the country. BMC Public Health 2011, 11(Suppl 4):S10.

7. Eliyara Ikehara E, Nardi SMT, Ferrigno ISV, Pedro HSP, Paschoal VD. Escala Salsa e grau de Incapacidades da Organização Mundial de Saúde: avaliação da limitação de atividades e deficiência na hanseníase. Acta Fisiatr. 2010; 17(4): 169 - 174 
8. Finger ME, Cieza A, Stoll J, Stucki G, Huber EO. Identification of intervention categories for physical therapy, based on the International Classification of Functioning, Disability and Health: a Delphi exercise. Physical Therapy. 2006; 86 (9): 1203-20.

9. Gray DB, Hendershot GE. The ICIDH-2: Developments for a new era of outcomes research. Arch Phys Rehabil 2000; 81(2): S10 - S14 (9).

10. Kirchberger I, Glaessel A, Stucki G, Cieza A. Validation of the comprehensive International Classification of Functioning, Disability and Health Core Set for Rheumatoid Arthritis: the perspective of physical therapists. Physical Therapy. 2007; 87:368-84.

11. Lima MAG, Neves RF, Tironi MOS, Nascimento AMDN, Magalhães FB. Avaliação da funcionalidade dos trabalhadores com LER/DORT: a construção do Core Set da CIF para LER/DORT ACTA FISIATR 2008; 15(4): 229 - 235

12. Machado, FN. Capacidade e Desempenho para a realização das atividades básicas de vida diária: um estudo com idosos dependentes. Dissertação de Mestrado. Universidade Federal de Minas Gerais. 2010.

13. McIntyre A, Tempest S. (2007). Two steps forward, one step back? A commentary on the disease-specific core sets of the International Classification of Functioning, Disability and Health (ICF). Disability and Rehabilitation. 2007; 29(18):1475-9.

14. OMS. Classificação Internacional de Funcionalidade, Incapacidade e Saúde. EDUSP. São Paulo; 2003. Tradução: Profa. Dra. Cassia Maria Buchalla.

15. Palisano RJ. A collaborative model of service delivery for children with movement disorders: a framework for evidence-based decision making. Physical Therapy. 2006; 86 (9): 1295-305.

16. Rauch A, Cieza A, Stucki G. How to apply the International Classification of Functioning, Disability and Health (ICF) for rehabilitation management in clinical practice. Eur J Phys Rehabil Med 2008; 44: 329-42 
17. Riberto M. Core Sets da Classificação Internacional de Funcionalidade, Incapacidade e Saúde. Revista Brasileira de Enfermagem 2011; 64(5): 938-46.

18. Sampaio RF, Madel TL. Funcionalidade e Incapacidade humana: explorando o escopo da classificação internacional da Organização Mundial da Saúde. Cad. Saúde Pública. 2009; 25 (3): 475-83.

19. Sampaio RF, Mancini MC, Gonçalves GGP, Bittencourt NFN, Miranda AD, Fonseca ST. Aplicação da Classificação Internacional de Funcionalidade, Incapacidade e Saúde (CIF) na prática clínica do fisioterapeuta. Revista Brasileira de Fisioterapia. 2005; 9: 129-36.

20. Schwarzkopf SR, Ewert T, Dreinhofer KE, Cieza A, et al. (2008). Towards an ICF Core Set for chronic musculoskeletal conditions: commonalities across ICF Core Sets for osteoarthritis, rheumatoid arthritis, osteoporosis, low back pain and chronic widespread pain. Clinical Rheumatology 27(11):1355-61

21. Stucki A, Stoll T, Cieza A, Weigl M, Giardinni A, Wever D, Kostanjsek N, Stucki G. ICF Core Sets for Obstructive Pulmonary Diseases. Journal of Rehabil Medicine 2004; Suppl 44: 114-20.

22. Weil M, Cieza A, Andersen C, Kollerits B, Amann E, Stucki G. Identification of relevant ICF categories in patients with chronic health conditions: a Delphi exercise. Journal of Rehabil Medicine 2004; Suppl. 44: 12-21.

23. World Health Organization. Towards a Common Language for Functioning, Disability and Health - ICF. [WHO/EIP/GPE/CAS/01.3] Genebra; 2002. 